\title{
IntechOpen
}

\section{Staphylococcus and Streptococcus}

\author{
Edited by Sahra Kırmusaoğlu
}





\section{Staphylococcus and Streptococcus}

Edited by Sahra Kırmusaoğlu 

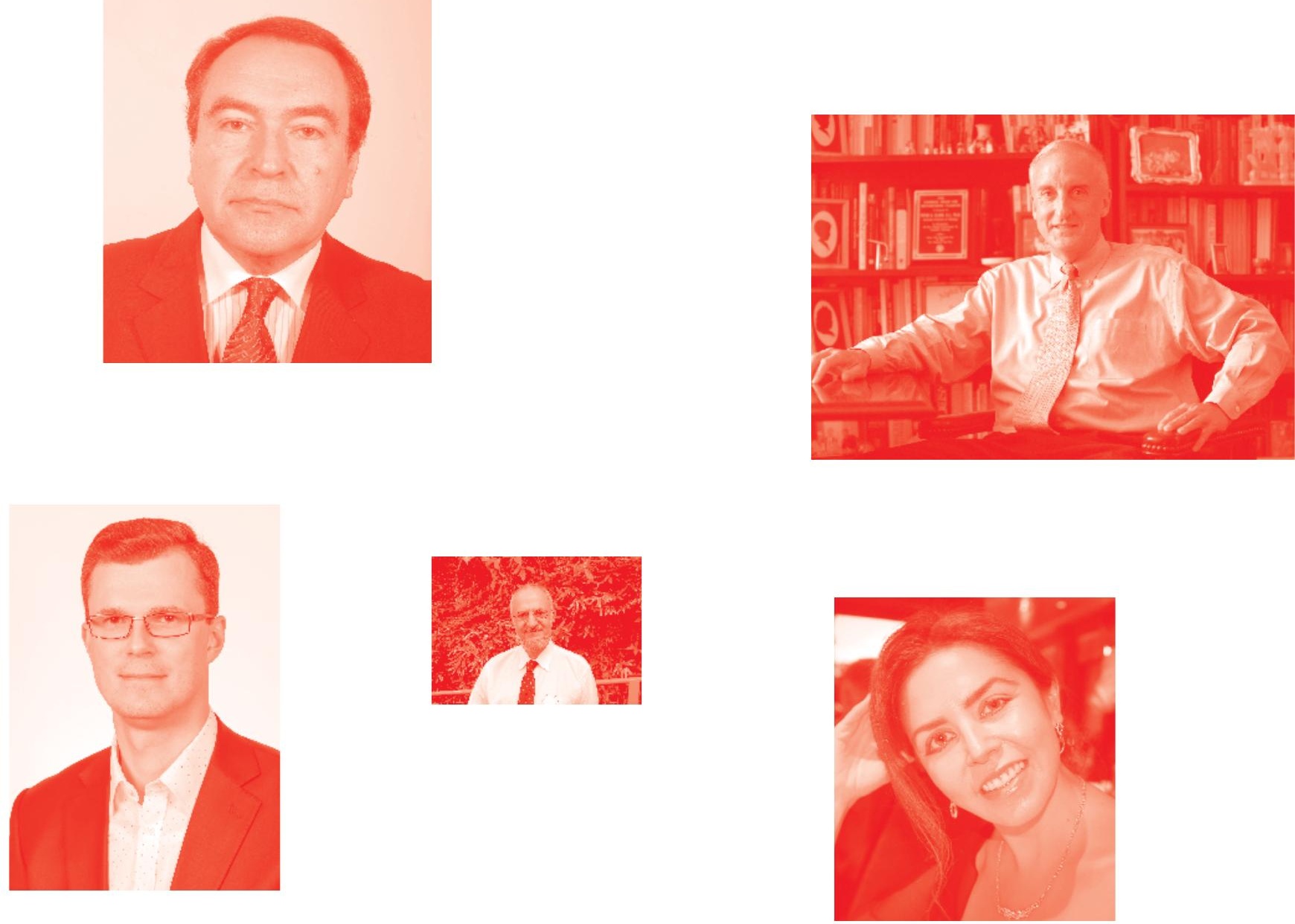

Supporting open minds since 2005
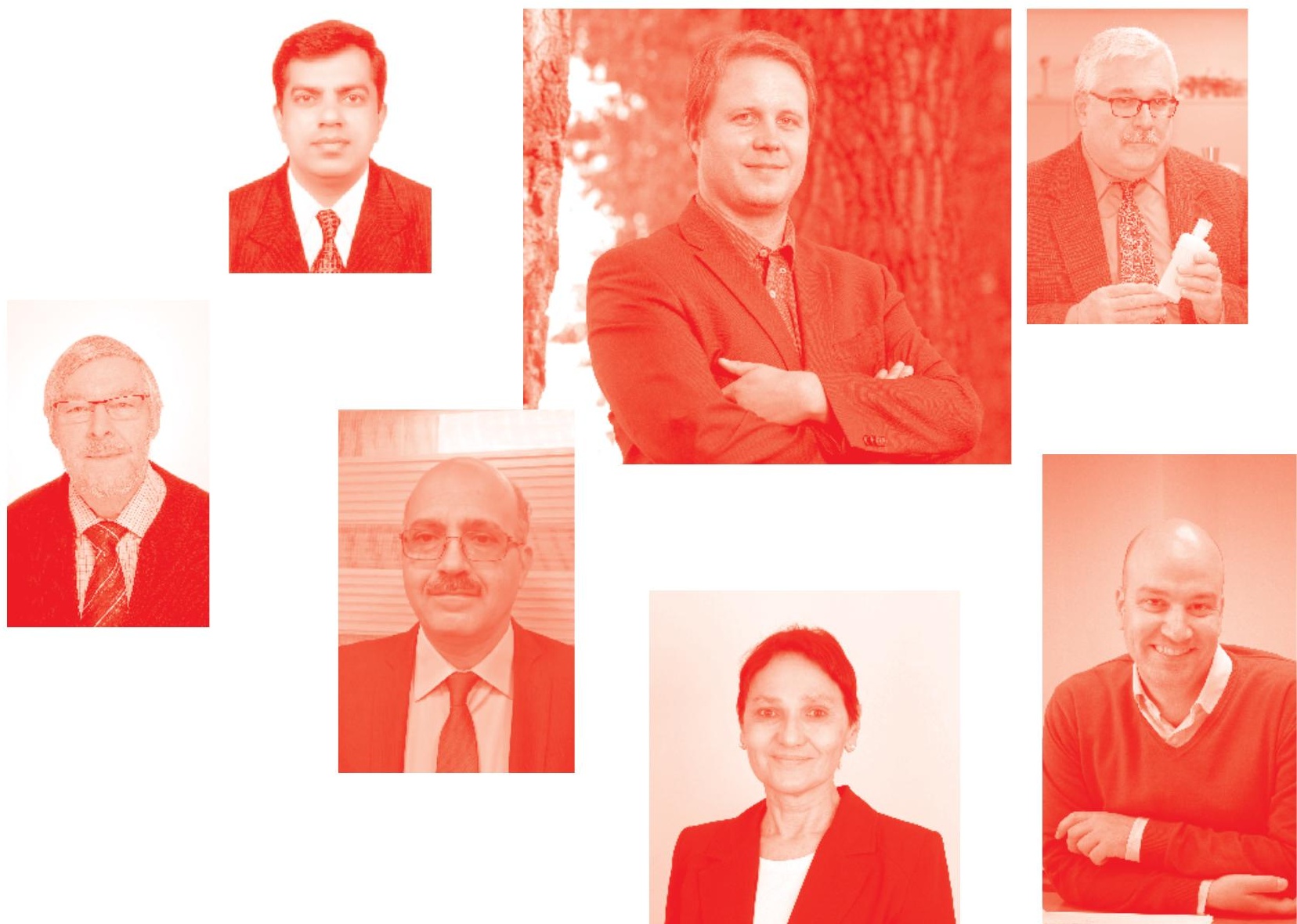
Staphylococcus and Streptococcus

http: //dx. doi.org/10.5772/intechopen. 77863

Edited by Sahra Kırmusaoğlu

Contributors

María Alejandra Bojanich, Mariano Daniel Orlietti, Valeria Velasco, Helia Bello, Mario QuezadaAguiluz, Ming-Chu Hsu, Ying-Yuan Zhang, Li-Wen Chang, Manju Pai, Venkatesh S Pai, Pratima Gupta, Anuradha Chakraborti, Sahra Kırmusaoğlu, Ruby Hp Law, Adam J. Quek, James C. Whisstock, Razique Anwer, Khalid Alqumaizi

(-) The Editor(s) and the Author(s) 2020

The rights of the editor(s) and the author(s) have been asserted in accordance with the Copyright, Designs and Patents Act 1988. All rights to the book as a whole are reserved by INTECHOPEN LIMITED . The book as a whole (compilation) cannot be reproduced, distributed or used for commercial or non-commercial purposes without INTECHOPEN LIMITED's written permission. Enquiries concerning the use of the book should be directed to INTECHOPEN LIMITED rights and permissions department (permissions@intechopen.com).

Violations are liable to prosecution under the governing Copyright Law .

\section{(cc) BY}

Individual chapters of this publication are distributed under the terms of the Creative Commons Attribution 3.0 Unported License which permits commercial use, distribution and reproduction of the individual chapters, provided the original author(s) and source publication are appropriately acknowledged. If so indicated, certain images may not be included under the Creative Commons license. In such cases users will need to obtain permission from the license holder to reproduce the material. More details and guidelines concerning content reuse and adaptation can be found at http : //www . intechopen . com/copyright-policy. html.

\section{Notice}

Statements and opinions expressed in the chapters are these of the individual contributors and not necessarily those of the editors or publisher. No responsibility is accepted for the accuracy of information contained in the published chapters. The publisher assumes no responsibility for any damage or injury to persons or property arising out of the use of any materials, instructions, methods or ideas contained in the book.

First published in London, United Kingdom, 2020 by IntechOpen

IntechOpen is the global imprint of INTECHOPEN LIMITED, registered in England and Wales,

registration number: 11086078, 7th floor, 10 Lower Thames Street, London,

EC3R 6AF, United Kingdom

Printed in Croatia

British Library Cataloguing-in-Publication Data

A catalogue record for this book is available from the British Library

Additional hard and PDF copies can be obtained from orders@intechopen.com

Staphylococcus and Streptococcus

Edited by Sahra Kırmusaoğlu

p. cm.

Print ISBN 978-1-78984-472-6

Online ISBN 978-1-78984-473-3

eBook (PDF) ISBN 978-1-78985-941-6 


\section{We are IntechOpen, \\ the world's leading publisher of Open Access books}

Built by scientists, for scientists

\section{$4,700+$}

Open access books available

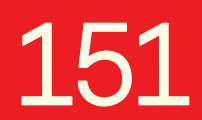

Countries delivered to
$120,000+$

International authors and editors

Our authors are among the

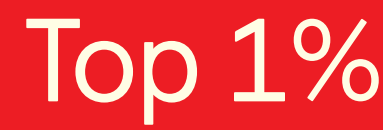

most cited scientists

Contributors from top 500 universities
$135 \mathrm{M}+$

Downloads

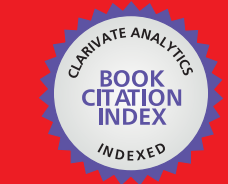

WEB OF SCIENCE ${ }^{\mathrm{MM}}$

Selection of our books indexed in the Book Citation Index in Web of Science ${ }^{\mathrm{TM}}$ Core Collection (BKCI)

\section{Interested in publishing with us? \\ Contact book.department@intechopen.com}

Numbers displayed above are based on latest data collected.

For more information visit www.intechopen.com 



\section{Meet the editor}

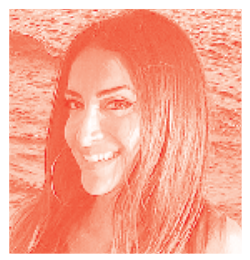

Dr. Kırmusaoğlu, $\mathrm{PhD}$, is an assistant professor of microbiology at the Department of Molecular Biology and Genetics, T.C. Haliç University. She specialized in microbiology at Abant Izzet Baysal University (Biology Department), Turkey. Her previous experience includes laboratory manager at microbiology laboratories in several research and private hospitals. Throughout her career, she collaborated with academicians/researchers from AIBU, METU, and Istanbul University Cerrahpaşa Faculty of Medicine, and has participated in various research projects. Dr. Kırmusaoğlu's research interests include pathogenic bacteria, bacterial biofilms, activities of antibiofilm and antimicrobial agents, antibacterial resistance, synergistic activities of antimicrobials in combination with new agents such as chemical and natural bioactive compounds against pathogenic bacteria such as antibiotic-resistant and biofilm-producing microorganisms, regulation of antibiotic resistance and virulence genes, pathogen-host interactions, bacterial pathogenesis, and microbiota. She has published several international research articles, books, book chapters, and congress proceedings. She is also the editor of Disinfection, Bacterial Pathogenesis and Antibacterial Control, and Antimicrobials, Antibiotic Resistance, Antibiofilm Strategies and Activity Methods published by IntechOpen. In addition to these, she wrote the book Genel Biyoloji Laboratuvar Kılavuzu (General Biology Laboratory Manual) published by Hipokrat Publisher. She has contributed to a chapter translation of the book Sherris Medical Microbiology by Ryan et al. as one of the translation authors of Sherris Tibbi Mikrobiyoloji, which is a Turkish translated book edited by Prof. Dr. Dürdal Us and Prof. Dr. Ahmet Başustaoğlu. 



\section{Contents}

Preface

Section 1

Virulence Factors and Pathogenesis

Chapter 1

Introductory Chapter: An Overview of the Genus Staphylococcus and Streptococcus

by Anıl Cebeci and Sahra Kırmusaoğlu

Chapter 2

Virulence Factors of Streptococcus mutans Related to Dental Caries by Bojanich María Alejandra and Orlietti Mariano Daniel

Chapter 3

Toward Better Understanding on How Group A Streptococcus

Manipulates Human Fibrinolytic System

by Adam J.H. Quek, James C. Whisstock and Ruby H.P. Law

Chapter 4

Cell Surface and Cytosolic Proteins of Group B Streptococcus Adding

New Dimensions in Its Colonization and Pathogenesis

by Manju Ohri Pai, Venkatesh Srinivasa Pai, Pratima Gupta

and Anuradha Chakraborti

Section 2

Antimicrobial Resistance

Chapter 5

61

Nemonoxacin (Taigexyn ${ }^{\circledR}$ ): A New Non-Fluorinated Quinolone

by Li-Wen Chang, Ming-Chu Hsu and Ying-Yuan Zhang

Chapter 6

Staphylococcus aureus in the Meat Supply Chain: Detection Methods, Antimicrobial Resistance, and Virulence Factors

by Valeria Velasco, Mario Quezada-Aguiluz and Helia Bello-Toledo

Chapter 7

An Emerging Multidrug-Resistant Pathogen: Streptococcus pneumoniae by Khalid I. Alqumaizi and Razique Anwer 



\section{Preface}

Staphylococcus spp. and Streptococcus spp. have not only got pathogenic isolates, but also non-pathogenic isolates. Staphylococcus spp. and Streptococcus spp. that are Gram positive cocci are the main pathogens in several infections. Virulence factors such as usual and unusual surface proteins encoded by resistance genes are the main causes of pathogenesis. Multidrug-resistant pathogens that are the main causes of morbidity and mortality worldwide have the ability to synthesize a number of destructive enzymes encoded by resistance genes such as $\beta$-lactamases. Resistant pathogens such as methicillin-resistant Staphylococcus aureus (MRSA), Streptococcus pneumoniae, Group A, and Group B Streptococcus have emerged throughout the world. To eliminate these resistant pathogens that cause untreatable, acute, and chronic infections, different new antimicrobials must be developed and used.

This book contains seven chapters from valued experts in Turkey, Argentina, China, Australia, Chile, India, and Saudi Arabia. The goal of this book is to provide information on the topics mentioned. The book will be useful for researchers interested in the study of staphylococcus and streptococcus, and antimicrobial resistance of staphylococcus and streptococcus.

I would like to thank all the authors who contributed to this book with their chapters. I would also like to thank Mr. Josip Knapic who assisted me in this project as the Author Service Manager and IntechOpen Publisher for their concern and encouragement in publishing this book.

Dr. Sahra Kırmusaoğlu

Assistant Professor, Haliç University, Faculty of Arts and Sciences, Department of Molecular Biology and Genetics, Beyoğlu-Istanbul, Turkey 

Section 1

\section{Virulence Factors and Pathogenesis}





\title{
Introductory Chapter: An Overview of the Genus Staphylococcus and Streptococcus
}

\author{
Anıl Cebeci and Sahra Kırmusaoğlu
}

\section{Introduction}

We live in a world that inhibits many life forms including microorganisms. Bacteria, an important member of these microorganisms, sometimes become a very tough enemy of the human being with the stimulation of the conditions and environment. Bacterial infections that are sourced from pathogenic bacteria are one of the leading causes of the human death worldwide. For instance, lower respiratory infections killed 3 million people globally in 2016 [1].

Among the most pathogenic bacteria for human, genera of Staphylococcus and Streptococcus come forward with their pathogenicity. Staphylococci and Streptococci are grouped as Gram-positive cocci. Staphylococci form clumps, whereas Streptococci grow in chains. They can be discriminated by catalase test because Staphylococci have the capability to produce catalase [2].

Staphylococci and Streptococci are together responsible of the pathogenesis of a variety of diseases such as wound infections, mastitis, toxic shock syndrome, scarlet fever, cystic fibrosis, nosocomial and community-acquired infections, periodontitis, and indwelling device-associated infections $[3,4]$.

\section{Virulence factors of Staphylococcus spp. and Streptococcus spp.}

\subsection{Toxins}

As a major human pathogenic bacterium, Staphylococcus aureus (S. aureus) has many virulence factors including staphylocoagulase (SC), protein A, staphylococcal enterotoxins (SEs), and leukotoxins.

$\mathrm{SC}$ is the cause of acute bacterial endocarditis. It binds to the blood prothrombin, and this complex induces the number and the colonization of bacteria via transformation of fibrinogen to fibrin [5]. Protein A is the vehicle of $S$. aureus for binding to Fc region of IgG. By this mechanism, pathogenic bacterium is surrounded by $\operatorname{IgG}$ and will not be recognized by the cells of human immunity system [6].

SEs belong to a huge family of staphylococcal and streptococcal exotoxins and are shown to be the main cause of toxic shock syndrome. These superantigens show their pathogenicity via binding to class II major histocompatibility complex (MHC) molecules that are located on the surface of the antigen-presenting cells and causing a toxic shock with stimulation of high numbers of T cells [7].

Additionally, leukotoxins of $S$. aureus can eliminate phagocytic cells of the mammalian immune system by killing them selectively [8]. 
Although they are the hosts of the mucosal surfaces of human, streptococci are associated with many infectious diseases like tonsillitis, endocarditis, pharyngitis, meningitis, and glomerulonephritis [9]. Group A streptococcus (GAS) which is known as the main cause of necrotizing fasciitis produce streptococcal pyrogenic exotoxins (Spes). Streptococcal toxic shock syndrome (STSS) is associated with various Spe proteins, including SpeA, SpeS and SpeG, streptococcal superantigen A (SSA), and streptococcal mitogenic exotoxin Z (SMEZ) and SMEZ2. As mentioned before, these superantigens induce $\mathrm{T}$ cells to proliferate massively and cause abnormal production of cytokines [10].

Hemolysin from Streptococcus pyogenes (S. pyogenes) and its equivalent, pneumolysin, from $S$. pneumoniae, not only form pores but also activate the inflammatory system elements. Again, streptolysin O (SLO) and streptolysin S (SLS) belong to this superantigen family [10].

\subsection{Biofilm formation}

Bacterial biofilm is the optimum environment for bacteria to survive. More than a nutrient poll, biofilm provides protection for its residents against harsh conditions, antibiotics, and other antimicrobial chemical agents. From the vision of indwelling device-associated infections and nosocomial and community-acquired infections, Staphylococcus epidermidis (S. epidermidis) and S. aureus are the main responsible organisms with the ability of forming biofilm [11].

S. aureus strains can bear the ica operon that express polysaccharide intracellular adhesin (PIA) which is termed as the main molecule in biofilm formation [12, 13]. With its positively charged molecular structure, PIA enhances the intercellular binding of negatively charged bacterial surface [14].

However, the biofilm can be structured without the adhesive effect of PIA. PIA-independent biofilms may be formed by different surface proteins such as biofilm-associated protein (Bap) and accumulation-associated proteins (Aap) of $S$. epidermidis $[12,13]$. More than that, protein A and some members of the fibronectin-binding proteins, cell wall-anchored proteins, and autolysins can help the formation of biofilm [14].

\section{Antibiotic resistance of Staphylococcus and Streptococcus}

Antibiotic resistance becomes a worldwide serious health threat due to the inappropriate prescribing, overuse, and the extensive agricultural use of antibiotics [15]. S. aureus, a well-known pathogenic bacterium, exhibits resistance to the some of the important and widely used antibiotics such as $\beta$-lactam antibiotics, tetracycline, and methicillin through its genome and extrachromosomal elements [16].

The genetic elements of $S$. aureus play a critical role in antibiotic resistance. $S$. aureus can hydrolase the $\beta$-lactam ring of penicillin by using the penicillinase which is expressed from the blaZ gene localized in $S$. aureus plasmid. This emerging feature can be observed more than 80 percent of the $S$. aureus strains [17].

Another example of plasmid-originated antibiotic resistance can be observed for tetracycline in $S$. aureus. Tet gene in conjugative plasmid of $S$. aureus encodes ribosomal protection protein which prevents the binding of tetracycline to ribosome and thus the inactivation of it [18].

The occurrence of $S$. aureus isolates that are resistant to $\beta$-lactam antibiotics provide the discovery of penicillinase-stable penicillins. One of these molecules, methicillin, is the medication of choice to treat $\beta$-lactam-resistant $S$. aureus infections. But some of the $S$. aureus isolates are also resistant to methicillin and different types 
of antibiotics such as macrolides and cephalosporins. Methicillin-resistant $S$. aureus (MRSA) isolates demonstrate their characteristics of multi-antibiotic resistance through their chromosomes and extrachromosomal elements. Penicillin binding protein $2 \mathrm{a}$ which is encoded by chromosomal mecA gene is the main reason of methicillin resistance of $S$. aureus $[19,20]$.

Enterococci are the members of the microflora of the intestinal system. But they are also opportunistic and nosocomial pathogens. Especially, they are accused of sepsis, endocarditis, and urinary tract infections in immunosuppressed patients [21].

These pathogens demonstrate a different feature compared to other Grampositive cocci: adaptation to different antimicrobials such as vancomycin quickly and exhibition of multidrug resistance [21].

Vancomycin is a member of glycopeptide antibiotics. It targets the precursors of peptidoglycan, while this system is crucial for the enterococcal cell wall biosynthesis. By binding to these precursors and preventing the transglycosylation and transpeptidation, vancomycin prevents the building and growing of bacterial cell wall [22]. But enterococci overcome this destructive problem with different van operon systems, for instance, $\operatorname{van} A, \operatorname{van} B, \operatorname{van} C$, and $\operatorname{van} D$. The common feature of these systems is to alter the peptidoglycan biosynthesis pathway with different molecules so that vancomycin cannot identify the molecule thus cannot interfere [22].

\section{Author details}

Anıl Cebeci and Sahra Kırmusaoğlu*

Faculty of Arts and Sciences, Department of Molecular Biology and Genetics, Halic University, Istanbul, Turkey

*Address all correspondence to: kirmusaoglu_sahra@hotmail.com

IntechOpen

(C) 2020 The Author(s). Licensee IntechOpen. This chapter is distributed under the terms of the Creative Commons Attribution License (http://creativecommons.org/licenses/ by/3.0), which permits unrestricted use, distribution, and reproduction in any medium, provided the original work is properly cited. (cc) BY 


\section{References}

[1] WHO. Global Health Estimates 2016: Deaths by Cause, Age, Sex, by Country and by Region, 2000-2016 [Internet]. 2018. Available from: http://www.who. int/healthinfo/global_burden_disease/ en/ [Accessed: December 04, 2019]

[2] Ryan KJ, Ray CG, Sherris JC. Sherris Medical Microbiology. 6th ed.

New York: McGraw Hill Medical; 2010

[3] Hall-Stoodley L, Stoodley P. Evolving concepts in biofilm infections. Cellular Microbiology. 2009;11:1034-1043. DOI: 10.1111/j.1462-5822.2009.01323.x

[4] Bjarnsholt T, Moser C, Jensen PO, Hoiby N, editors. Biofilm Infections. 1st ed. Heidelberg: Springer Science Business Media, LLC; 2011. pp. 215-225. DOI: 10.1007/978-1-4419-6084-9

[5] Panizzi P, Friedrich R, FuentesPrior P, Bode W, Bock PE. The staphylocoagulase family of zymogen activator and adhesion proteins. Cellular and Molecular Life Sciences. 2004;61:2793-2798. DOI: $10.1007 /$ s00018-004-4285-7

[6] Foster TJ, McDevitt D. Surfaceassociated proteins of Staphylococcus aureus: Their possible roles in virulence. FEMS Microbiology Letters. 1994;118:199-205. DOI: 10.1111/j.15746968.1994.tb06828.x

[7] Pinchuk IV, Beswick EJ, Reyes VE. Staphylococcal enterotoxins. Toxins (Basel). 2010;2:2177-2197. DOI: 10.3390/ toxins 2082177

[8] Rainard P, Corrales JC, Barrio MB, Cochard T, Poutrel B. Leucotoxic activities of Staphylococcus aureus strains isolated from cows, ewes, and goats with mastitis: Importance of LukM/LukF'-PV leukotoxin. Clinical and Diagnostic Laboratory Immunology. 2003;10:272277. DOI: $10.1128 /$ cdli.10.2.272-277.2003
[9] Nobbs AH, Lamont RJ, Jenkinson HF. Streptococcus adherence and colonization. Microbiology and Molecular Biology Reviews. 2009;73:407-450. DOI: 10.1128/ MMBR.00014-09

[10] Alouf JE, Müller-Alouf H. Staphylococcal and Streptococcal superantigens: Molecular, biological and clinical aspects. International Journal of Medical Microbiology. 2003;292:429440. DOI: $10.1078 / 1438-4221-00232$

[11] Otto M. Staphylococcal biofilms. In: Romeo T, editor. Bacterial Biofilms. Current Topics in Microbiology and Immunology. Vol. 322. Berlin/ Heidelberg: Springer; 2008. pp. 207-228. DOI: 10.1007/978-3-540-75418-3_1

[12] Kirmusaoglu S. Staphylococcal biofilms: Pathogenicity, mechanism and regulation of biofilm formation by quorum sensing system and antibiotic resistance mechanisms of biofilm embedded microorganisms. In: Dhanasekaran D, Thajuddin N, editors. Microbial Biofilms-Importance and Applications. Croatia, Eastern Europe: InTech; 2016. pp. 189-209. DOI: $10.5772 / 62943.522 p$. ISBN: 978-953-51-2436-8; Print ISBN: 978-953-51-2435-1

[13] Kirmusaoglu S. The methods for detection of biofilm and screening antibiofilm activity of agents. In: Kırmusaoglu S, editor. Antimicrobials, Antibiotic Resistance, Antibiofilm Strategies and Activity Methods. London, United Kingdom: IntechOpen; 2019. pp. 99-115. DOI: 10.5772/intechopen.84411. ISBN: 978-1-78985-790-0

[14] Speziale P, Pietrocola G, Foster TJ, Geoghegan JA. Protein-based biofilm matrices in Staphylococci. Frontiers in Cellular and Infection 
Microbiology. 2014;4:171. DOI: 10.3389/ fcimb.2014.00171

[15] Ventola CL. The antibiotic resistance crisis: Part 1: Causes and threats. P \& T. 2015;40:277-283

[16] Kırmusaoğlu S. MRSA and MSSA: The mechanism of methicillin resistance and the influence of methicillin resistance on biofilm phenotype of Staphylococcus aureus. In: Enany S, Alexander LEC, editors. The Rise of Virulence and Antibiotic Resistance in Staphylococcus aureus. Rijeka, Croatia: IntechOpen; 2017. pp. 25-41. DOI: $10.5772 / 65452$.

[17] Leonard FC, Markey BK. Meticillinresistant Staphylococcus aureus in animals: A review. Veterinary Journal. 2008;175:27-36. DOI: 10.1016/j. tvj1.2006.11.008

[18] Chopra I, Roberts M. Tetracycline antibiotics: Mode of action, applications, molecular biology, and epidemiology of bacterial resistance. Microbiology and Molecular Biology Reviews. 2001;65:232-260. DOI: 10.1128/MMBR.65.2.232-260.2001

[19] Macheboeuf P, Contreras-Martel C, Job V, Dideberg O, Dessen A. Penicillin binding proteins: Key players in bacterial cell cycle and drug resistance processes. FEMS Microbiology Reviews. 2006;30:673-691

[20] Sauvage E, Kerff F, Terrak M, Ayala JA, Charlier P. The penicillinbinding proteins: Structure and role in peptidoglycan biosynthesis. FEMS Microbiology Reviews. 2008;32:234-258. DOI: 10.1111/j.1574-6976.2008.00105.x

[21] Fisher K, Phillips C. The ecology, epidemiology and virulence of Enterococcus. Microbiology. 2009;155:1749-1757

[22] Sujatha S, Praharaj I. Glycopeptide resistance in Gram-positive cocci: A review. Interdisciplinary Perspectives on Infectious Diseases. 2012;2012:781679.

DOI: $10.1155 / 2012 / 781679$ 



\title{
Virulence Factors of Streptococcus mutans Related to Dental Caries
}

\author{
Bojanich María Alejandra and Orlietti Mariano Daniel
}

\begin{abstract}
Streptococcus mutans (S. mutans) has important virulence factors related to the etiology and pathogenesis of dental caries. Through mechanism of adhesion to a solid surface, $S$. mutans is able to colonize the oral cavity and form dental biofilm, which is composed of a matrix of exopolysaccharides that affect the physical and biochemical structure of the biofilm. The additional properties that allow $S$. mutans to colonize the oral cavity include the generation of acid (acidogenicity), the interaction with other bacterial species colonizing this ecosystem and the ability to survive in an acidic environment. In addition, these microorganisms can tolerate the acidic environment (aciduricity) due, at least in part, to the ATPases located in the plasma membrane responsible for the extrusion of the cytoplasmic proton. Changes in environmental $\mathrm{pH}$ can modify the fatty acid and proteins composition of the plasma membrane of $S$. mutans, inducing the alteration of its permeability. The different dental surfaces or biofilms can affect the lipid composition of the bacterial membrane by altering the virulence factors of S. mutans, such as acid survival and ATPase activity.
\end{abstract}

Keywords: Streptococcus mutans, virulence factors, biofilms, membrane fatty acid, ATPases

\section{Introduction}

In the oral cavity, on the teeth surface, organic and inorganic substances coming from the saliva, the gingivocrevicular fluid and microorganisms accumulate. These deposits are called integuments acquired from the enamel and are related to the appearance of the most prevalent diseases of the oral cavity, such as dental caries and periodontal disease. Therefore, it is necessary to understand the chemical composition and odontopathogenic power of these acquired integuments, particularly the role played by $S$. mutans in the oral cavity, since this microorganism is considered one of the most common agents in the development of dental caries in humans [1]. One of the characteristics that contributes to the pathogenicity of this microorganism is its ability to metabolize fermentable sugars (sucrose) and consequently the production of various organic acids, which lower the $\mathrm{pH}$ of the oral medium. Over time, the low $\mathrm{pH}$ of the medium produces the demineralization of the dental element, hence the development of dental caries. S. mutans has diverse virulence factors such as acidogenesis, acid survival and proton ATPase activity (related to the lipid and protein components of its membrane), among others. This enables it to survive in low $\mathrm{pH}$ environments and provides it survival advantages over other common bacteria in the oral ecosystem [2]. 


\section{Acquired integuments from enamel}

The acquired structures of enamel include following structures:

- Acquired enamel pellicle (AEP)

- Dental biofilm (DB)

- Dental calculations or dental tartar

In this chapter, the acquired enamel pellicle and dental biofilm will be specifically explained.

\section{Acquired enamel pellicle}

Saliva is almost never in direct contact with the surface of the tooth, since there is a separation between them provided by a heterogeneous coating: the AEP.

It is an acellular organic $0.1-10 \mu \mathrm{m}$ thick pellicle, totally free of microorganisms. The AEP forms on the surfaces of the teeth by selective adsorption of proteins, peptides and other molecules present in saliva and gingivocrevicular fluid, as well as others from bacteria and desquamated epithelial cells $[3,4]$.

\subsection{Chemical composition of the acquired enamel pellicle}

AEP has a very complex and heterogeneous chemical composition. The chemical composition of this integument plays an important role in the formation of dental biofilm, since some of its biomolecules act as receptors that enable the adherence of oral microorganisms.

The following proteins constitute the AEP: proline-rich acidic proteins (PRPs), statins, high molecular weight mucins, cystatins, histatins, amylase, lactoferrin, lactoperoxidase and secretory immunoglobulin A (IgAs). Also to a lesser extent, serum albumin, carbonic anhydrase, IgG, IgM, various complement fractions and enzymes such as glycosyltransferases of microbial origin. The existence of peptides, a product of the partial proteolysis of salivary proteins, has also been demonstrated.

Regarding the carbohydrates that compose it, there are mainly glucose, galactose, hexuronic acid and amino sugars such as glucosamine and galactosamine. Other glucides, such as sialic acid, are present in the AEP. Carbohydrates are involved in the process of colonization of the pellicle, because many of the adhesins found on the surface of microorganisms bind to carbohydrates located in the AEP.

Other representative biomolecules in this integument are lipids such as glycolipids, acylglycerols, cholesterol, phospholipids and free fatty acids.

The hydrophobic character of the lipids averts the demineralization of the enamel by preventing the diffusion of the acids originated by the metabolism of the microorganisms present in the biofilm, together with its capacity to modulate the colonization of microorganisms of the AEP.

On the other hand, the chemical composition of the AEP varies depending on the type of surface on which it was formed (different faces and regions of the tooth, restoration materials, prosthesis or orthodontic appliances). For example, the chemical composition of the one formed on the root cement differs considerably from the one formed on the enamel, due to the special chemical and structural characteristics of both tissues and the higher proportion of proteins provided by the gingivocrevicular fluid on the cement. 
The AEP is formed within minutes and modified later by enzymes, which is coming from the saliva, bacteria, desquamated epithelial cells and polymorphonuclear leukocytes (transported by the gingivocrevicular fluid).

In this way, various components adsorbed at first to the enamel are rapidly degraded, which is the reason why they cannot be found in the mature integument. The most susceptible to enzymatic degradation proteins are those rich in proline, statins and histatins, whereas cystatins, amylase and other proline-rich proteins are more resistant $[3,4]$.

\subsection{Acquired enamel pellicle training process}

The formation of this integument is given by the combination of ionic, hydrophobic, hydrogen bridge and van der Waals attractions that are established between the buccal surfaces (dental enamel, cement, mucous membranes, etc.) and the organic components suspended in the saliva.

The enamel or adamantine substance is made up of $96 \%$ mineral salts of hydroxyapatite (HA) crystals. The negative charge (phosphate groups) of the HA crystals attracts the ionic calcium present in saliva $(\mathrm{Ca}++)$. The amino acids with anionic side chains, which form part of the salivary proteins, establish electrostatic bonds with calcium. The amino acids with cationic side chains interact directly with the phosphate groups of the HA through ionic bonds and in this way the proteins are adsorbed to it.

The formation of AEP occurs in two stages. In the initial stage, the protein cover increases three times its thickness, mainly proline-rich proteins are added forming globular structures (from 20 to $300 \mathrm{~nm}$ arranged in the form of clusters), which are afterwards fused, forming long units that cover the whole enamel. In the second stage, by action of proteolytic enzymes the molecular conformation of the pellicle is altered and the globular structure gets lost. The first phase is quantitatively the most important, while the second one, which corresponds to the process of maturation of the integument, has functional importance in relation to the bacterial colonization $[3,4]$.

\subsection{Acquired enamel pellicle functions}

AEP has different functions, among which are:

- Protective barrier of enamel from acidic substances from the diet or formed during bacterial metabolism. Therefore, it prevents demineralization and acid erosion.

- Promotion of the enamel remineralization process. Constituent proteins of the acquired film such as staterins and proline-rich proteins favor the stabilization of calcium and phosphate ions under supersaturation conditions. These participate in the maturation of the enamel after the eruption of the teeth (posteruptive maturation).

- Reduction of tooth friction forces developed during chewing.

- Prevention of the drying of the surfaces it covers, due to the presence of mucoproteins that are capable of retaining water.

The AEP also provides sites for the adhesion of oral microorganisms, giving rise to the formation of the dental biofilm. In addition, lactoferrin (another protein present in the film) fixes iron, essential for bacterial metabolism. As counterpart, 
has been observed that certain proteins and enzymes present in the AEP affect the development of the biofilm bacteria. The presence of lysozyme in the pellicle destabilizes the bacterial wall producing cell lysis and lactoperoxidase forms compounds that inhibit the metabolism of glucose in bacteria $[3,4]$.

\section{Dental biofilm}

The DB is a dense bacterial mass, constituted by different types of microorganisms organized in a coccoid, filamentous or bacillary form, embedded in an intermicrobial matrix that accumulates on the structures of the tooth. It is metabolically active, organized and potentially pathogenic. Inside the DB a continuous reorganization and bacterial succession take place. Therefore, this organized bacterial complex survives the challenges of a constantly changing environment.

It is of utmost importance to understand the dental biofilm as an ecosystem, where a complex of bacteria and their products are embedded in an abiotic extracellular material of bacterial, salivary and dietary origin.

$70 \%$ of the DB consists of microorganisms. The remaining $30 \%$ is made up of organic and inorganic components. Water represents $80 \%$ (it allows the dissolution of minerals and nutrients within the environment), proteins $40 \%$, carbohydrates $(\mathrm{CH})$ between 13 and $18 \%$. Glucose is the principal $\mathrm{CH}$, which can be found in two forms: extra and intracellular polysaccharides. The proteins of the biofilm come from bacteria, gingivocrevicular fluid and saliva. The main proteins are amylase, lysozyme, albumin and immunoglobulins IgA and IgG.

The architecture of the dentobacterial deposits is an important factor both for the regulation of microbial physiology and for the ecology of the place. The microbial behavior depends on the thickness of the deposit, its density, its ratio of bacterial cells/organic matrix and the presence of channels in this structure [5].

\subsection{Factors that influence the development of dental biofilm}

In the development of $\mathrm{DB}$, various factors are involved:

- Anatomy, position and structure of the teeth: bacteria colonize different types of dental surfaces because they have fimbriae, exopolysaccharides and hydrophobic. All these properties are implicated in its capacity to adhere to the surface.

- Bacterial metabolism: aerobic or anaerobic.

- Presence and quantity of bacterial nutrients.

- Composition of saliva and gingivocrevicular fluid: $\mathrm{pH}$, ions, temperature and fluidity favor the production of biofilm on the tooth surface.

- Host diet: fermentable carbohydrates (cariogenic), consistency, frequency and speed of sweep of the oral cavity.

- Oral hygiene maintenance.

\subsection{Structure of dental biofilm}

The three-dimensional character of the bacteria is reflected in the structure of the DB. It may be: (a) immature: the one that takes place after a few hours of formation or

(b) mature: the one that takes place several days after its appearance, which is considered 
metabolically active and organized. The accumulation of bacteria on the surface of the tooth is a result of the balance between adhesion, growth and removal of bacteria. It reaches a saturation point where it is no longer possible to increase its volume. Inside the DB structure there is reorganization and bacterial succession continuously [5].

\subsection{Supragingival dental biofilm}

The supragingival dental biofilm is located from the gingival margin to the dental crown. Gram-positive microorganisms predominate, mainly Streptococcus spp., among them the most abundant are $S$. sanguis, S. sobrinus and especially $S$. mutans. Actinomyces sp., such as $A$. viscosus, $A$. naeslundii and $A$. israelii as well as other varieties. Among the Gram-negative bacteria anaerobic such as Fusobacterium, Prevotella and Porphyromonas predominate [6].

\subsection{Dental biofilm formation process}

The process of forming the dental biofilm is characterized by a series of ordered stages:

1. Bacterial transport to the acquired film: almost simultaneously with the formation of the acquired film, microorganisms proceeding from the salivary flow, tongue, desquamated cells of the mucosa (bacteria adhered to aforesaid cells) and other microorganisms with inherent mobility capacity found in the oral environment start to adhere to the dental surface. Between zero and 4 hours after correct oral hygiene, few bacteria are observed on the surface of the teeth.

2. Primary colonization: later interactions between bacterial proteins (adhesins) and specific receptors of the acquired film allow the irreversible adhesion of the first colonizing microorganisms. Gram-positive and Gram-negative bacteria predominate, including coccoid and filamentous forms. Diverse ionic and electrostatic interactions, covalent bonds as well as other molecular interactions are established. Probably one of the most important adhesive mechanisms is mediated by glucans (extracellular polysaccharides synthesized by bacteria). This allows bacteria not only to adhere to the surface but also to add to each other.

Adherent microcolonies are originated by a mucosal layer surrounding several cells. At this stage the DB is still very thin; Streptococcus sanguis is probably the first colonizer. The metabolism is aerobic and the microbial nutrition comes from the salivary glycoproteins and sugars in the diet. Other primary colonizers are Streptococcus mitis, Streptococcus oralis, Actinomyces naeslundii, and to a lesser extent other bacteria, most of them aerobic and facultative anaerobes.

3. Coadhesion phenomenon (secondary and tertiary colonization): it takes place between the primary and late colonizers and is characterized by an active multiplication of bacteria, aggregation (taxonomically related bacteria) and coaggregation (bacteria that have little to do from the taxonomic point of view). Interactions are mediated between adhesins, lectins, and specific receptors, which increases the complexity of the microbial mass. Diverse phenomena occur, leading to qualitative changes in the ecosystem, such as competition for nutrients, production of $\mathrm{H}_{2} \mathrm{O}_{2}$, release of bacteriocins, oxygen consumption and others. The extracellular polymers constitute the matrix that surrounds the bacteria, which guarantees their firm adhesion. Among bacteria there are numerous water channels that allow the diffusion of nutrients and elimination of metabolic waste. 
4. Detachment of bacteria: the attached bacteria can be released in response to changes that occur in the environment (e.g. $\mathrm{pH}$, concentration of specific ions, etc.). The production of inhibitory substances against other bacteria can also influence this phenomenon. These changes lead also to a competition for nutrients and the creation of unfavorable conditions for the growth of certain bacterial species [7].

In the already formed DB, channels or open spaces that go from the outside to the surface of the enamel are observed, which allow the penetration and distribution of molecules in its interior. The bacterial metabolism guarantees the right environment for the growth of bacteria ( $\mathrm{pH}$ and adequate amount of oxygen). Some of them split polymers into smaller units, others are able to reduce sulfates, and others obtain energy from simple metabolic products.

The surface of the tooth is an indispensable natural habitat for S. mutans, since this organism cannot be detected in the mouth until the eruption of the teeth and disappears shortly after the loss of the teeth. S. mutans is able to form DB through a series of mechanisms such as the expression of the SpaP surface adhesin and the ability to synthesize insoluble extracellular polysaccharides that improve its accumulation in the tooth [8].

Within biofilms, bacteria have developed their own signals or communication systems through small molecules which allows them to survive in unfavorable and densely populated environments. In addition, this signal system favors the expression of genes associated with the caries or with the acid tolerance of the environment in which they develop. The transfer of genetic information, explaining the antibiotic resistance among native microbiota species, has also been described. Bacteria regulate these physiological processes through a mechanism called quorum sensing (QS), defined as a bacterial mechanism of intercellular communication to control the expression of genes in response to population density. Due to a particular environmental stimulus, bacterial cells can communicate and behave collectively to provide significant benefits in host colonization, defense against competitors and adaptation to different physical variants [8].

The QS system consists generally of three components: (a) a signal peptide and (b) a double regulatory system (DRS), which in turn has a (c) histidine kinase (HK) sensor attached to the membrane and an intracellular response regulator (RR). $S$. mutans is a bacterium that has evolved into a "lifestyle" biofilm in order to survive and persist in its natural environment. The Quorum detection system, essential for genetic competence in $S$. mutans (cell-cell signaling system), involves at least five genetic products encoded by cslAB (comAB) and comCDE [9].

The genes comC, comD, and comE are adjacent within the chromosome and constitute a peptide signaling system (PSS) including a generation pathway and a response pathway, respectively. The comC and comDE genes encode, respectively, a peptide precursor of the PSS, the sensor protein (HK) and an intracellular response regulator (RR) [9].

The other two genes, cslA and cslB, are located in a separate region of the chromosome and encode a CSP-specific secretion apparatus consisting of an ATPbinding cassette transporter (ComA) and an accessory protein to ComA (ComB), which presumably participate in the processing and export of the CSP. ComE is responsible for the regulatory response of the QS system producing activities dependent on cell density (bacteriocins) (Figure 1).

This quorum sensing system works optimally when cells live actively in the growing dental biofilm, suggesting that cell-cell signaling is the system that could play a role in the formation of $S$. mutans biofilms $[9,10]$. 


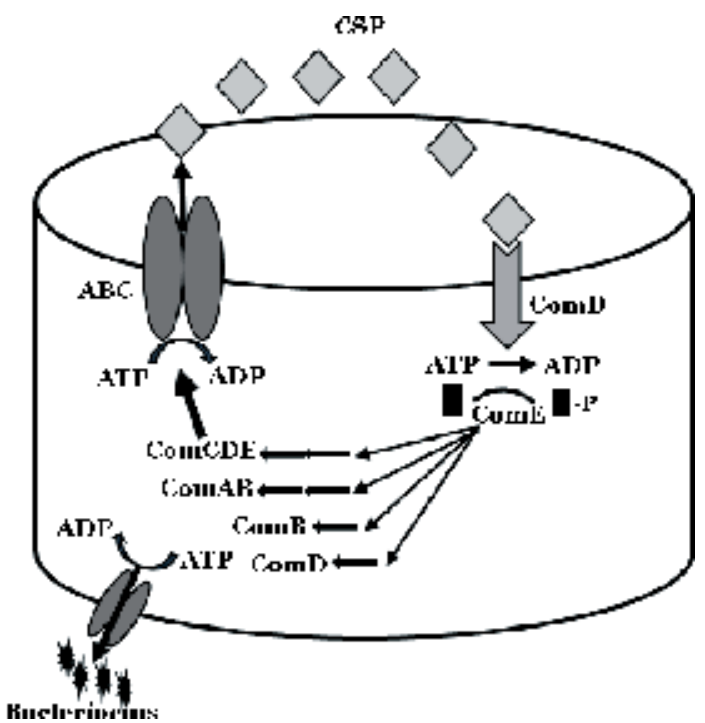

Figure 1.

Scheme of the quorum detection system Com CDE and its genes regulated in S. mutans. The ComCDE encodes a signal peptide precursor, which is exported through a specific ABC transporter and generates a competing stimulating peptide (CSP). The Com CDE encodes a component transduction system that specifically detects and responds to CSP. When it reaches a critical concentration CSP interacts with the ComD receptor protein and activates its ComE response regulator. The phosphorylated ComE, in turn, activates the genes downstream, which triggers the signaling cascade for the production of activities dependent on cell density (bacteriocins).

\subsection{Cariogenicity of dental biofilm}

The DB of the oral surfaces establishes a dynamic balance with the host's defenses, compatible with the maintenance of the integrity of the tissues. Oral diseases occur when the composition and metabolic activities of dental biofilm communities are disturbed by the $\mathrm{pH}$, oxygen tension and nutrients of the environment. These ecological changes in the DB result in an increase in the proportion of pathogenic microorganisms, which have more virulent structural and enzymatic determinants than those of microorganisms related to healthy conditions. Caries is a disease associated with the supragingival dental biofilm. It is produced by the action of acidogenic bacteria, which degrade fermentable carbohydrates of the diet and produce acids as result of their metabolism [11].

The cariogenicity of the dental biofilm increases with the retention of bacterial nutrients and the greater permanence of organic acids in it. The structure of the dental biofilm allows these acids to be longer in contact with the tooth surface, causing the demineralization process [12].

S. mutans has important properties that enable it to predominate in the dental biofilm and induce the development of caries. These properties are known as virulence factors and provide the microorganism with survival advantages over other bacteria common to the oral ecosystem [13].

Among these cariogenicity factors are:

Acidogenic: production of acid (mainly lactic acid) through the fermentation of refined sugars such as sucrose and glucose. This causes the environmental $\mathrm{pH}$ to drop to values of 5.5 or $4.5, \mathrm{pH}$ called critical, which initiate the demineralization of tooth enamel.

Aciduric: factor that refers to the capacity of the microorganism to continue lowering the $\mathrm{pH}$ in acidic conditions. 
Acidophilic: ability to grow and survive in acid $\mathrm{pH}$. Not all bacteria resist these conditions. This is a fundamental domain element in the dental biofilm.

Synthesis of intracellular polysaccharides: these are homopolysaccharides and have a major role as nutritional reserve.

Synthesis of extracellular polysaccharides: permit the synthesis of a mucous layer constituted by polysaccharides, provided a high availability of sugars in the medium, such as water, soluble glycans (dextrans), hydroinsoluble glycans (mutans) and water-soluble fructans (levans).

Post-short pH effect: despite rapid decreases in ambient $\mathrm{pH}$, a rapid physiological recovery of the microorganism occurs. This mechanism prevents the entry of new molecules of sucrose by activating pyruvate kinase or generating alkaline products resulting from protein catabolism.

Synthesis of cell adhesion proteins: antigenic proteins found in the wall of $S$. mutans and initiate adhesion to the tooth surface. They may have different functions depending on the region of the protein in question: aggregation (hydrophobic amino terminal region), and adhesion (amino terminal region rich in alanine). On the other hand, they can also bind to collagen in the dentinal tubules, an important property in the development of root caries. This suggests that these molecules possess several receptors, which interact with the secretory component of IgAs, albumin, agglutinins and salivary glycoproteins.

Glucan receptor proteins: these are extracellular products of bacteria which associate or bind glucans in the presence of sucrose and therefore are involved in the formation processes of the dental biofilm. All glucan binding proteins show affinity for glycans rich in $\alpha-1.6$ glycosidic bonds.

Mutacin production: also called bacteriocins, are substances of peptide nature with antimicrobial activity. S. mutans through these molecules can eliminate other bacterial species from the dental biofilm, giving this microorganism an ecological advantage for colonization.

Each of these properties acts in coordination to alter the ecology of the dental biofilm by increasing the proportions of $S$. mutans over other acidogenic and acidresistant species in the environment [13].

In addition, the ability of $S$. mutans to use sucrose to promote its adhesion and accumulation in the dental biofilm is very significant. This provides the microorganism a pathogenic potential if the physiology of the host and the general ecology of the oral microbiota allow it.

\subsection{Biochemistry of the dental biofilm}

Bacteria possess the ability to metabolize a large amount of organic and inorganic compounds. Said metabolism has as its purpose the supply of carbon and energy necessary for its growth and reproduction.

In the absence of oxygen, $S$. mutans metabolizes glucose giving as final product lactic acid. Depending on the metabolic conditions, it can also synthesize glycogen for energy reserves and, in the event of a sucrose deficit, degrade it to obtain energy.

The fermentable carbohydrates of the diet are the main source of energy for most of the bacteria present in the dental biofilm. The association of the consumption of sugars with dental caries depends on the bioavailability and the structural characteristics of the DB [5].

\subsection{Extracellular cleavage of sucrose}

Sucrose is a low molecular weight disaccharide, soluble in water, easy to diffuse through the biofilm and converted into organic acids by bacteria such as $S$. mutans and Lactobacillus sp. 
For their splitting, these bacteria produce and secrete a family of enzymes called glucosyltransferases (Gtfs), which hydrolyze sucrose into glucose and fructose. These enzymes take the glucose molecule and bind it to a pre-existing glucose chain. In this way, the chain lengthens and gives rise to the extracellular polysaccharides (glucans).

S. mutans produces at least three genetically different $\mathrm{Gtfs}$, each of which synthesizes a glucan structurally different from sucrose. GtfB synthesizes mainly insoluble glucan rich in $\alpha-1.3$ glycosidic bonds. GtfC produces a mixture of solubles (with mostly $\alpha-1.6$ bonds) and insoluble glycans, and GtfD predominantly forms soluble glucans. Each one plays a different role in the formation of the dental biofilm [5].

$\mathrm{GtfC}$ adsorbed to the enamel within the biofilm, while GtfB binds avidly to the bacteria, promotes cell clustering and improves the cohesion of the biofilm. GtfD, on the other hand, forms a soluble polysaccharide, easily metabolizable and acts as a primer for GtfB.

When the enzymes involved in the sucrose break are the fructosyltransferases (Ftfs), the final product are extracellular polysaccharides of the levans type: water solubles fructans, glycosidic bond type: $\alpha-2.6$ and $\alpha-1.2$ (Figure 2).

Soluble glucans and fructans have a nutritional function in the absence of exogenous carbohydrate intake. This is because they are easily degradable by enzymes such as glucanases and fructanases. On the other side, insoluble glucans are difficult degraded by bacteria and have greater adherent properties, intervening in the socalled glucan-mediated unions; important for the formation of the dental biofilm in which the Gtfs themselves and host receptors also participate [5].

The organic acids resulting from the bacterial metabolism of fermentable carbohydrates are, in addition to lactic, acetic, butyric and carboxylic. Lactic acid produces the most notorious changes; since the greater extracellular concentration of it, the more accentuated is the $\mathrm{pH}$ drop of the dental biofilm, up to the critical level of dissolution of hydroxyapatite (inorganic enamel component) which is around 5.5 (Figure 3 ).

\subsection{Acid survival of Streptococcus mutans in the dental biofilm}

The microorganisms involved in the caries must be able not only to grow, but must possess the ability to survive in acidic environments.

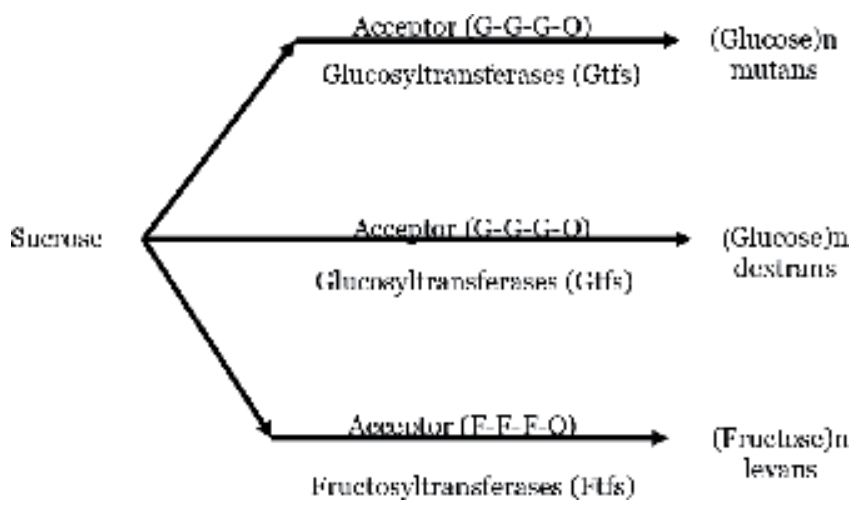

Figure 2.

Enzymatic cleavage of sucrose. Glucosyltransferases (Gtfs) hydrolyze sucrose into glucose and fructose. These enzymes take the glucose molecule and bind it to a pre-existing glucose chain [acceptor (GGGO)]. The chain lengthens and gives rise to extracellular polysaccharides (mutans and dextrans). Fructosyltransferases (Ftfs) hydrolyze sucrose, take the fructose molecule and bind it to a pre-existing fructose chain [acceptor (FFFO)] and the final product is the levans polysaccharides. 


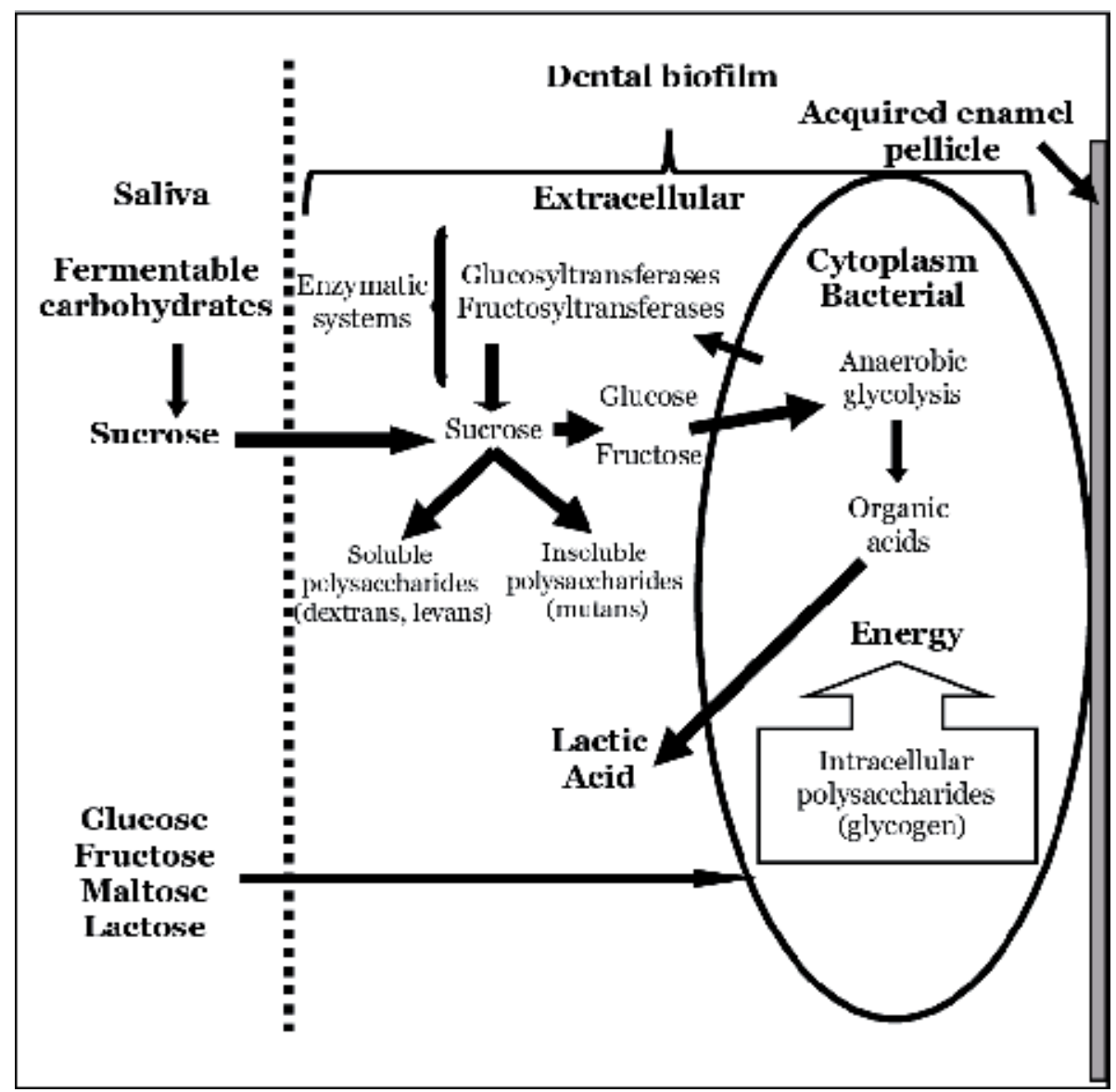

Figure 3.

Schematic representation of bacterial metabolic activity in the dental biofilm. Metabolism of various carbohydrates (including glucose and fructose) by bacterial biofilm. Production and secretion of a significant amount of lactic acid, which can cause demineralization of teeth structure that can finally result in the development of decay.

S. mutans and S. sobrinus have a higher average acid production rate compared to other oral streptococci such as S. mitis, S. oralis, S. gordonii, S. sanguis, S. intermedius, S. anginosus, S. constellatus and S. vestibularis [14].

There is a different acidification capacity of the $S$. mutans medium as it comes from different carious dental surfaces: either a carious smooth tooth surfaces (CSTS) or a carious occlusal tooth surfaces (COTS).

The strains developed in CSTS possess greater cariogenic capacity, probably induced by the different ecosystem developed in the smooth surface decayed, showing the particular importance of it [15].

The acidogenic power (virulence factor) of $S$. mutans can lead to ecological changes in the microbiota of the dental biofilm, which includes an increase in the proportion of acid-producing $S$. mutans to the environment and the decrease in the microbiota sensitive to said acidity (Streptococcus mitis, oralis and sanguis).

Accompanying its acidogenic power, S. mutans possesses the characteristic of acid tolerance. It retains its ability to survive even at $\mathrm{pH}$ levels that are inhibitory for some bacterial species ( $\mathrm{pH} 4.4$ ), this being a distinctive feature of this species [14].

In CSTS, S. mutans is more acidogenic and has greater resistance and survival to the acidity of the medium, therefore these microorganisms developed in CSTS have greater cariogenic capacity compared with those developed in COTS [15]. 
One of the strategies for increasing the acid survival of S. mutans in CSTS is to change the fatty acid profile of its membrane from saturated and short chains to monounsaturated and long chains at $\mathrm{pH}$ 5. These changes induce an increase in the interrelation of the acidic chains in the lipid bilayer, which allows correlate it with the increase of its stability (greater rigidity) [15].

\section{Activity of the F-ATPase and P-ATPase of Streptococcus mutans membrane}

F-ATPase and P-ATPase are present in the membrane of $S$. mutans to maintain intracellular homeostasis. These constitutive enzymes represent ATPases with proton pump function. The induction of proton pumps in acidic environments and the consequent expulsion of protons from the cell to the exterior helps to maintain a high cytoplasmic $\mathrm{pH}$ in comparison to its environment. The activity of these enzymes is very important for the acid tolerance of microorganisms such as $S$. mutans, in such a way that the optimum $\mathrm{pH}$ of the F-ATPases are directly related to the capacity of the microorganism to survive in acidic conditions ( $\mathrm{pH}$ 5) [15].

In addition to the F-ATPases, there is a $100-\mathrm{kDa}$ membrane protein called P-ATPase that can maintain a cytosolic $\mathrm{pH}$ close to neutrality during the growth of the microorganism. This is a different protein from F-ATPase, due to its sensitivity to orthovanadate and lansoprazole [16].

In the intracellular metabolism of $S$. mutans, protons from the anaerobic glycolytic pathway acidify the cytoplasm, but glycolytic enzymes as well as other cellular functions, are sensitive to inhibition by intracellular acidity. Therefore, the function of the F- and P-ATPase is to translocate of protons to the outside and to maintain a $\mathrm{pH}$ gradient across the cytoplasmic membrane compatible with life.

The increase of the activity of the F-ATPase and the membrane P-ATPase of microorganisms developed in acid environment indicates that the enzymatic activity is one of the main mechanisms of the acid tolerance for oral streptococci [16].

S. sobrinus has a higher acid resistance than S. mutans; the differences in the mechanisms of acid tolerance between the two microorganisms are due to the fact that $S$. sobrinus is genetically tolerant acid [15].

As mentioned above, in the plasma membrane there are integral or transmembrane proteins (F-ATPase and P-ATPase). The interactions between this type of membrane proteins and the surrounding lipid environment are important to determine its structure and function.

The integral proteins of the lipid bilayer require that the hydrophobic transmembrane region of the protein matches the hydrophobic region of the lipids, in order to avoid an unfavorable energetic contact in said regions. When there are no coincidences in the hydrophobic lipid-protein zones, misalignments occur, leading to a phase separation or segregation of the lipid components with the proteins, creating domains enriched in one of the two components.

Furthermore, the length of the acidic chains of the bilayer lipids affects the state of protein aggregation or hydrophobic lipid-protein mismatch [15].

When the length of the acidic chain is greater than the hydrophobic extension of the protein, it tends to aggregate forming dimers, separating from the lipid and decreasing the hydrophobic interaction between the two. On the other hand, when the length of the chain is smaller than the hydrophobic zone of the protein, monomeric aggregates of the protein are produced with lipids trapped inside them, establishing interactions with the protein. With lengths of intermediate chains, coincidences with the hydrophobic zones of the protein take place and this adopts a monomeric form, leaving the totality of its hydrophobic surface in total coincidence with that of the lipids [15]. 
The non-coincidence in the hydrophobic zone leads to the separation of the lipids in relation to the protein components, and to the formation of domains with a predominance of lipids or proteins.

The greater hydrophobic contact of the lipid with the protein occurs in the CSTS and this favors the greater activity of the ATPase. On the other side, the lower hydrophobic lipid/protein contact in the COTS produces a mismatch between the lipid and protein component, which negatively affects the enzymatic functionality (total ATPase).

Therefore, a correlation between the hydrophobic regions of the protein and that of the surrounding lipids is necessary for the optimal functionality thereof.

In addition, the hydrophobic thickness of the bilayer must match the hydrophobic thickness of the protein embedded in the bilayer because of the high-energy costs that occur when the acyl chains of the fatty acids or the hydrophobic amino acids contact with water. The lack of coincidence between the hydrophobic thicknesses of the lipid bilayer and the protein leads to the distortion of the lipid bilayer, or of the protein, or both, to minimize the mismatch [15].

The acyl chains neighboring a membrane protein adjust its length to match the hydrophobic thickness of the protein. Indeed, when the hydrophobic thickness of the bilayer is less than that of the protein, the lipid chains neighboring the protein are "stretched" to provide a thicker bilayer, creating a positive curvature (exocytosis). Conversely, when the hydrophobic thickness of the bilayer is greater than that of the protein, the lipid chains are "compressed" to provide a thinner bilayer, creating a negative curvature (endocytosis). The relatively small changes in the binding of lipids with proteins are due to changes in the lengths of the acyl chains.

In conclusion, the acyl chains are "stretched" or "compressed" to provide, as much as possible, a complete hydrophobic match with the protein zone. This leads to changes in the spontaneous curvature of the lipid bilayer coupled with possible conformational changes or distortion of the membrane protein to provide the strongest interactions. Both the lipid and the protein modified to favor the best interaction, with the result of an optimal activity. The function of the protein is dependent on the structure of the lipid that surrounds it.

The different organization of the microbial membrane according to the dental surface where $S$. mutans are developed are exemplified in Figures 4 and 5, which show how lipids and proteins interact and how this interaction can affect the enzymatic activity of ATPase (virulence factor).

In CSTS, the increase of long-chain unsaturated fatty acids improves the interrelation of these with the hydrophobic sectors of the ATPase protein, which contributes to the greater enzymatic activity or greater expulsion of $\mathrm{H}^{+}$to the outside (Figure 4), so in CSTS, the virulence factor of S. mutans is increased. On the other hand, when chains of membrane fatty acids are shorter and more saturated as in COTS, spaces or "pockets" can occur between the lipid and the protein, influencing the behavior of ATPase. In this case, the contact zones between the hydrophobic portion of the protein and that of the fatty acids did not coincide completely (Figure 5). Consequently, of this mismatch the enzymatic activity is diminished and there is not sufficient expulsion of $\mathrm{H}^{+}$to the exterior (decreased virulence factor).

The change in the membrane fatty acid profile of $S$. mutans and the changes in total ATPase activity are simultaneous processes.

The greater enzymatic activity in CSTS would relate to changes in the organization of the membrane, induced by changes in lipid composition, which favor the best interaction between the hydrophobic segments of both components lipid and protein [15]. 


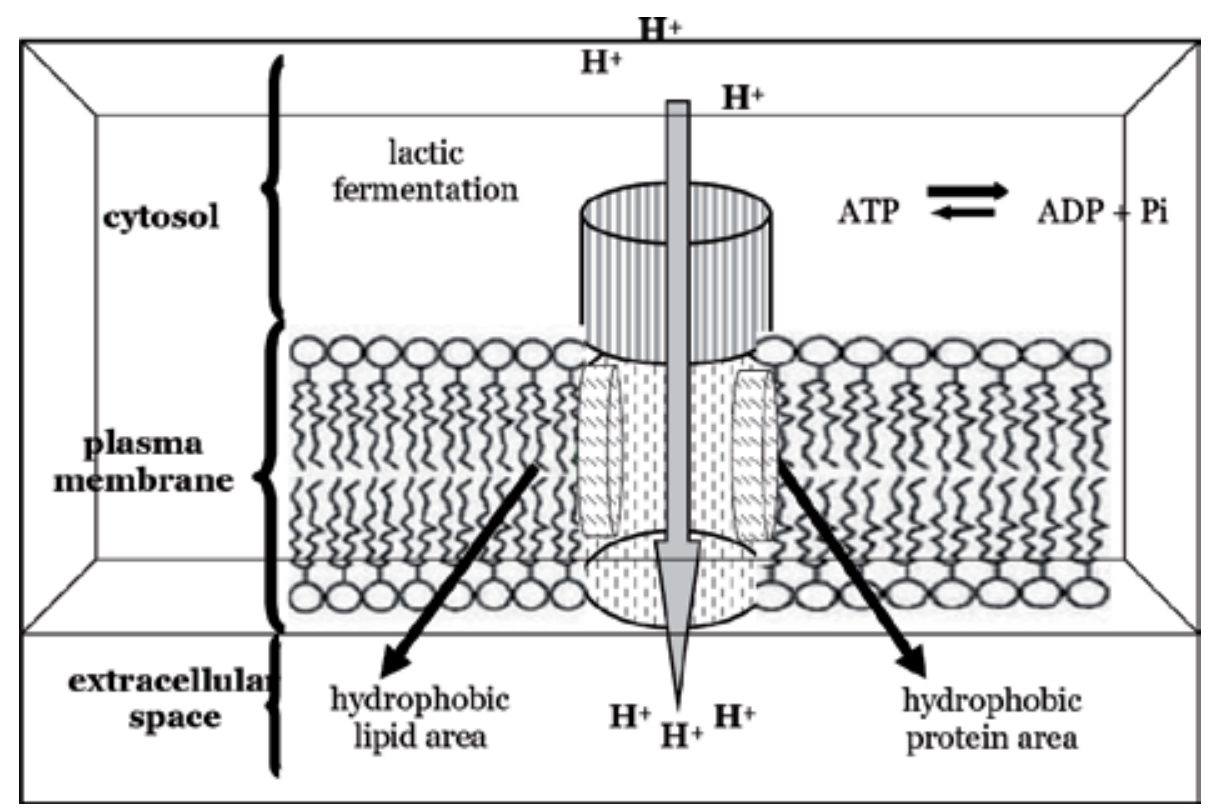

Figure 4.

Lipid-protein interaction in CSTS. The hydrophobic region of the acyl chains coincides with the entire hydrophobic region of the protein. In this case, the enzyme functionality (higher ATPase activity) is favored by better protein-lipid hydrophobic matching, preventing distortion of both parties.

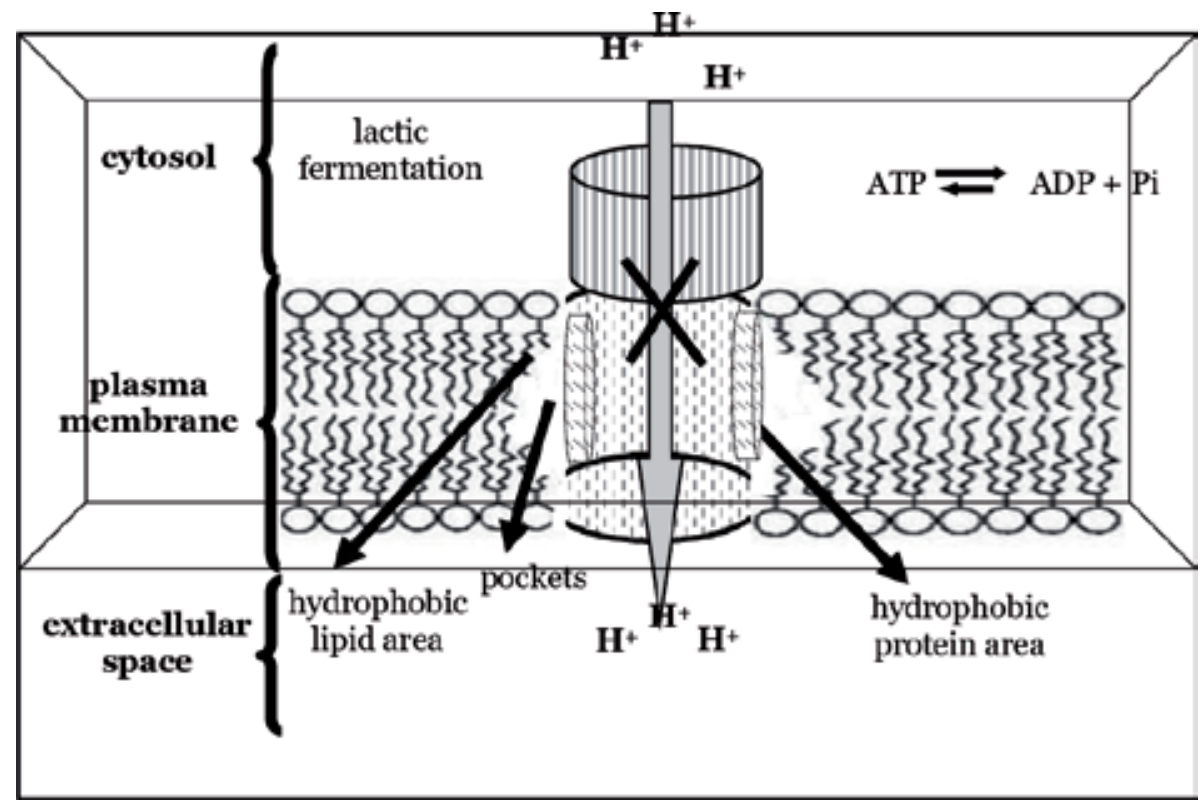

Figure 5.

Lipid-protein interaction in COTS. The hydrophobic region of the acyl chains does not fully coincide with the hydrophobic region of the protein, creating "pockets" due to a mismatch between the lipid and protein components, affecting adversely the enzyme functionality.

\section{Conclusions}

The main virulence factors of $S$. mutans are its ability to utilize sucrose to promote adhesion and accumulation in dental biofilms, its acidogenicity and its 
tolerance to acids. The acid survival of $S$. mutans depends both on the $\mathrm{pH}$ of the medium and on the composition of fatty acids and proteins plasma membrane (F-ATPase and P-ATPase).

As with most host-microbe interactions, these attributes only provide the organism with pathogen potential. The physiology of the host and the overall oral flora ecology may or may not suppress this potential.

The advance in the knowledge of how complex and heterogeneous can be the disease of the caries, according to the surface or the biofilms where it develops, can be useful to design new strategies of therapy in the treatment of this disease.

\section{Acknowledgements}

The selfless collaboration of Dr. Ana Maria Zarate is greatly appreciated. We would like to thank the Department of Biological Chemistry. Department of Microbiology. Oral Biology Department School of Dentist, National University of Córdoba. Argentina.

This work was funded by SECyT-Universidad Nacional de Córdoba (UNC) [04745/2014].

\section{Conflict of interest}

We declare that there is no conflict of interest that could be perceived as prejudicing the impartiality of the research reported.

\section{Author details}

Bojanich María Alejandra* and Orlietti Mariano Daniel

Department of Biological Chemistry, Department of Microbiology, Oral Biology

Department, School of Dentistry, National University of Córdoba, Córdoba,

Argentina

*Address all correspondence to: mariaalejandraboja@gmail.com

\section{IntechOpen}

(C) 2020 The Author(s). Licensee IntechOpen. This chapter is distributed under the terms of the Creative Commons Attribution License (http://creativecommons.org/licenses/ by/3.0), which permits unrestricted use, distribution, and reproduction in any medium, provided the original work is properly cited. (cc) BY 


\section{References}

[1] Simón-Soro A, Mira A. Solving the etiology of dental caries. Trends in Microbiology. 2015;23(2):76-82. DOI: 10.1016/j.tim.2014.10.010

[2] Zhu W, Liu S, Zhuang P, Liu J, Wang Y, Lin H. Characterization of acid-tolerance-associated small RNAs in clinical isolates of Streptococcus mutans: Potential biomarkers for caries prevention. Molecular Medicine Reports. 2017;16(6):9242-9250. DOI: 10.3892/mmr.2017.7751

[3] Hannig M, Joiner A. The structure, function and properties of the acquired pellicle. Monographs in Oral Science. 2006;19:29-64. DOI: 10.1159/000090585

[4] Hannig M, Hannig C. The pellicle and erosion. Monographs in Oral Science. 2014;25:206-214. DOI: $10.1159 / 000360376$

[5] Krzyściak W, Jurczak A, Kościelniak D, Bystrowska B, Skalniak A. The virulence of Streptococcus mutans and the ability to form biofilms. European Journal of Clinical Microbiology \& Infectious Diseases. 2014;33(4):499-515. DOI: 10.1007/s10096-013-1993-7

[6] Wake N, Asahi Y, Noiri Y, Hayashi M, Motooka D, Nakamura S, Gotoh K, Miura J, Machi H, Iida T, Ebisu S. Temporal dynamics of bacterial microbiota in the human oral cavity determined using an in situ model of dental biofilms. NPJ Biofilms Microbiomes. Aug 10 2016;2:16018. DOI: 10.1038/ npjbiofilms.2016.18. eCollection 2016

[7] Gibbons RJ, Hay DI. Adsorbed salivary acidic proline-rich proteins contribute to the adhesion of Streptococcus mutans JBP to apatitic surfaces. Journal of Dental Research. 1989;68(9):1303-1307. DOI: 10.1177/00220345890680090201

[8] Koo H, Falsetta ML, Klein MI. The exopolysaccharide matrix: A virulence determinant of cariogenic biofilm. Journal of Dental Research. 2013;92(12):1065-1073. DOI: 10.1177/0022034513504218

[9] Cvitkovitch DG, Li YH, Ellen RP. Quorum sensing and biofilm formation in streptococcal infections. The Journal of Clinical Investigation. 2003;112(11):1626-1632. DOI: 10.1172/ JCI20430

[10] Li YH, Tang N, Aspiras MB, Lau PC, Lee JH, Ellen RP, et al. Aquorumsensing signaling system essential for genetic competence in Streptococcus mutans is involved in biofilm formation. Journal of Bacteriology. 2002;184(10):2699-2708. DOI: 10.1128/ JB.184.10.2699-2708.2002

[11] Klein MI, Hwang G, Santos PH, Campanella OH, Koo H. Streptococcus mutans-derived extracellular matrix in cariogenic oral biofilms. Frontiers in Cellular and Infection Microbiology. 2015;5:10. DOI: 10.3389/fcimb.2015.00010

[12] Deng DM, ten Cate JM.

Demineralization of dentin by

Streptococcus mutans biofilms grown in the constant depth film fermentor. Caries Research. 2004;38(1):54-61. DOI: 10.1159/000073921

[13] JA1 B. Virulence properties of Streptococcus mutans. Frontiers in Bioscience. 2004;9:1267-1277. pmid: 14977543

[14] Baker JL, Faustoferri RC, Quivey RG Jr. Acid-adaptive mechanisms of Streptococcus mutans-the more we know, the more we don't. Molecular Oral Microbiology. 2017;32(2):107-117. DOI: 10.1111/omi.12162

[15] Bojanich MA, Calderón RO. Streptococcus mutans membrane lipid composition: Virulence factors and structural parameters. Archives of Oral 
Staphylococcus and Streptococcus

Biology. 2017;81:74-80. DOI: 10.1016/j. archoralbio.2017.04.023

[16] Magalhães PP, Paulino TP, Thedei G Jr, Larson RE, Ciancaglini P. A 100 kDa vanadate and lanzoprazole-sensitive ATPase from Streptococcus mutans membrane. Archives of Oral Biology. 2003;48(12):815-824. pmid: 14596871 


\title{
Toward Better Understanding on How Group A Streptococcus Manipulates Human Fibrinolytic System
}

\author{
Adam J.H. Quek, James C. Whisstock and Ruby H.P. Law
}

\begin{abstract}
Group A Streptococcus pyogenes (GAS) is a human pathogen that commonly causes superficial infections such as pharyngitis, but can also lead to systemic and fatal diseases. GAS infection remains to be a major threat in regions with insufficient medical infrastructures, leading to half a million deaths annually worldwide. The pathogenesis of GAS is mediated by a number of virulence factors, which function to facilitate bacterial colonization, immune evasion, and deep tissue invasion. In this review, we will discuss the mechanism of molecular interaction between the host protein and virulence factors that target the fibrinolytic system, including streptokinase (SK), plasminogen-binding group A streptococcal M-like protein (PAM), and streptococcal inhibitor of complement (SIC). We will discuss our current understanding, through structural studies, on how these proteins manipulate the fibrinolytic system during infection.
\end{abstract}

Keywords: hemolytic Streptococcus, streptokinase, plasminogen-binding streptococcal M protein, streptococcal inhibitor of complement, plasmin, host-pathogen coevolution

\section{Introduction}

Group A Streptococcus (GAS) is a strict human pathogen that leads to diverse clinical manifestations, ranging from superficial infections, such as pharyngitis, to severe cases of streptococcal toxic shock syndrome and necrotizing fasciitis mainly in children and young adults [1]. GAS infection can also lead to a range of post-streptococcal autoimmune sequelae such as acute rheumatic fever, rheumatic heart disease, and acute glomerulonephritis [2,3]. Life-threatening systemic GAS infection is more prevalent in, but not limited to, regions with insufficient medical infrastructures and is estimated to cause more than half a million deaths annually worldwide $[4,5]$. Through coevolution, GAS has perfected its ability to manipulate the host fibrinolytic system for invasion. In human, the plasminogen/plasmin $(\mathrm{Plg} / \mathrm{Plm})$ system plays a key role in fibrinolysis, tissue remodeling, and wound healing [6-9]. This review aims to focus on the current understanding on molecular mechanisms adopted by GAS to hijack the host Plg/Plm system during infection. 


\section{The plasminogen/plasmin system}

The early observation that streptococci stimulate fibrinolysis by Dr. William S. Tillett in 1933 [10] had triggered the subsequent discoveries on how streptococci manipulated the fibrinolytic system to facilitate blood clot dissolution [11]. The actual protein responsible for the clot lysis is in fact a constituent of the human plasma, instead of the bacteria, and is not fibrinolytic until activated by the streptococcal protein named streptokinase (SK) $[12,13]$. This human lytic factor is plasmin (Plm), an activated form of plasminogen (Plg).

\subsection{Structure of Plg}

Plasmin $(\mathrm{Plm})$ is a plasma serine protease responsible for many physiological functions such as cell migration [14], wound healing [15], inflammation [16], and prohormone processing [17]. Plm circulates in an inactive zymogen form called plasminogen (Plg).

Primarily synthesized and secreted by the liver [18], native Plg is a $89-92 \mathrm{kDa}$ glycoprotein comprising of seven domains: an N-terminal PAN-apple domain (PAp), followed by five homologous kringle domains (KR-1 to KR-5) and a serine protease domain (SP) (Figure 1a) [19, 20]. The PAp domain is important for maintaining a compact conformation (closed) in the circulation [21]. Each KR domain has a lysine-binding site (LBS) that consists of the Asp-X-Asp/Glu motif (except KR-3 which has the Asp-X-Lys mutation) that recognizes and binds to surface lysine or arginine residues, such that the KR domains facilitate the binding of $\mathrm{Plg}$ and $\mathrm{Plm}$ to substrates and targets (such as fibrin and cell surface receptors) which leads to the conformational change from close to open. SP is the catalytic domain. In the zymogen form, residues $\mathrm{His}_{603}, \mathrm{Asp}_{646}$, and $\mathrm{Ser}_{741}$ (also called the catalytic triad) adopt an inactive configuration.

\subsection{Physiological activation of Plg}

In mammals, the two key physiological Plg activators are tissue-type (tPA) and urokinase-type (uPA) Plg activators (Figure 1b). Activation of Plg requires its colocalization with the activators; the expression of these activators is regulated both spatially and temporally in vivo [22-24]. Thus, Plm plays a key role in fibrinolysis intravascularly on the surface of fibrin clots in the presence of tPA and cellular migration and tissue remodeling extravascularly in the presence of uPA bound on cell surfaces.

Upon binding to the targets, Plg adopts an open conformation. The activation loop, which is obstructed by the linker between KR-3 and KR-4 in the closed conformation, becomes exposed. The activation bond $\left(\operatorname{Arg}_{561}-\mathrm{Val}_{562}\right)$ is then proteolytically cleaved by uPA and tPA $[25,26]$. The nascent $\mathrm{N}$-terminal $\mathrm{Val}_{562}$ moves by $11.6 \AA$ forming a salt bridge with $\mathrm{Asp}_{740}$; this triggers a series of conformational changes and thus allows the formation of a functional substrate binding site and catalytic pocket (Figure 1c). In Plm, the heavy chain (N-terminal domains, $63 \mathrm{kDa}$ ) and the light chain (SP domain, $25 \mathrm{kDa}$ ) are linked together by two disulfide bonds, between $\mathrm{Cys}_{558}$-Cys 566 and $\mathrm{Cys}_{548}$-Cys $_{666}$.

Serine protease inhibitors (termed serpins [27]) play a key regulatory role to ensure that there is no aberrant activation of Plg nor free Plm in the circulation. Under physiological conditions, the activity of plasminogen activators is modulated by their specific plasminogen activator inhibitors (PAI-1 and PAI-2) (Figure 1b) [28]. Active Plm which is not physically immobilized is removed immediately from the circulation by Plm-specific inhibitor $\alpha 2$-antiplasmin ( $\alpha 2-\mathrm{AP})[29,30]$. 

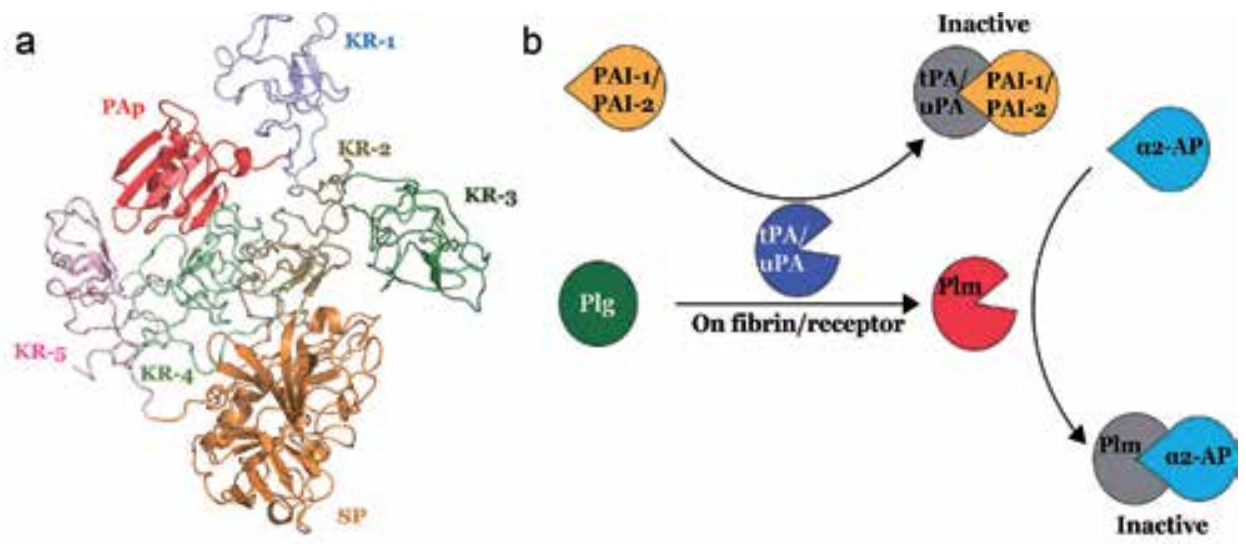

C

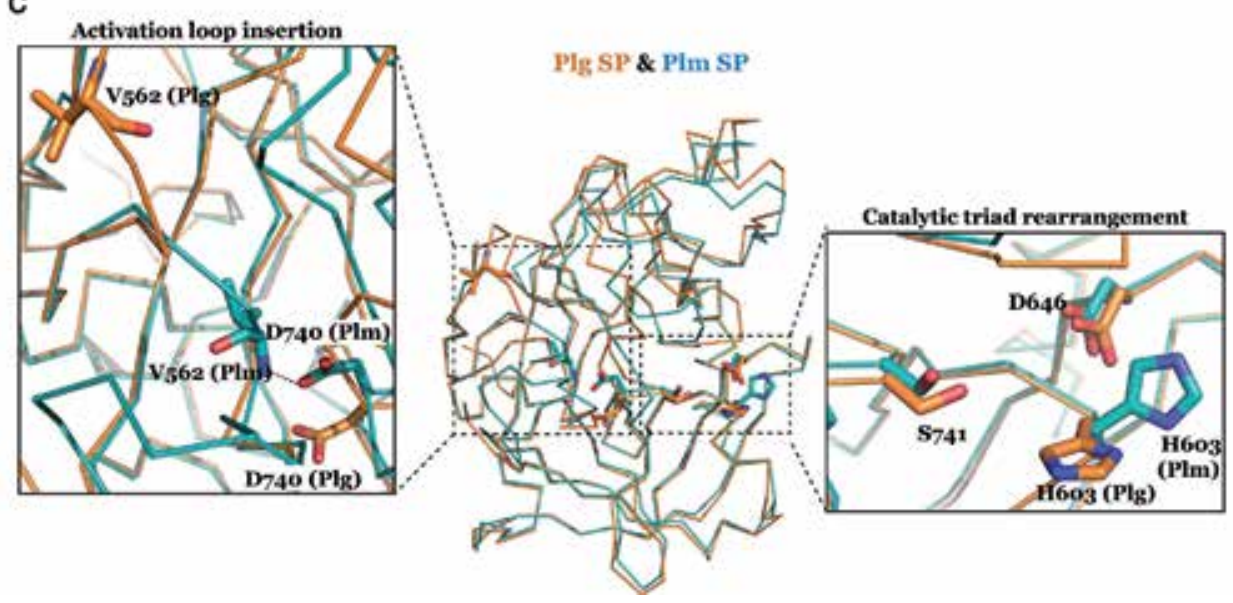

Figure 1.

The structure and function of human plasminogen (Plg). (a) Cartoon representation of the X-ray crystal structure of Plg in the closed conformation (PDB ID: 4DUR) [21]. The seven domains of Plg are the PANapple (PAp), kringles 1-5 (KR-1 to KR-5), and serine protease (SP) domains, shown in different colors. $(b)$ The Plg/Plm system. Plg is converted to active plasmin (Plm) by activators, urokinase plasminogen activator $(u P A)$ and tissue plasminogen activator $(t P A)$, on fibrin or receptor. The activators are regulated by serine protease inhibitors (serpins), plasminogen activator inhibitors (PAI-1 and PAI-2). Plm, upon released from its site of action, is inhibited by $\alpha 2$-antiplasmin ( $\alpha 2-A P)$. (c) Conformational change in the SP domain during Plm formation. Superposition of the SP domains of Plg (PDB ID: 4DUR) [21] and Plm (PDB ID:

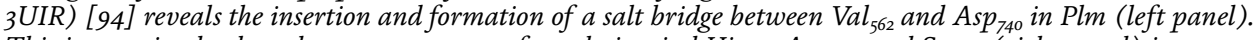
This interaction leads to the rearrangement of catalytic triad His $_{603}$, Asp $_{646}$, and Ser $_{741}$ (right panel) into an active conformation.

\section{Streptokinase}

\subsection{Structure and function of SK}

SK is secreted by GAS as a $47 \mathrm{kDa}$ protein and consists of three homologous domains, termed $\alpha, \beta$, and $\gamma$, held together by flexible linker loops. Each domain adopts a $\beta$-grasp fold consisting of $4-5$-stranded $\beta$ sheets and a central $\alpha$-helix or a coiled coil [31]. The interaction between $\mathrm{Plg} / \mathrm{Plm}$ and SK is evolutionarily conserved and strictly species specific $[32,33]$. SK variants secreted by GAS isolated from different species (e.g., from human, pig, and horse) are incapable of any cross-species reactivity and therefore are predicted to share not only low sequence identity but also low structural homology [32]. 
The X-ray crystallography studies on the binary complex of Plm SP domain $(\mu \mathrm{Plm})$ and SK reveal that SK wraps around the SP domain forming a horseshoe-shaped structure [31,34] (Figure 2) and further superposition of the full-length closed Plg with the $\mu$ Plm-SK structures suggests that the interaction between SK and Plg can occur with Plg, which remains in its closed conformation without any steric clashes (Figure 2) [35]. This observation provides fundamental insights to the mode of Plg activation by SK, as discussed in the next section.

SK is not a protease, nor it activates $\mathrm{Plg}$ by proteolytically cleaving the activation loop as uPA or tPA mentioned above. It forms a 1:1 stoichiometric complex with Plg through a rapid binding reaction, with an association rate of $5.4 \times 10^{7} \mathrm{M}^{-1} \mathrm{~s}^{-1}$ [36]. Binding of SK to free Plg results in the formation of catalytically active $\mathrm{Plg}\left(\mathrm{Plg}^{*}\right)$ (Figure 3). The SK-Plg* binary complex $[37,38]$ cleaves Plg, either in closed or open conformation, to form Plm.

The Plm generated has a much higher ( 57,000-fold) affinity for SK than Plg ( $K_{D} 11 \mathrm{pM}$ and $624 \mathrm{nM}$, respectively), such that the Plg in the SK-Plg* complex would be replaced by Plm to form the final and irreversible SK-Plm complex (Figure 3) $[39,40]$. The inhibitory capacity of $\alpha 2$-AP reduces significantly with a 10,000-fold lower affinity for the SK-Plm complex than Plm (rate constant of $1.4 \times 10^{2}$ and $5.4 \times 10^{7} \mathrm{M}^{-1} \mathrm{~s}^{-1}$, respectively) [36, 41]; accordingly, GAS infection could potentially generate an unregulated pericellular proteolytic (i.e., Plm) activity within the host.

\subsection{Plg activation by SK}

How does SK activate Plg without cleaving the activation loop? The current model suggests that the $\mathrm{N}$-terminal $\mathrm{Ile}_{1}$ residue of SK inserts into the binding cleft of $\mathrm{Val}_{562}$ in the SP domain and forms a salt bridge with Asp 740 . Accordingly, it induces a conformational change and formation of a functional catalytic site [42-44]. This "molecular sexuality" mechanism of cofactor-induced zymogen activation is also reported in the activation of prothrombin- 2 by staphylocoagulase from Staphylococcus aureus [45].
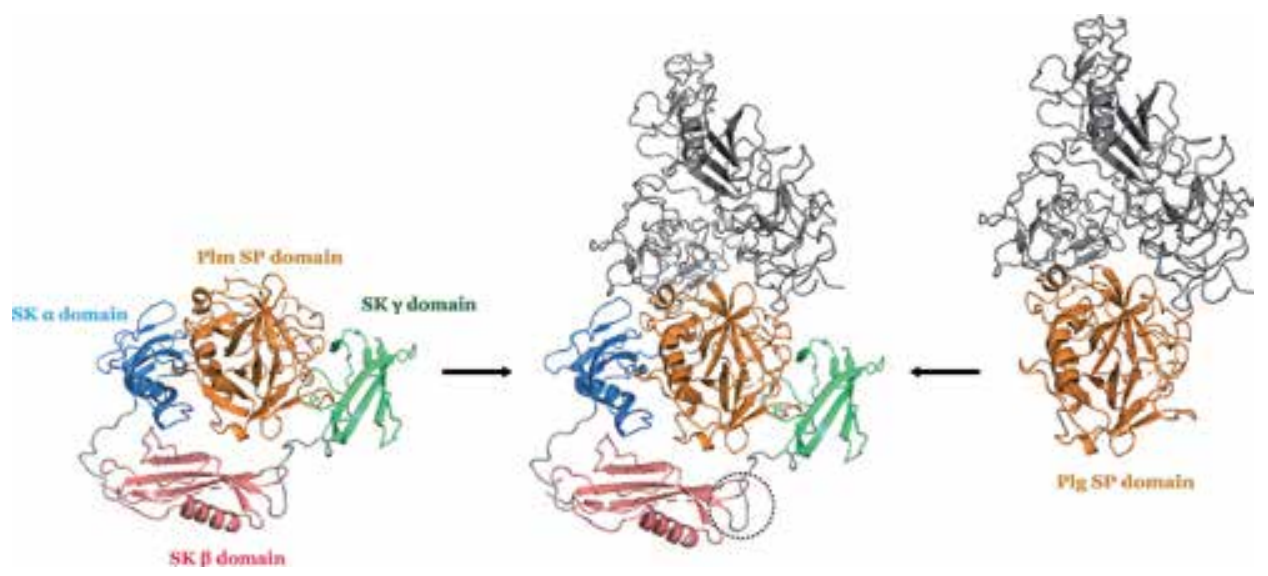

Figure 2.

Crystal structure of SK- $\mu$ Plg and in silico docking model of SK-Plg encounter complex (left panel). Structure of $S K-\mu P \lg$ (Plg SP domain) complex (PDB ID: $1 B M L$ ) [31]. SK $\alpha, \beta$, and $\gamma$ domains are colored blue, pink and green, respectively, whereas $\mu$ Plg is shown in orange. (Middle panel) Superposition of the SK- $\mu$ Plg structure and (right panel) full-length Plg generate the structural model of SK-Plg encounter complex. This model suggests that the SK can bind to closed Plg without any steric interference. Dashed circle highlights the proposed Plg substrate binding region (250-loop) in the $\beta$ domain of SK. 


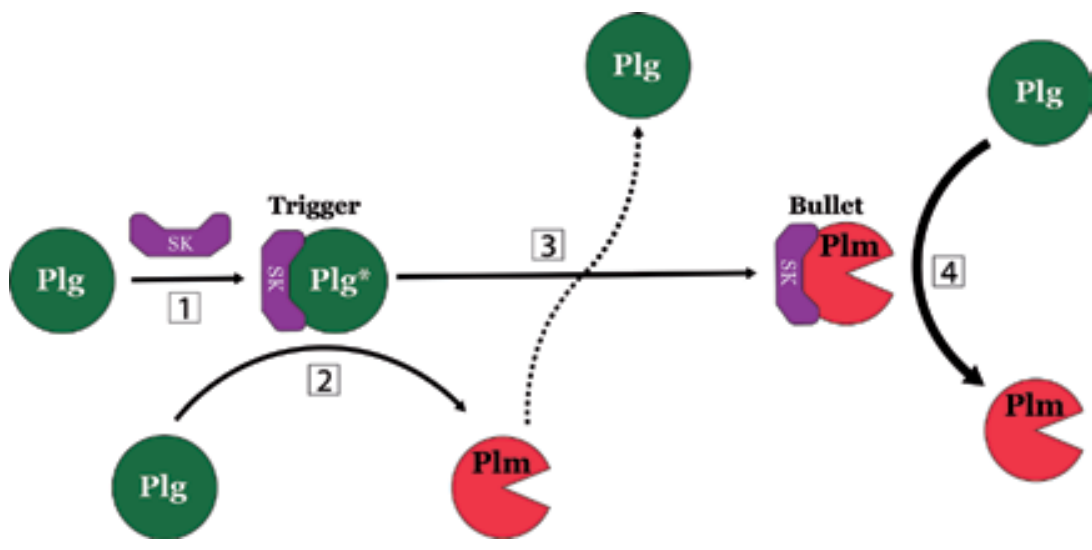

Figure 3.

Mechanism of SK-mediated Plg activation. (1) The first catalytic (named trigger) cycle is initiated by the binding of free Plg to SK and the generation of the proteolytically active SK-Plg* complex. (2) SK-Plg*activates free Plg substrate to Plm. (3) Plm displaces Plg in the SK-Plg* complex to form the final and irreversible SK-Plm complex. (4) In the second catalytic (named bullet) cycle, the SK-Plm activator complex converts free Plg to Plm at a fast rate.

The activation loop of Plg has evolved, via negative selection, to be a poor substrate of Plm [46], to minimize the risks of autoactivation. Binding to SK, however, changes the shape of the substrate binding pocket. In doing so, SK-Plg* and SK-Plm becomes highly specific in the binding and cleavage of the Plg activation loop [47], and this leads to a total deregulation of the fibrinolytic system.

Lastly, how does SK-Plg* or SK-Plm access the activation loop of Plg which is shielded in the closed conformation as previously discussed? Published data suggested that SK mediates a conformational change in the substrate Plg. Specifically, the substrate binding site of SK-Plm is situated at the tip of the protruding 250-loop region (residues $\mathrm{Ala}_{251}-\mathrm{Ile}_{264}$ ) of SK $\beta$ domain (Figure 2) [34]. Mutation studies reveal that residues $\mathrm{Arg}_{253}, \mathrm{Lys}_{256}$, and $\mathrm{Lys}_{257}$ of the same 250-loop can also bind simultaneously to the substrate Plg via its LBS of KR-5 domain [48], forming a ternary complex $[31,49,50]$. Thus, it is foreseeable that SK $\beta$ domain peels KR-5 away from the PAp domain which leads to the formation of an open Plg with its activation loop exposed.

Further, SK has a 20-fold higher affinity for Plg in the open conformation, presumably due to additional interactions with other KR domains [40, 51]. Specifically, the C-terminal Lys $_{414}$ of SK $\gamma$ domain has been shown to interact with KR-4 LBS $[52,53]$. Apart from Lys L $_{414}$, other Lys residues located at the $\beta$ and $\gamma$ domains might also be involved in binding to other KRs; together they promote a remarkably high-affinity interaction between SK and Plg/Plm in their open conformation [54]. However, without any structural data on the co-complexes of the relevant domains, the exact mechanism of the LBS-dependent interactions remains to be speculative.

\subsection{Classification of streptokinase}

All invasive GAS strains express SK to enhance dissemination $[55,56]$ and colonization within the host [57]. Interestingly, the SK alleles are polymorphic and can be subdivided into two phylogenetic lineages based on the highly variable $\beta$ domain [38], namely, cluster 1 (SK1) and cluster 2 (SK2) (Figure 4a) $[38,58,59]$. The sequence identities of $\alpha, \beta$, and $\gamma$ domains between GAS strains are 77, 55, and $84 \%$, respectively [60]. GAS from different clusters show different properties in $\mathrm{Plg}$ activation, receptor expression, and receptor binding. 
(a)
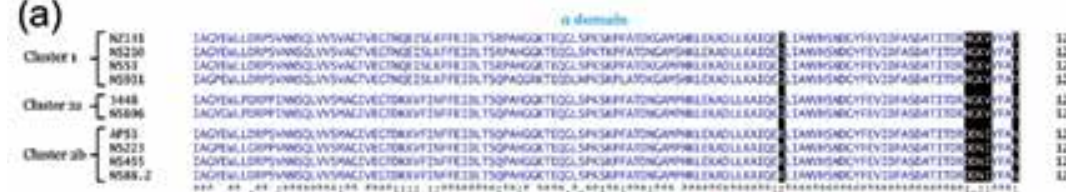

10
100
100
100
100
100
100
100
100
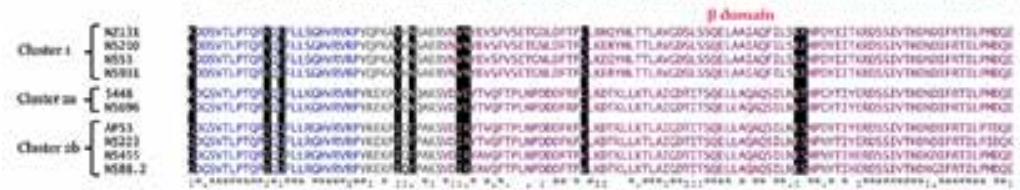

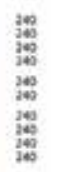

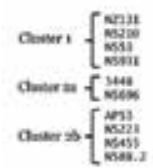

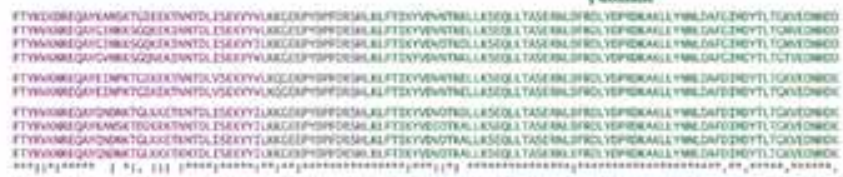

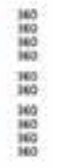
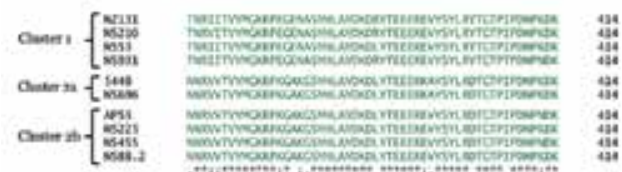

(b)

Cluster 1 and 2a SK

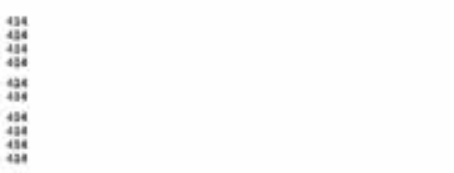

Cluster 2b SK

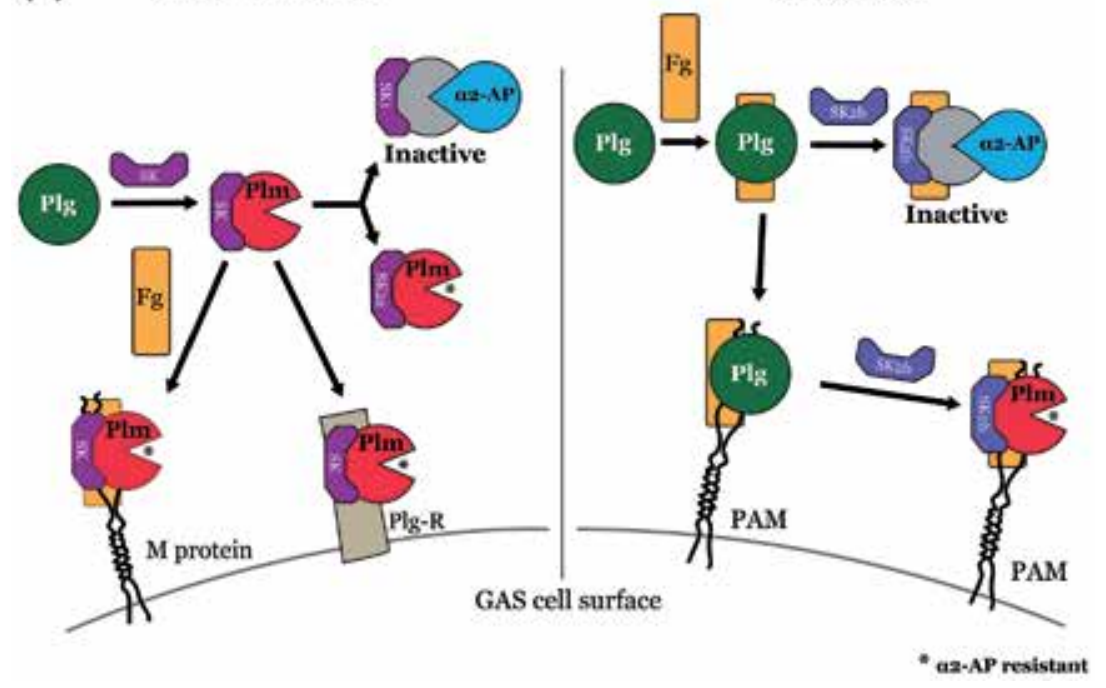

Figure 4.

(a) Allelic variants of streptokinase (SK) from GAS. Sequence alignment of cluster $1,2 a$ and $2 b$ SK clinical isolates. $\alpha, \beta$, and $\gamma$ domain regions are colored blue, pink, and green, respectively. "*," ":," and "." denote for strictly conserved, strongly similar, and weakly similar residues, respectively. Alignment was performed using the Clustal Omega multiple sequence alignment server (EMBL-EBI). Protein sequence GenBank accession numbers NZ131, ACI61887.1; NS210, AGA54152.1; NS53, AGA54154.1; NS931, AGA54153.1; 5448, AFJ44175.1; NS696, AFJ44174.1; AP53, AGA54155.1; NS223, AGA54156.1; NS455, AGA54157.1; and NS88.2, AGA54158.1. (b) Cartoon illustration of the functional differences of SK clusters. Left: Cluster 1 and 2 a SK can directly activate Plg in a 1:1 complex and localize to the bacterial cell surface via plasminogen receptors or indirectly via fibrinogen-binding M protein. Cluster 1 SK-Plm complex is susceptible to $\alpha 2-A P$ inhibition. Cluster $2 a$ SK-Plm and cell surface-bound complexes are $\alpha 2-A P$ resistant. Right: Cluster $2 b$ SK must first form a ternary complex with fibrinogen $(\mathrm{Fg})$ and Plg before binding onto cell surface via PAM or M protein. Unless bound to PAM, SK-Plg-Fg is inhibited by $\alpha 2-A P$.

SK1-Plg complex is enzymatically active (Figure $4 \mathbf{b}$ ) but has been shown to be susceptible to $\alpha 2$-AP inhibition [37]. Furthermore, SK1-Plg can bind to fibrinogen (Fg) and form the Fg-SK1-Plg ternary complex without any changes to the enzymatic activity [37]. SK1-Plg binds directly to Plg receptors such as 
glyceraldehyde-3-phosphate dehydrogenase and enolase, whereas Fg-SK1-Plg binds to $\mathrm{M}$ protein receptor such as M1.

SK2 is further subdivided into two clusters-SK2a and SK2b. Like SK1, SK2a expresses $\mathrm{M}$ protein and other $\mathrm{Plg}$ receptors, and the SK2a-Plg* complex is enzymatically active. One striking difference is that both SK2a-Plg* and SK2a-Plm are resistant to $\alpha 2-\mathrm{AP}$ inhibition. SK2b on the other hand is co-expressed with a specific $\mathrm{Plg}$ receptor called plasminogen-binding group A streptococcal M-like protein (PAM, see next section) $[38,59]$. SK2b has a lower affinity for Plg (30-fold lower than SK1 and SK2a) [37], and the SK2b-Plg complex is enzymatically inactive. Thus, Plg activation by SK2b is strictly limited to the bacterial cell surface [61]. Upon formation of the quaternary complex of PAM-SK2b-Plg-Fg, this complex is resistant to $\alpha 2$-AP (Figure $\mathbf{4 b}$ ).

The polymorphism and functional differences between the SK variants result in different physiopathology of streptococcal infection [59]. For example, the PAMexpressing SK2b strains where Plm activity is restricted to the cell surface are able to sustain much longer-lasting skin infections [37, 62].

\section{Plg-binding group A streptococcal M-like protein (PAM)}

M protein is the major virulence determinant of GAS [63]. It belongs to a family of dimeric coiled-coil surface-associated proteins. Under the electron microscope, it appears as a fibrillar coat on the bacteria surface [64]. The protein sequence of $M$ proteins is highly variable especially in the first 50 residues at the $\mathrm{N}$-terminus, known as the hypervariable region (HVR). Strain typing based on HVR sequence has identified more than $250 \mathrm{M}$ subtype to date [65]. The variable region confers affinity to different host molecules, such as Fg [66], immunoglobulin [67], complement factor $H$ [68], etc. There has been a number of reviews published on the sequence pattern and function of the M protein family [64, 69] and therefore will not be covered in the current paper. Here, we will focus on the structure and function of PAM, which is a specific Plg receptor that mediates Plg activation by SK $2 \mathrm{~b}$.

\subsection{Structure of PAM}

PAM is encoded by the emm gene situated in the multiple gene activator (mga) regulon. The mga regulon contains varying number of emm or emm-like genes and forms the basis of the five different emm patterns (type A-E). PAM-positive GAS strains are exclusively emm pattern D [70,71].

PAM has the overall domain architecture of an $M$ protein, which includes a hypervariable region (HVR) at the $\mathrm{N}$-terminus followed by variable $\mathrm{A}$ and $\mathrm{B}$ repeat domains and the conserved $\mathrm{C}$ and $\mathrm{D}$ domains and an anchor region (Figure 5a). In the precursor protein, there is a signal sequence that precedes the HVR and is removed upon secretion. The anchor region consists of an LPTXG motif that is responsible for sortase-mediated crosslinking of the C-terminus to the cell wall peptidoglycan [64].

To date, no binding target or function has been assigned to the HVR region. However, as this region extends the farthest from the cell surface, it might serve as a hypermutatable decoy which promotes GAS evasion from the host immunity as observed for the HVR of M1 and M5 proteins [72].

The A repeat domain consists of up to two tandem repeats termed a1 and a2. The a1a2 repeats each harbor a conserved Plg-binding motif consisting of an arginine-histidine dipeptide (termed the $\mathrm{RH}$ motif). PAM variants differ mainly 
(a)
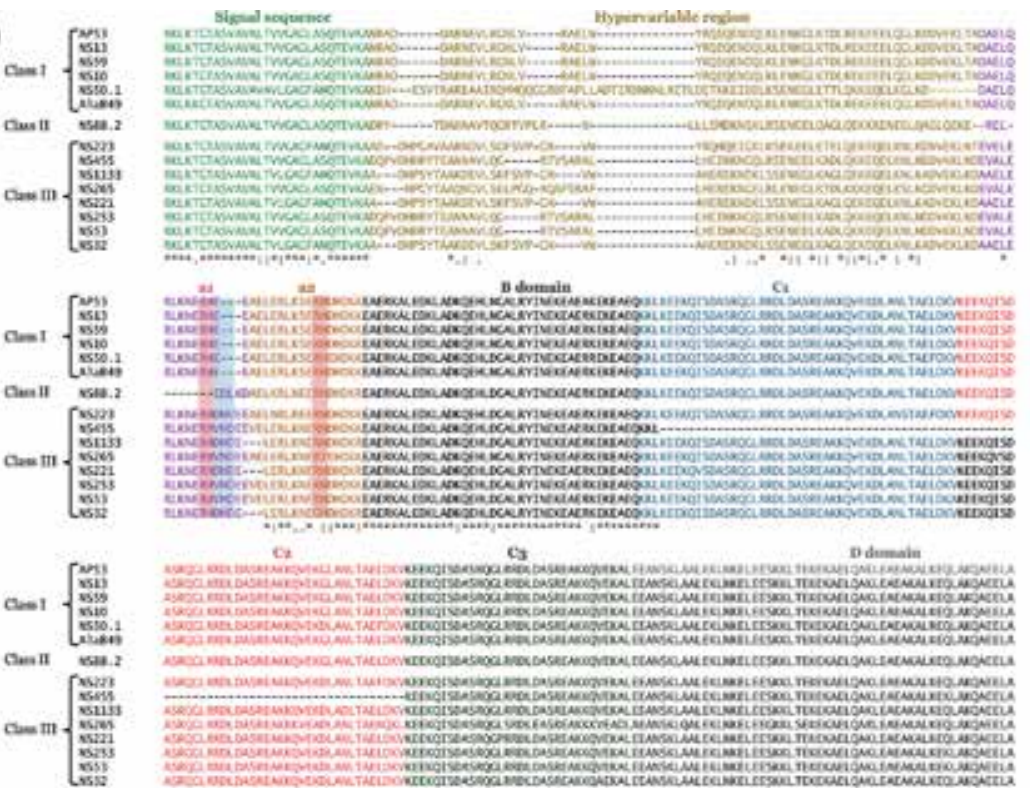

$\mathrm{Cz}$

cs

D dumain
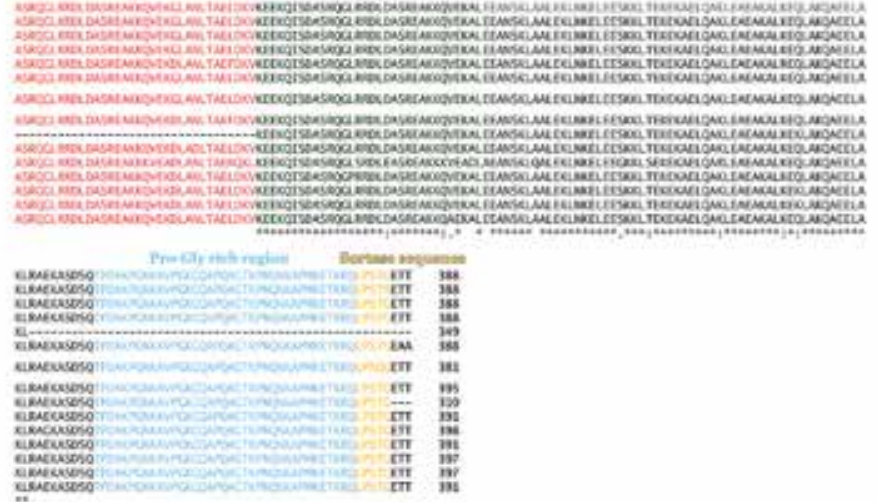

(b)
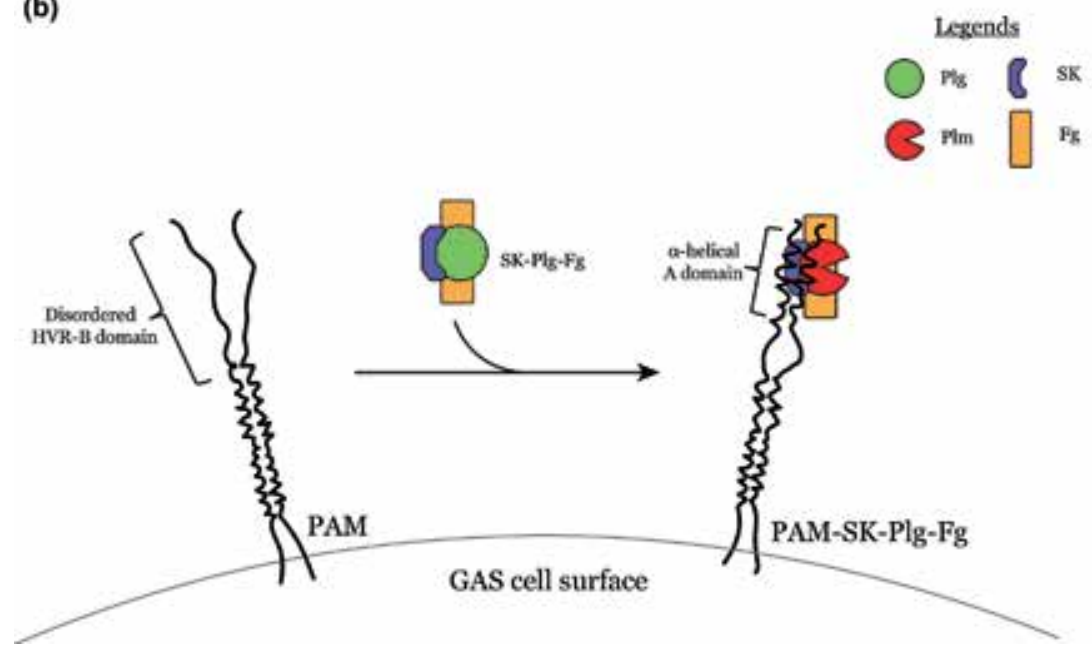

Figure 5 .

(a) PAM variants from emm pattern D GAS strains. Sequence alignment of PAM variants shown is divided into three classes: I, II, and III. RH motifs in a1 and a2 repeats are highlighted in red, and the three-residue insertions between $a_{1}$ and a2 in class III PAM are highlighted in blue. For clarity, residues before signal sequence and after sortase sequence were removed. "**,":", and "." denote strictly conserved, strongly similar, and weakly similar residues, respectively. Alignment was performed using the Clustal Omega multiple sequence alignment server (EMBL-EBI). Protein sequence GenBank accession numbers $A P_{53}, C A A 80222.1$; NS13, AAQ64521.2; NS59, AAQ64518.2; NS10, AAQ64516.2; NS50.1, AAQ64519.3; AlaB49, AEQ25265.1; NS88.2, AAQ64526.2; NS223, AAQ64524.2; NS455, AAQ64527.2; NS1133, AAQ64517.2; NS265, AAQ64525.2; NS221, AAZ66743.1; NS253, AAQ64523.2; NS53, AAQ64522.3; and NS32, AAQ64520.2. (b) Cartoon illustration of the conformational change of PAM and Plg binding. It is proposed that the $N$-terminal portion of PAM (from HVR to B domain) is largely disordered and transforms to a helical structure upon binding to Plg. The structural change serves to enhance the intermolecular interactions. 
in the HVR and A repeat region [71] and can be divided into three classes based on the A domain arrangements, namely, I, II, and III (Figure 5a). All classes have the a2 repeat, class I has both a1a2 repeats, class II only has a2, and class III has both a1a2 repeats as in class I, but the repeats are separated by a three-residue insertion. In bacterial strains such as $\mathrm{PAM}_{\mathrm{NS} 265}$ and $\mathrm{PAM}_{\mathrm{NS} 32}$, the second $\mathrm{RH}$ motif is mutated to Arg-Tyr and Gly-His, respectively (Figure 5a). Despite these variations, all PAM bind to human Plg with high affinities [71, 73, 74].

Based on NMR studies [74], the structure of the HVR and A domain is predominantly disordered, and the binding to Plg results in a major conformational change and formation of $\alpha$-helical structures (Figure 5b). This observation was further supported by experimental data published in a recent study [75], where it is revealed that the conformation switch can be detected even without binding to $\mathrm{Plg}$, and the alternation between disordered and a dimeric $\alpha$-helical structure occurs in a temperature-dependent manner, similar to the M1 protein reported previously [76]. This observation could be explained by a conformation sampling of the flexible domains.

Other than the aforementioned dynamic and dimeric interaction at the $\mathrm{N}$-terminal HVR and A domains, the current structure model of PAM is a coiledcoil dimer, which is stabilized via the $\mathrm{C}$ and $\mathrm{D}$ domains' interaction [74]. It is proposed that at least two $\mathrm{C}$ domains are required for a stable dimer formation. However, $\mathrm{PAM}_{\mathrm{NS} 455}$, one of the smallest PAM variants identified to date, contains only one $\mathrm{C}$ domain (Figure 5a). While it has been shown that $\mathrm{PAM}_{\mathrm{NS} 455}$ has high affinity for Plg [71], the question remains if and how $\mathrm{PAM}_{\mathrm{NS} 455}$ maintains the dimeric assembly.

\subsection{Binding mechanism of PAM to Plg}

PAM binds to both Plg and Plm directly with high affinity $\left(K_{\mathrm{D}}\right.$ of $\left.\sim 1 \mathrm{nM}\right)[77,78]$ through the RH motifs in the A repeat region to Plg KR2 domain (Figure 6) [79].

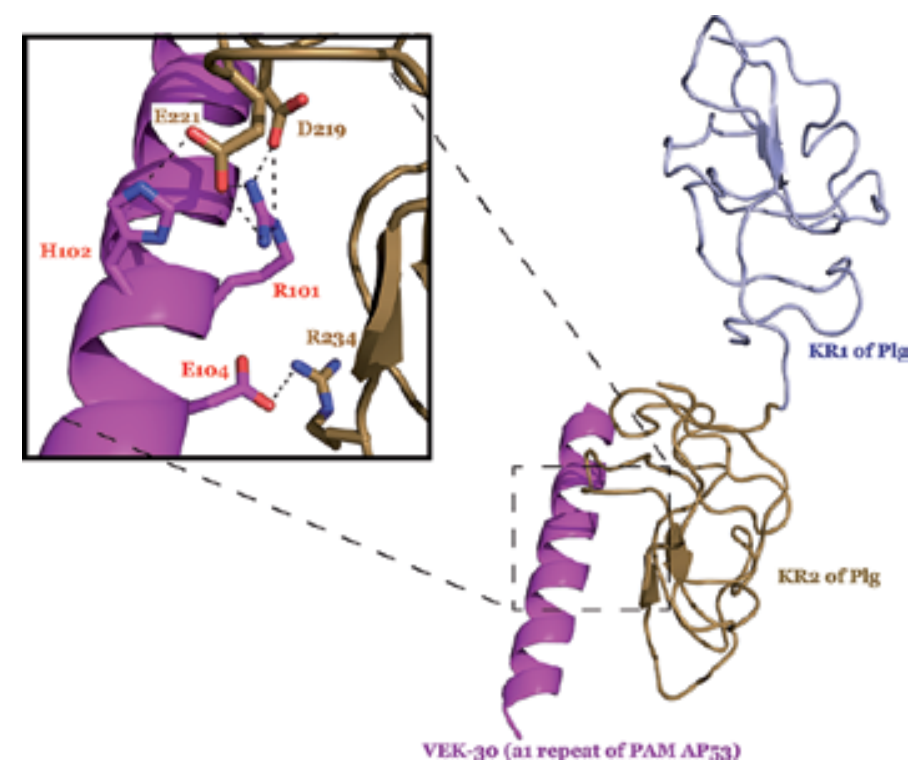

Figure 6.

$X$-ray crystal structure of angiostatin (KR1-KR2) and VEK-30 complex (PDB ID 2DOI). VEK-30 (magenta), a peptide derived from PAM AP53, binds to KR2 (brown) primarily by its RH (R101 and H102) motif (sticks) interacting with the LBS residues D219 and E221 (inset). Together, R101, H102, and E104 form a lysine isostere that is recognized by the LBS of KR2. KR1 (light-blue) does not play a role in the complex formation [80]. 
Based on the crystal structures of the a1 repeat-KR2 binary complex, the side chains of the RH motif residues $\mathrm{Arg}_{101}$ and $\mathrm{His}_{102}$ form a pseudo-lysine moiety (called the lysine isostere) and bind to the LBS of KR2 [79, 80]. Peripheral residues of the RH motif such as $\mathrm{Asp}_{91}$, Glu $\mathrm{Gl}_{93}, \mathrm{Leu}_{97}, \mathrm{Lys}_{98}$, and $\mathrm{Glu}_{104}$ mediate further intermolecular interaction via binding to residues of KR2 outside the LBS, namely, $\mathrm{Tyr}_{200}, \mathrm{Arg}_{220}, \mathrm{Arg}_{234}$, and $\operatorname{Trp}_{235}$ [80]. These additional interactions play important roles in stabilization of the complex. Of these residues, $\mathrm{Tyr}_{200}$ and $\mathrm{Arg}_{220}$ are unique to KR2, accordingly; these residues may drive the specificity of the A repeats toward the KR2 domain. In doing so, PAM is expected to bind not only tightly to Plg but also without competing with SK binding [80]. Further structural studies would be required to validate this hypothesis.

Outside the A repeats-KR2 binding interface, there are many questions remained to be addressed regarding the interaction between Plg and PAM. For instance, both a1 and a2 were shown to bind KR2 [81], but would a single PAM monomer bind to two Plg? Further, KR2 in closed Plg is inaccessible. How does PAM bind to KR2? Does it induce a conformational change of Plg prior to the complex formation [78]? Furthermore, the N-linked glycosylation of Plg at KR3 in Plg glycoform I reduces its affinity for PAM [82]; does KR3, which does not have a functional LBS, mediate exosite(s) interaction with PAM?

\section{Streptococcal inhibitor of complement (SIC)}

Streptococcal inhibitor of complement (SIC) is a 31-kDa secreted virulence factor found in M1 and M57 GAS serotypes. SIC is named after its inhibitory function of complement-mediated cell lysis. SIC binds to complement system regulators such as histidine-rich glycoprotein, clusterin, and membrane attack complex C5b-C9 (Figure 7a) [83]. Subsequent research revealed that SIC also binds to antimicrobial peptides [84, 85], extracellular histones [86], fibrin [87], thrombin [87], and plasminogen [87]. Accordingly, the physiological role of SIC is to manipulate the host defense system for infection and invasion. Of particular interest to the current review is that it inhibits the fibrinolytic system through binding to $\mathrm{Plg}$ [87].

\subsection{Structure and function of SIC}

SIC consists of an N-terminal signal peptide that is cleaved upon secretion; the mature form has a short repeat region followed by three tandem repeats of about 30 residues each (Figure $\mathbf{7 b}$ ). The three-dimensional structure of SIC is currently unknown, and there is no apparent sequence identity with proteins in the database such as Pfam.

Additional to its well-known roles in suppressing the host defense system, SIC has been shown to modulate the fibrinolytic system [87]. It was proposed that SIC inhibits SK-mediated Plg activation. Specifically, SIC-positive GAS entrapped in the fibrin clot allows its survival for much longer than the SICnegative strain. The entrapped bacteria colonize before its dissemination from the primary infection sites.

SIC is expressed in the early growth phase of M1 GAS; its role, which is to temporally regulate the activity of SK, is only reported in a recent study. It was shown that the Plg-binding motif(s) in SIC is located at the C-terminal 200 residues which presumably binds the Plg KR domains [87]. Significantly, although 
Toward Better Understanding on How Group A Streptococcus Manipulates Human...

DOI: http://dx.doi.org/10.5772/intechopen.88182

(a)

Inhibition of membrane attack complex

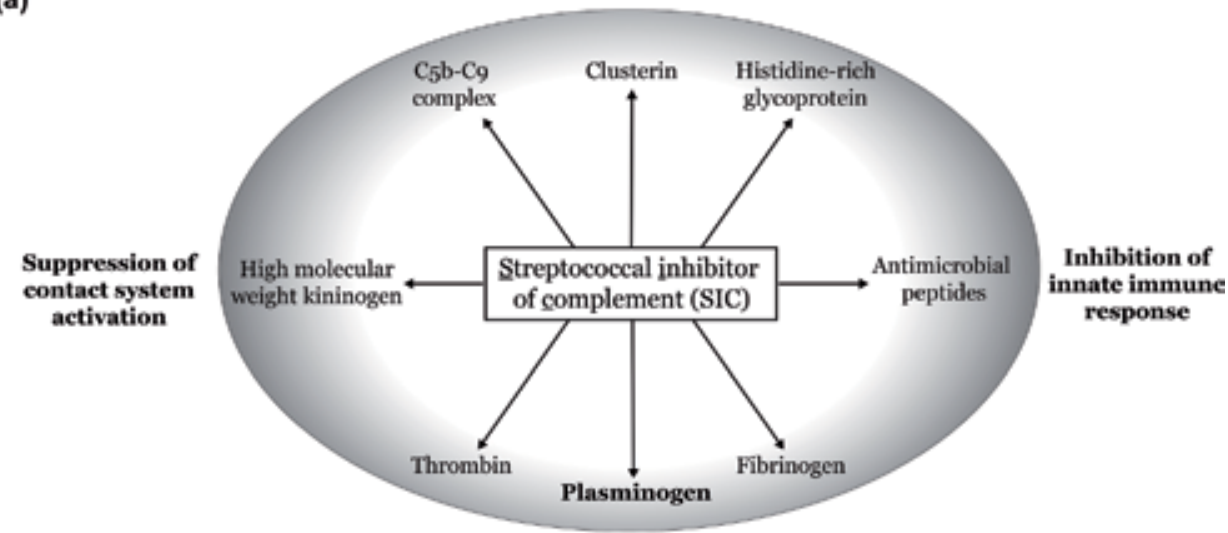

(b)

Modulation of clot formation and fibrinolysis

\section{Signal sequence}

M1

MNIRNKIENSKTLLFTSLVAVALLGATQPVSAETYTSRNFDWSGDDWSGDDWPEDDWSGD 60

MNIRNKIENSKTLLFTSLVAVALLGATQPVSAETYTSRNFDWSG-----DDWPEDDWSGD 55

M57 -MQIKKIKLSKSLLFTSLAAVALLGATQPVSAEMYTSRNFCWSGDDWSGDDWSGDDWSGD 59

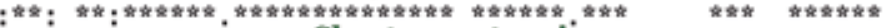
Short repeat region

M1 GLSKYDRSCVGLSQYCWSKYCWSSD KEEWPEDW 93

M1_AP1 GLSKYDRSCVGLSQYGWSQYCWSSDKEEWPEDW 88 GLSKYDRSGVGLSQYCWSKYCWSSDKEDWPEDDWSEDDWSNDYWSKYCWSSNKEDWPEDW 119

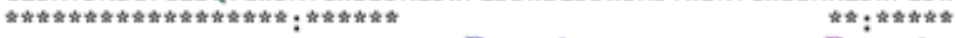

\begin{tabular}{|c|c|}
\hline & Repeat 1 \\
\hline M1 & PEDDWSSDKKDETEDKTRPPYGEALGTCYEKRDDWCGPGTVATDPYTPPYCGALGTCYEK \\
\hline 11_AP1 & PEDDWSSDKKDETEDKTRPPYGEALGTGYEKRDDWCGPGTVATDPYTPPYGGALGTGYEK \\
\hline 157 & 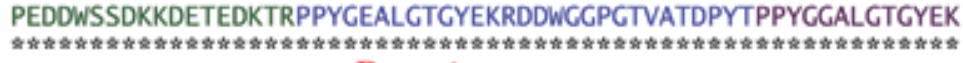 \\
\hline
\end{tabular}

M1 RDDWCGPGTVATDPYTPPYGGALGTGYEKRDDWRGPGHIPKPENEQSPNPLHIPEPPQIE 213 M1_AP1 RDDWGGPGTVAIDPYTPPYGEALGTGYEKRDDWRGPGHIPKPENEQSPNPSHIPEPPQIE 208 M57 RDDWGGPGTVATDPYTPPYGGALGTGYEKRDDWGGPGHKP--KNEQSPNPSHIPEPPQIE 237

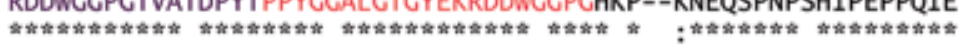

\section{C-terminal region}

M1 WPQWNGFDGLSFGPSDWCQSEDTP--PSEPRVPEKPQHT------PQKNPQESDFDRGF 264 M1_AP1 WPQWNGFDELSFGPSDWCQSEDAPRFPSEPRVPEKPQHT-------PQKNPQESDFDRGF 261 M57 WPQWNGFDGLSSGPSCWGRSEDTPHSPSCPRIPECNIPPGLPQAPETPRTDEDDEYQKGF 297

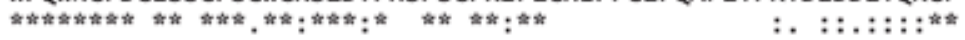

\begin{tabular}{|c|c|}
\hline M1 & SAGLKAKNSGRGIDFEGFQYGCWSDEYKKGYMQAFGTPYTPSAT \\
\hline M1_AP1 & SAGLKAKNSGRGIDFEGFQYGCWSDEYKKGYMQAFGTPYTPSAT \\
\hline M57 & 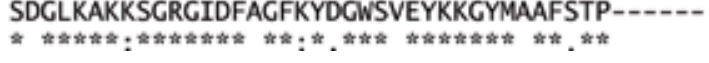 \\
\hline
\end{tabular}

Figure 7.

(a) Streptococcal inhibitor of complement (SIC), a multifunctional protein, binds to a number of proteins and peptides that are involved in the formation of membrane attack complex [83], activation of contact system [95], antimicrobial activities [96], and clot formation and fibrinolysis [87]. Together, SIC facilitates bacterial survival, colonization, and immune evasion. (b) Sequence alignment of SIC from strains M1 and M57. Sequence alignment shows variability in the number of repeats in the short repeat region (green), whereas the three tandem repeats (1-3) are highly conserved. "“*,":," and "." denote strictly conserved, strongly similar, and weakly similar residues, respectively. Alignment was performed using the Clustal Omega multiple sequence alignment server (EMBL-EBI). Protein sequence GenBank accession numbers $M_{1}, A A K_{34693.1 ;} M_{1} A P_{1}$, $A K G 28717.1$; and M57, AAP31326.1.

SIC does not bind to Plm, it binds specifically to Plg via competing with SK for $\mathrm{Plg}$. It remains to be determined experimentally whether the C-terminal domain of SIC also binds to the Plg KR5 and/or the SP domains like SK, as discussed previously. 


\section{Conclusion}

The fibrin network plays a pivotal role in innate immune defense via entrapping pathogens within the primary infection sites. GAS infection studies in animals have provided strong evidence that GAS has the ability to manipulate the host fibrinolytic system at many levels $[88,89]$. On one hand, hijacking the host $\mathrm{Plg} / \mathrm{Plm}$ on the bacterial surface has provided an energy-efficient strategy to break down the fibrin network during dissemination $[55,57,90]$, and this is achieved with the aid of PAM. Using GAS strains which express both SK2b and PAM genes, it was shown that inactivation of either genes significantly reduces virulence [59]. SIC, on the other hand, allows the bacteria to make use of the fibrin network as a shelter during the initial colonization phase, and it simultaneously inhibits the complement system in order to ensure the survival of bacteria in the early infection phase. The combined effects of these virulent factors perhaps allow the SIC-expressing M1 strain to be one of most invasive GAS [91].

GAS has evolved into a formidable pathogen through its millennial of coexistence with human host and natural selection; it is invasive and also evasive through manipulating the host immunity with a plethora of virulent factors. The three extracellular virulent factors discussed in this review modulate specifically the fibrinolytic system via an assembly of Plg modulators. Ironically, these virulence factors are capable of outranking the human counterparts in terms of efficiencies and affinities. SK, for instance, is the most efficacious Plg activator ever discovered, and therefore it was the first therapeutic approved for the treatment of thrombotic disorders including myocardial infarction [92] and pulmonary embolism [93]. With the increasing prevalence of antibiotic-resistant superbugs, GAS infection is expected to post a risk to public health worldwide. Better understanding on the molecular mechanisms of how these virulent factors manipulate the host immunity will provide insight on future development of treatments for GAS infection.

\section{Acknowledgements}

This work was supported in part by the Australian National Health Medical Research Council. J. C. W. is an Australian Laureate Research Fellow.

\section{Conflict of interest}

There is no conflict of interest. 


\section{Author details}

Adam J.H. Quek ${ }^{1,2}$, James C. Whisstock ${ }^{1,2,3}$ and Ruby H.P. Law ${ }^{1,2 *}$

1 ARC Centre of Excellence in Advanced Molecular Imaging, Monash Biomedicine Discovery Institute, Monash University, Clayton, VIC, Australia

2 Department of Biochemistry and Molecular Biology, Infection and Immunity Program, Monash Biomedicine Discovery Institute, Monash University, Clayton, VIC, Australia

3 South East University-Monash Joint Institute, Institute of Life Sciences, Southeast University, Nanjing, China

*Address all correspondence to: ruby.law@monash.edu

\section{IntechOpen}

(C) 2019 The Author(s). Licensee IntechOpen. This chapter is distributed under the terms of the Creative Commons Attribution License (http://creativecommons.org/licenses/ by/3.0), which permits unrestricted use, distribution, and reproduction in any medium, provided the original work is properly cited. (cc) BY 


\section{References}

[1] Ralph AP, Carapetis JR. Group A streptococcal diseases and their global burden. Current Topics in Microbiology and Immunology. 2013;368:1-27

[2] Cunningham MW. Post-streptococcal autoimmune sequelae: Rheumatic fever and beyond. In: Ferretti JJ, Stevens DL, Fischetti VA, editors. Streptococcus Pyogenes: Basic Biology to Clinical Manifestations. The University of Oklahoma Health Sciences Center; 2016. pp. 893-930

[3] Chaturvedi S, Boyd R, Krause V. Acute post-streptococcal glomerulonephritis in the Northern Territory of Australia: A review of data from 2009 to 2016 and comparison with the literature. The American Journal of Tropical Medicine and Hygiene. 2018;99:1643-1648

[4] Carapetis JR, Steer AC, Mulholland EK, Weber M. The global burden of group A streptococcal diseases. The Lancet Infectious Diseases. 2005;5:685-694

[5] Sims Sanyahumbi A, Colquhoun S, Wyber R, Carapetis JR. Global disease burden of group A streptococcus. In: Ferretti JJ, Stevens DL, Fischetti VA, editors. Streptococcus Pyogenes: Basic Biology to Clinical Manifestations. 2016. pp. 661-704

[6] Sanderson-Smith ML, De Oliveira DM, Ranson M, McArthur JD. Bacterial plasminogen receptors: Mediators of a multifaceted relationship. Journal of Biomedicine \& Biotechnology. 2012;2012:272148. DOI: 10.1155/2012/272148

[7] Verhamme IM, Panizzi PR, Bock PE. Pathogen activators of plasminogen. Journal of Thrombosis and Haemostasis. 2015;13:S106-S114. DOI: 10.1111/ jth.12939
[8] Lahteenmaki K, Kuusela P, Korhonen TK. Bacterial plasminogen activators and receptors. FEMS Microbiology Reviews. 2001;25:531-552

[9] Korhonen TK. Fibrinolytic and procoagulant activities of Yersinia pestis and salmonella enterica. Journal of Thrombosis and Haemostasis. 2015;13:S115-S120. DOI: 10.1111/ jth.12932

[10] Sherry S. Personal reflections on the development of thrombolytic therapy and its application to acute coronary thrombosis. American Heart Journal. 1981;102:1134-1138

[11] Tillett WS, Garner RL. The fibrinolytic activity of hemolytic streptococci. The Journal of Experimental Medicine. 1933;58:485-502

[12] Christensen LR, Macleod CM. A proteolytic enzyme of serum: Characterization, activation, and reaction with inhibitors. The Journal of General Physiology. 1945;28:559-583

[13] Kunitz M. Formation of trypsin from trypsinogen by an enzyme produced by a mold of the genus Penicillium. The Journal of General Physiology. 1938;21:601-620

[14] Saksela O. Plasminogen activation and regulation of pericellular proteolysis. Biochimica et Biophysica Acta. 1985;823:35-65

[15] Romer J, Bugge TH, Pyke C, Lund LR, Flick MJ, Degen JL, et al. Plasminogen and wound healing. Nature Medicine. 1996;2:725

[16] Ploplis VA, French EL, Carmeliet P, Collen D, Plow EF. Plasminogen deficiency differentially affects 
recruitment of inflammatory cell populations in mice. Blood. 1998;91:2005-2009

[17] Bai H, Nangia S, Parmer RJ. The plasminogen activation system and the regulation of catecholaminergic function. Journal of Biomedicine and Biotechnology. 2012;2012:721657

[18] Raum D, Marcus D, Alper CA, Levey R, Taylor PD, Starzl TE. Synthesis of human plasminogen by the liver. Science. 1980;208:1036-1037

[19] Novokhatny VV, Kudinov SA, Privalov PL. Domains in human plasminogen. Journal of Molecular Biology. 1984;179:215-232

[20] Castellino FJ, Powell JR. Human plasminogen. Methods in Enzymology. 1981;80:365-378

[21] Law RH, Caradoc-Davies T, Cowieson N, Horvath AJ, Quek AJ, Encarnacao JA, et al. The X-ray crystal structure of full-length human plasminogen. Cell Reports. 2012;1:185-190. DOI: 10.1016/j. celrep.2012.1002.1012

[22] Miles LA, Dahlberg CM, Plow EF. The cell-binding domains of plasminogen and their function in plasma. The Journal of Biological Chemistry. 1988;263:11928-11934

[23] Plow EF, Freaney DE, Plescia J, Miles LA. The plasminogen system and cell surfaces: Evidence for plasminogen and urokinase receptors on the same cell type. The Journal of Cell Biology. 1986;103:2411-2420

[24] Tsurupa G, Medved L. Fibrinogen alpha $\mathrm{C}$ domains contain cryptic plasminogen and tPA binding sites. Annals of the New York Academy of Sciences. 2001;936:328-330
[25] Summaria L, Hsieh B, Robbins KC. The specific mechanism of activation of human plasminogen to plasmin. The Journal of Biological Chemistry. 1967;242:4279-4283

[26] Hoylaerts M, Rijken DC, Lijnen HR, Collen D. Kinetics of the activation of plasminogen by human tissue plasminogen activator. Role of fibrin. Journal of Biological Chemistry. 1982;257:2912-2919

[27] Collen D. On the regulation and control of fibrinolysis. Edward Kowalski memorial lecture. Thrombosis and Haemostasis. 1980;43:77-89

[28] Pannekoek H, Veerman H, Lambers H, Diergaarde P, Verweij CL, van Zonneveld AJ, et al. Endothelial plasminogen activator inhibitor (PAI): A new member of the Serpin gene family. The EMBO Journal. 1986;5:2539-2544

[29] Coughlin PB. Antiplasmin: The forgotten serpin? FEBS Journal. 2005;272:4852-4857

[30] Lu BGC. Analysis of the interaction between $\alpha 2$-antiplasmin and plasmin(ogen) [Doctor of Philosophy thesis]. Australian Centre for Blood Diseases, Monash University; 2013

[31] Wang X, Lin X, Loy JA, Tang J, Zhang XC. Crystal structure of the catalytic domain of human plasmin complexed with streptokinase. Science. 1998;281:1662-1665

[32] Caballero AR, Lottenberg R, Johnston KH. Cloning, expression, sequence analysis, and characterization of streptokinases secreted by porcine and equine isolates of Streptococcus equisimilis. Infection and Immunity. 1999;67:6478-6486

[33] Gladysheva IP, Turner RB, Sazonova IY, Liu L, Reed GL. Coevolutionary patterns in plasminogen activation. Proceedings of the National Academy 
of Sciences of the United States of America. 2003;100:9168-9172

[34] Wang X, Tang J, Hunter B, Zhang $\mathrm{XC}$. Crystal structure of streptokinase beta-domain. FEBS Letters. 1999;459:85-89

[35] Law RH, Abu-Ssaydeh D, Whisstock JC. New insights into the structure and function of the plasminogen/plasmin system. Current Opinion in Structural Biology. 2013;23:836-841. DOI: 10.1016/j.sbi.2013.1010.1006

[36] Cederholm-Williams SA, De Cock F, Lijnen HR, Collen D. Kinetics of the reactions between streptokinase, plasmin and alpha 2-antiplasmin. European Journal of Biochemistry. 1979;100:125-132

[37] Cook SM, Skora A, Gillen CM, Walker MJ, McArthur JD. Streptokinase variants from Streptococcus pyogenes isolates display altered plasminogen activation characteristics-Implications for pathogenesis. Molecular Microbiology. 2012;86:1052-1062. DOI: 10.1111/mmi.12037

[38] McArthur JD, McKay FC, Ramachandran V, Shyam P, Cork AJ, Sanderson-Smith ML, et al. Allelic variants of streptokinase from Streptococcus pyogenes display functional differences in plasminogen activation. The FASEB Journal. 2008;22:3146-3153. DOI: $10.1096 /$ fj.3108-109348

[39] Boxrud PD, Fay WP, Bock PE. Streptokinase binds to human plasmin with high affinity, perturbs the plasmin active site, and induces expression of a substrate recognition exosite for plasminogen. The Journal of Biological Chemistry. 2000;275:14579-14589

[40] Boxrud PD, Bock PE. Coupling of conformational and proteolytic activation in the kinetic mechanism of plasminogen activation by streptokinase. The Journal of Biological Chemistry. 2004;279:36642-36649
[41] Wiman B. On the reaction of plasmin or plasmin-streptokinase complex with aprotinin or $\alpha 2$-antiplasmin. Thrombosis Research. 1980;17:143-152

[42] Reddy KN, Markus G. Mechanism of activation of human plasminogen by streptokinase. Presence of active center in streptokinase-plasminogen complex. The Journal of Biological Chemistry. 1972;247:1683-1691

[43] Boxrud PD, Verhamme IM, Fay WP, Bock PE. Streptokinase triggers conformational activation of plasminogen through specific interactions of the amino-terminal sequence and stabilizes the active zymogen conformation. The Journal of Biological Chemistry. 2001;276:26084-26089

[44] Wang S, Reed GL, Hedstrom L. Deletion of Ile1 changes the mechanism of streptokinase: Evidence for the molecular sexuality hypothesis. Biochemistry. 1999;38:5232-5240

[45] Friedrich R, Panizzi P, FuentesPrior P, Richter K, Verhamme I, Anderson PJ, et al. Staphylocoagulase is a prototype for the mechanism of cofactor-induced zymogen activation. Nature. 2003;425:535-539

[46] Hervio LS, Coombs GS, Bergstrom RC, Trivedi K, Corey DR, Madison EL. Negative selectivity and the evolution of protease cascades: The specificity of plasmin for peptide and protein substrates. Chemistry \& Biology. 2000;7:443-453

[47] Parry MA, Zhang XC, Bode I. Molecular mechanisms of plasminogen activation: Bacterial cofactors provide clues. Trends in Biochemical Sciences. 2000;25:53-59

[48] Tharp AC, Laha M, Panizzi P, Thompson MW, Fuentes-Prior P, Bock PE. Plasminogen substrate 
recognition by the streptokinaseplasminogen catalytic complex is facilitated by Arg253, Lys256, and Lys257 in the streptokinase betadomain and kringle 5 of the substrate. The Journal of Biological Chemistry. 2009;284:19511-19521. DOI: 10.11074/ jbc.M19109.005512

[49] Alkjaersig N, Fletcher AP, Sherry S. Xi-Aminocaproic acid: An inhibitor of plasminogen activation. The Journal of Biological Chemistry. 1959;234:832-837

[50] Young KC, Shi GY, Wu DH, Chang LC, Chang BI, Ou CP, et al. Plasminogen activation by streptokinase via a unique mechanism. The Journal of Biological Chemistry. 1998;273:3110-3116

[51] Boxrud PD, Bock PE. Streptokinase binds preferentially to the extended conformation of plasminogen through lysine binding site and catalytic domain interactions. Biochemistry. 2000;39:13974-13981

[52] Panizzi P, Boxrud PD, Verhamme IM, Bock PE. Binding of the $\mathrm{COOH}$ terminal lysine residue of streptokinase to plasmin(ogen) kringles enhances formation of the streptokinase plasmin(ogen) catalytic complexes. The Journal of Biological Chemistry. 2006;281:26774-26778

[53] Verhamme IM, Bock PE. Rapidreaction kinetic characterization of the pathway of streptokinase-plasmin catalytic complex formation. The Journal of Biological Chemistry. 2008;283:26137-26147. DOI: 10.21074/ jbc.M804038200

[54] Verhamme IM, Bock PE. Rapid binding of plasminogen to streptokinase in a catalytic complex reveals a three-step mechanism.

The Journal of Biological Chemistry. 2014;289:28006-28018. DOI: 10.21074/ jbc.M28114.589077
[55] Sun H, Ringdahl U, Homeister JW, Fay WP, Engleberg NC, Yang AY, et al. Plasminogen is a critical host pathogenicity factor for group A streptococcal infection. Science. 2004;305:1283-1286

[56] Nitzsche R, Rosenheinrich M, Kreikemeyer B, Oehmcke-Hecht S. Streptococcus pyogenes triggers activation of the human contact system by streptokinase. Infection and Immunity. 2015;83:3035-3042. DOI: 10.1128/ IAI.00180-00115

[57] Nitzsche R, Kohler J, Kreikemeyer B, Oehmcke-Hecht S. Streptococcus pyogenes escapes killing from extracellular histones through plasminogen binding and activation by streptokinase. Journal of Innate Immunity. 2016;8:589-600

[58] Kapur V, Kanjilal S, Hamrick MR, Li LL, Whittam TS, Sawyer SA, et al. Molecular population genetic analysis of the streptokinase gene of Streptococcus pyogenes: Mosaic alleles generated by recombination. Molecular Microbiology. 1995;16:509-519

[59] Kalia A, Bessen DE. Natural selection and evolution of streptococcal virulence genes involved in tissuespecific adaptations. Journal of Bacteriology. 2004;186:110-121

[60] Zhang Y, Liang Z, Glinton K, Ploplis VA, Castellino FJ. Functional differences between Streptococcus pyogenes cluster 1 and cluster $2 \mathrm{~b}$ streptokinases are determined by their beta-domains. FEBS Letters. 2013;587:1304-1309. DOI: 10.1016/j.febslet.2013.1302.1033

[61] Cook SM, Skora A, Walker MJ, Sanderson-Smith ML, McArthur JD. Site restricted plasminogen activation mediated by group A streptococcal streptokinase variants. The Biochemical Journal. 2013;22:22

[62] Bessen DE, Sotir CM, Readdy TL, Hollingshead SK. Genetic correlates 
of throat and skin isolates of group A streptococci. The Journal of Infectious Diseases. 1996;173:896-900

[63] Lancefield RC. Current knowledge of type-specific $M$ antigens of group $A$ streptococci. Journal of Immunology. 1962;89:307-313

[64] Fischetti VA. M protein and other surface proteins on streptococci. In: Ferretti JJ, Stevens DL, Fischetti VA, editors. Streptococcus Pyogenes: Basic Biology to Clinical Manifestations. Oklahoma City, OK: The University of Oklahoma Health Sciences Center; 2016. pp. $27-54$

[65] McMillan DJ, Dreze PA, Vu T, Bessen DE, Guglielmini J, Steer AC, et al. Updated model of group A streptococcus $M$ proteins based on a comprehensive worldwide study. Clinical Microbiology and Infection: The Official Publication of the European Society of Clinical Microbiology and Infectious Diseases. 2013;19:E222-E229

[66] Glinton K, Beck J, Liang Z, Qiu C, Lee SW, Ploplis VA, et al. Variable region in streptococcal M-proteins provides stable binding with host fibrinogen for plasminogenmediated bacterial invasion. The Journal of Biological Chemistry. 2017;292:6775-6785

[67] Hong K. Human IgG binding ability of streptococcal M3 protein: Its related complement activation-dependent M3 protein polymerization. FEMS Immunology and Medical Microbiology. 1997;18:163-174

[68] Horstmann RD, Sievertsen HJ, Knobloch J, Fischetti VA.

Antiphagocytic activity of streptococcal $M$ protein: Selective binding of complement control protein factor $\mathrm{H}$. Proceedings of the National Academy of Sciences of the United States of America. 1988;85:1657-1661
[69] Ghosh P. Variation, indispensability, and masking in the $M$ protein. Trends in Microbiology. 2018;26:132-144

[70] Sanderson-Smith ML, Walker MJ, Ranson M. The maintenance of high affinity plasminogen binding by group A streptococcal plasminogenbinding M-like protein is mediated by arginine and histidine residues within the $\mathrm{a} 1$ and $\mathrm{a} 2$ repeat domains. The Journal of Biological Chemistry. 2006;281:25965-25971

[71] Sanderson-Smith M, Batzloff M, Sriprakash KS, Dowton M, Ranson $M$, Walker MJ. Divergence in the plasminogen-binding group $\mathrm{A}$ streptococcal M protein family: Functional conservation of binding site and potential role for immune selection of variants. The Journal of Biological Chemistry. 2006;281:3217-3226

[72] Lannergard J, Gustafsson MC, Waldemarsson J, Norrby-Teglund A, Stalhammar-Carlemalm M, Lindahl G. The hypervariable region of Streptococcus pyogenes M protein escapes antibody attack by antigenic variation and weak immunogenicity. Cell Host \& Microbe. 2011;10:147-157

[73] Yuan Y, Zajicek J, Qiu C, Chandrahas V, Lee SW, Ploplis VA, et al. Conformationally organized lysine isosteres in Streptococcus pyogenes $\mathrm{M}$ protein mediate direct high-affinity binding to human plasminogen. The Journal of Biological Chemistry. 2017;292:15016-15027

[74] Qiu C, Yuan Y, Zajicek J, Liang Z, Balsara RD, Brito-Robionson T, et al. Contributions of different modules of the plasminogen-binding Streptococcus pyogenes $\mathrm{M}$-protein that mediate its functional dimerization. Journal of Structural Biology. 2018;204:151-164

[75] Qiu C, Yuan Y, Liang Z, Lee SW, Ploplis VA, Castellino FJ. Variations in the secondary structures of PAM 
proteins influence their binding affinities to human plasminogen. Journal of Structural Biology. 1 May 2019;206(2):193-203

[76] McNamara C, Zinkernagel AS, Macheboeuf P, Cunningham MW, Nizet V, Ghosh P. Coiled-coil irregularities and instabilities in group A streptococcus $\mathrm{M} 1$ are required for virulence. Science. 2008;319:1405-1408

[77] Berge A, Sjobring U. PAM, a novel plasminogen-binding protein from Streptococcus pyogenes. The Journal of Biological Chemistry. 1993;268:25417-25424

[78] Bhattacharya S, Liang Z, Quek AJ, Ploplis VA, Law R, Castellino FJ. Dimerization is not a determining factor for functional high affinity human plasminogen binding by the group A streptococcal virulence factor PAM and is mediated by specific residues within the PAM a1a2 domain. The Journal of Biological Chemistry. 2014;289:21684-21693. DOI: 10.21074/ jbc.M21114.570218

[79] Rios-Steiner JL, Schenone M, Mochalkin I, Tulinsky A, Castellino FJ. Structure and binding determinants of the recombinant kringle-2 domain of human plasminogen to an internal peptide from a group A streptococcal surface protein. Journal of Molecular Biology. 2001;308:705-719

[80] Cnudde SE, Prorok M, Castellino FJ, Geiger JH. X-ray crystallographic structure of the angiogenesis inhibitor, angiostatin, bound to a peptide from the group A streptococcal surface protein PAM. Biochemistry. 2006;45:11052-11060

[81] Quek AJH, Mazzitelli BA, Wu G, Leung EWW, Caradoc-Davies TT, Lloyd GJ, et al. Structure and Function Characterization of the a1a2 Motifs of Streptococcus pyogenes M Protein in Human Plasminogen
Binding. Journal Molelcular Biology. 2019;2836(19)30424-304330

[82] De Oliveira DM, Law RH, Ly D, Cook SM, Quek AJ, McArthur JD, et al. Preferential acquisition and activation of plasminogen glycoform II by PAM positive group A streptococcal isolates. Biochemistry. 2015;54:3960-3968. DOI: 10.1021/acs. biochem.3965b00130

[83] Akesson P, Sjoholm AG, Bjorck L. Protein SIC, a novel extracellular protein of Streptococcus pyogenes interfering with complement function. The Journal of Biological Chemistry. 1996;271:1081-1088

[84] Frick IM, Akesson P, Rasmussen M, Schmidtchen A, Bjorck L. SIC, a secreted protein of Streptococcus pyogenes that inactivates antibacterial peptides. The Journal of Biological Chemistry. 2003;278:16561-16566

[85] Fernie-King BA, Seilly DJ, Lachmann PJ. The interaction of streptococcal inhibitor of complement (SIC) and its proteolytic fragments with the human beta defensins. Immunology. 2004;111:444-452

[86] Westman J, Chakrakodi B, Snall J, Morgelin M, Bruun Madsen M, Hyldegaard O, et al. Protein SIC secreted from Streptococcus pyogenes forms complexes with extracellular histones that boost cytokine production. Frontiers in Immunology. 2018;9:236

[87] Frick IM, Shannon O, Neumann A, Karlsson C, Wikstrom M, Bjorck L. Streptococcal inhibitor of complement (SIC) modulates fibrinolysis and enhances bacterial survival within fibrin clots. The Journal of Biological Chemistry. 2018;293:13578-13591

[88] Li Z, Ploplis VA, French EL, Boyle $\mathrm{MD}$. Interaction between group $\mathrm{A}$ streptococci and the plasmin(ogen) system promotes virulence in a mouse 
skin infection model. The Journal of Infectious Diseases. 1999;179:907-914

[89] Khil J, Im M, Heath A, Ringdahl U, Mundada L, Cary Engleberg N, et al. Plasminogen enhances virulence of group A streptococci by streptokinasedependent and streptokinaseindependent mechanisms. The Journal of Infectious Diseases. 2003;188:497-505

[90] Sumitomo T, Nakata M, Higashino M, Yamaguchi M, Kawabata S. Group A streptococcus exploits human plasminogen for bacterial translocation across epithelial barrier via tricellular tight junctions. Scientific Reports. 2016;7:20069

[91] Chatellier S, Ihendyane N, Kansal RG, Khambaty F, Basma H, NorrbyTeglund A, et al. Genetic relatedness and superantigen expression in group A streptococcus serotype M1 isolates from patients with severe and nonsevere invasive diseases. Infection and Immunity. 2000;68:3523-3534

[92] Fletcher AP, Alkjaersig N, Smyrniotis FE, Sherry S. The treatment of patients suffering from early myocardial infarction with massive and prolonged streptokinase therapy. Transactions of the Association of American Physicians. 1958;71:287-296

[93] Hirsh J, Hale GS, McDonald IG, McCarthy RA, Cade JF. Resolution of acute massive pulmonary embolism after pulmonary arterial infusion of streptokinase. The Lancet. 1967;2:593-597

[94] Millers EKI, Johnson LA, Birrell GW, Masci PP, Lavin MF, de Jersey J, et al. The structure of human microplasmin in complex with Textilinin-1, an Aprotinin-like inhibitor from the Australian Brown Snake. PLoS One. 2013;8(1):e54104. DOI: 10.1371/ journal.pone.0054104. [Epub 2013 Jan 15]
[95] Akesson P, Herwald H, Rasmussen M, Hakansson K, Abrahamson M, Hasan AA, et al. Streptococcal inhibitor of complement-mediated lysis (SIC): An anti-inflammatory virulence determinant. Microbiology. 2010;156:3660-3668

[96] Frick IM, Shannon O, Akesson P, Morgelin M, Collin M, Schmidtchen A, et al. Antibacterial activity of the contact and complement systems is blocked by SIC, a protein secreted by Streptococcus pyogenes. The Journal of Biological Chemistry. 2011;286:1331-1340 


\title{
Cell Surface and Cytosolic Proteins of Group B Streptococcus Adding New Dimensions in Its Colonization and Pathogenesis
}

\author{
Manju Ohri Pai, Venkatesh Srinivasa Pai, Pratima Gupta \\ and Anuradha Chakraborti
}

\section{Abstract}

Streptococcus agalactiae or Group B streptococcus (GBS) is an opportunistic human pathogen known for their invasive diseases caused in newborns, pregnant women, and nonpregnant adults. This pathogen even being an asymptomatic colonizer of adult humans, still they result in a broad range of disease manifestations starting from mild skin diseases to pneumonia, meningitis, and septicemia. Of the 10 GBS capsular types, the majority of invasive neonatal diseases are associated with the serotype III. GBS is a pathogen that has developed some strategies to resist host immune defenses. The formidable array of GBS virulence factors makes this bacterium at the forefront of neonatal pathogens. The involvement of bacterial components in the host-pathogen interaction of GBS pathogenesis and its related diseases is thought to be due to a variety of virulence factors expressed by Streptococcus agalactiae. Pathogenic factors of streptococcus promote infections by their coordinated activity. These factors/determinants initially get a stimulus by the communication between specific ligands and their respective receptors in a hostpathogen interaction. These in turn activate adhesion and invasion mechanisms by mediating the attachment of pathogen via cell wall associated/secretory proteins, e.g., adhesins followed by their entry into the host cell eventually deciding their fate to live by activation of mechanisms like phagocytosis. These mediators/determinants also modulate the immune responses by the host toward the pathogen. A number of new GBS surface-exposed or secreted proteins have been identified (GBS immunogenic bacterial adhesion protein, leucine-rich repeat of GBS, serinerich repeat proteins), the three-dimensional structures of known streptococcal proteins ( $\alpha \mathrm{C}$ protein, C5a peptidase) have been solved, and an understanding of the pathogenetic role of "old" and new determinants has been better defined in recent years. Recently, a 39kDa Invasion Inhibitory Factor (IIF) was isolated from GBS playing an important role in its invasion. A homogeneous non-toxic $39 \mathrm{kDa}$ factor from the cytosol of GBS showing a homology with xenobiotic response element type transcriptional regulator protein adds another quill to the GBS protein panama, thus indicating that such protein molecules can be efficiently explored as suitable vaccine candidates. These observations add a novel aspect to bacterial pathogenesis where bacteria's own intracellular protein component can act as a potential therapeutic candidate by decreasing the severity of disease thus promoting its invasion inhibition. 
Keywords: group B streptococcus (GBS), Streptococcus agalactiae, pathogenesis, cytosolic proteins, invasion

\section{Introduction}

Fry, in 1938 was the first to report Lancefield Group B $\beta$-hemolytic streptococci in three patients with puerperal sepsis [1]. After that, many sporadic cases were reported from different parts of the world in next 30 years but still this organism remained unexplored and unnoticed for most of the clinicians [2-4]. Then after reports of emerging GBS infections in neonates was followed up by increasing reports of infections in neonates followed by reports from pregnant women with localized uterine infection or chorioamnionitis commonly associated with bacteremia. The prognosis was found good with antimicrobial therapy. In other adults, the underlying infection often leads to fatality [5]. Till the 1990s, the scenario of GBS infection was the same, then after there was a substantial decline in reports of GBS infections. Current nomenclature designates polysaccharide antigens as type antigens with antigenically distinct types, Serotype Ia through IX, now are characterized. Complete genome sequence of type III and V (most common and virulent serotypes) opened new avenues for identification of novel potential vaccine targets $[6,7]$. Early concepts suggested a thick, rigid peptidoglycan layer external to the cytoplasmic membrane surrounded by concentric layers of cell wall antigens. In accordance with the Lancefield's classification, there are different Group specific carbohydrates. These group specific carbohydrates were initially thought to be covered by a type-specific capsular polysaccharide (CPS), which was further deciphered by a study model showing evidences where group B carbohydrate and the CPS are linked independently to cell wall peptidoglycan [8]. Immunoelectron techniques using reference strains with homologous type-specific antisera reveals abundant CPS on Lancefield prototype strains Ia, II, III, IV, V, and VI, whereas less dense capsules are found on type Ib [9-11]. Studies also reveal that the expression of these capsular structures can be regulated by altering the cell growth. In addition, the ultrastructural studies using immunogold labeling and transmission electron microscopy shows that $\mathrm{C}$ protein also has a surface location along with GBS piluslike structures that extend from the bacterial surface $[12,13]$.

\section{GBS disease outcomes}

GBS is also known to be a leading cause of pneumonia and sepsis in newborns which can lead to fatal complications. As a resident of the maternal genital tract, during delivery, it may become a major cause of colonization and infection in the newborns. The neonate gets exposed to this organism through the birth canal through an ascending route in-utero via the intact or ruptured membranes, thus leading to neonatal infections. A vertical transmission of $29-85 \%$ with a mean rate of approximately $50 \%$ was reported among newborns born to women from whom GBS was isolated either from their vagina or rectum or both during delivery. In contrast, only $5 \%$ of neonates are reported to be asymptomatically colonized at one or more sites during their first $48 \mathrm{~h}$ of life from mothers who are culture negative for GBS [14]. The risk of a neonate acquiring colonization by the vertical route correlates directly with the density of colonization (inoculum size). Majorly the transmission route is fecal oral. The GBS colonization acquired vertically or horizontally in neonates or young infants usually persists for weeks or months. 
The mode of transmission likely is fecal-oral. Whether acquired by vertical or horizontal mode, colonization of mucous membrane sites in neonates and young infants usually persists for weeks or months [15].

It has also emerged as the third most common cause of infantile pyogenic meningitis [1,2]. Exposure of pregnant females to this organism in developed and developing countries seem to be similar however, it is confusing to see an apparent lower incidence of GBS in less developed or developing countries. The data shows that in developed countries, neonatal GBS disease occurs 0.4-1.4 per 1000 live births with a fatality of up to $60 \%$. Studies conducted in different centers during the 1990's in developing nations fail to identify this pathogen [16]. Recent studies in Malawi, however had mixed results showing GBS as an important cause of neonatal sepsis [17] while very few studies are from India, showing 6.2\% Early onset disease (EOD) burden and Nigeria still fail to report any disease burden [18-20] Several reasons are hypothesized that why the disease burden may be low in certain developing countries. First, there may be low maternal GBS colonization, which could then lead to low neonatal disease burden. Secondly, poor or less awareness among the pregnant mothers for GBS testing during their course of pregnancy. Few studies conducted in developing countries have reported quantitative maternal genital colonization, and those that have, reported a low prevalence of maternal GBS colonization [21]. In 2002, the implementation of guidelines to prevent early onset neonatal sepsis and screening at 35-37 week of gestation of pregnant women tremendously decreased the incidence of GBS infections [22]. Maternal postpartum sepsis and infective endocarditis are also important complications associated with GBS infections [5, 23, 24]. In the recent years, osteomyelitis and septic arthritis often involving the knee, hip, or shoulder joints are also part of the GBS disease spectrum specially seen in adults [25].

\subsection{Host-bacterial interactions in pathogenesis}

Pathogenesis of any organism is a multistep, sequential invasion in the host cells mediated by specific molecules (may it be proteins, lipids or carbohydrate-protein complexes), which bring about the pathogen-host cell interaction by standard receptor-ligand interactions. Group B Streptococcus pathogenesis is also thought to be a multistep process [26]. In the ocean of many other pathogenic bacteria, GBS encodes a number of virulence factors for its pathogenesis. The colonization and breaching of mucosal surfaces by GBS thus allows its entry to normally sterile sites like blood stream, CNS and fetal membranes [27, 28]. The main virulence factor of GBS is thought to be pore forming toxins (Beta hemolysins/cytolysins and CAMP factor) and sialic acid rich CPS. Their virulence potential is because of its antiphagocytic properties [29]. Till date, nine serotypes (I to IX) on the basis of the capsular polysaccharide have been reported. The CPS also has a pivotal role in preventing complement activation, therefore does not influence adherence of GBS to epithelial cells but does reduce internalization [30]. Previous reports have shown that Serotype III accounts for approximately $50 \%$ of all neonatal infections as well as approximately $90 \%$ of cases of neonatal meningitis in US [31, 32]. Our earlier study has also shown that Type III isolates are more predominant as compared to other serotypes both in their invasiveness and biofilm formation [33]. Despite the advancement of the understanding about various virulence factors, their understanding on the regulation and use of these virulence tools has not yet been much explored. Thus, intensive investigations are done to elucidate the pathogenesis of GBS infection in neonates. The exclusive clinical features of GBS infection pose several questions that provide an agenda for hypothesis development (a hypothetical model) and experimental testing (Figure 1): 
1. How does the organism colonize pregnant women and gain access to the infant before or during delivery?

2. How do these bugs gain entry to the bloodstream and cross the blood-brain barrier?

3. How does GBS evade host innate immune defenses?

\section{What factors of GBS induce sepsis?}

5. Is there any role of intracellular factors of GBS in its pathogenesis?

6. How does the regulation of virulence factors occur during infection?

Some advancement in knowledge of pathogenesis has been achieved through development of cell culture systems and animal models. Many cell surface proteins, and other moieties including lipid moieties have been studied for their role in hostpathogen interactions. However, not much about the cytosolic proteins of GBS is known. The group B streptococcal virulence factors defined to date, with proposed role in pathogenesis, are shown in Table 1 and discussed briefly below.

The process of human infection by group B Streptococcus (GBS) is complex and multifactorial. Adhesion and invasion of streptococci into the host cell involves a number of pathogen-host cell interactions (Figure 2). Their entry and survival inside the respiratory epithelial cells may represent a mechanism by which these bacteria gain access into the blood circulation [35-37]. Two main cell types, respiratory epithelial cells and resident alveolar macrophages, are encountered by GBS infecting the lung [38-40]. The former is the sentinel barrier for the streptococcal transcytosis into deeper tissues and thereafter into the bloodstream. Streptococcal surface-associated proteins are critically important in the host- pathogen relationship as they can provide initial contact of the bacteria with its intended host before internalization [41]. An immunologic response is generated once GBS penetrates into lung tissue or bloodstream of newborn infant. This is followed by invitation to

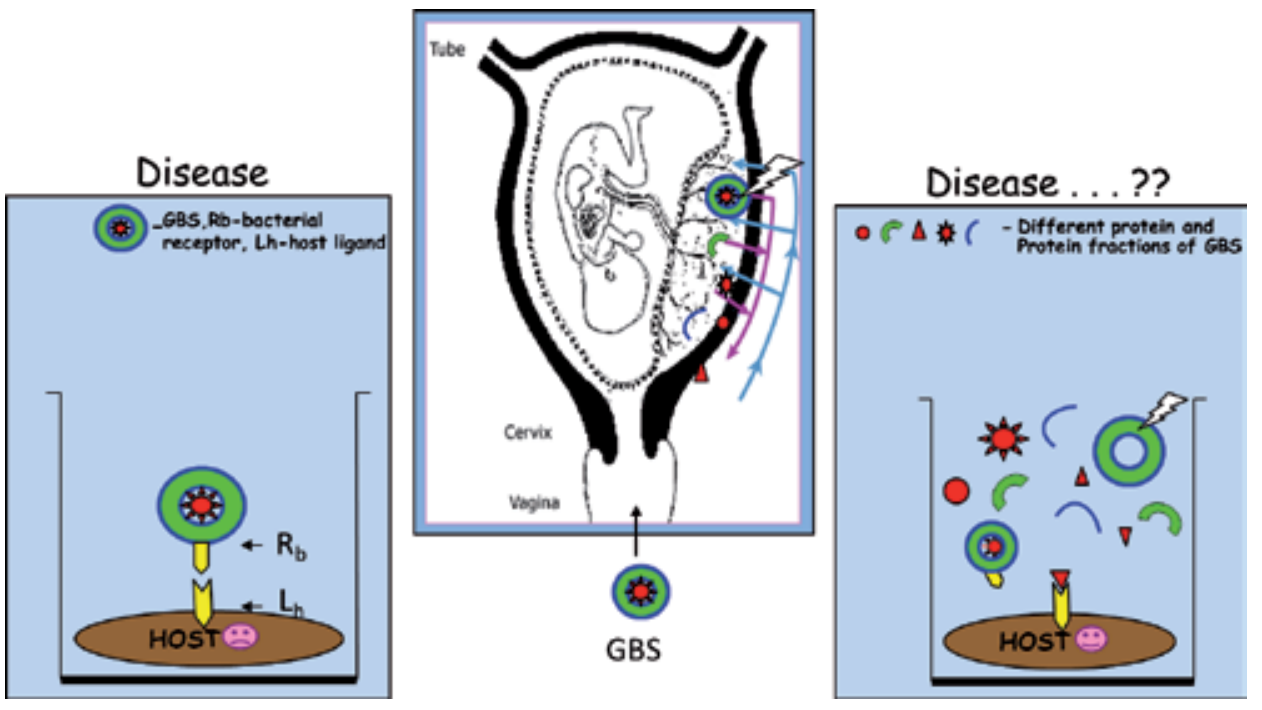

Figure 1.

Hypothetical model of host-pathogen interaction of GBS. 
Cell Surface and Cytosolic Proteins of Group B Streptococcus Adding New Dimensions... DOI: http://dx.doi.org/10.5772/intechopen.89102

\begin{tabular}{|c|c|}
\hline Virulence factor & Role in pathogenesis \\
\hline \multicolumn{2}{|c|}{ Host cell adherence and invasion } \\
\hline C surface protein & Adherence and invasion of epithelial cells \\
\hline Lipoteichoic acid & Attachment of epithelial cells \\
\hline Fibrinogen receptor, FbsA & Attachment of epithelial cells \\
\hline C5a peptidase & Adherence and invasion of epithelial cells \\
\hline Surface protein Lmb & Attachment of epithelial cells \\
\hline Spb1 surface protein & Invasion of epithelial barriers \\
\hline iagA gene & Promotes blood brain barrier invasion \\
\hline \multicolumn{2}{|l|}{ Host tissue insult } \\
\hline Beta-hemolysin/cytolysin & Damage and spread through tissues \\
\hline Hyaluronate lyase & Promotes spread through host tissues \\
\hline CAMP factor & Direct tissue injury \\
\hline \multicolumn{2}{|l|}{ Molecules in immune evasion } \\
\hline Exopolysaccharide capsule & Blocks opsonophagocytic clearance \\
\hline C5a peptidase, ScpP & Inhibits neutrophil recruitment \\
\hline CAMP factor & Impairment of antibody function \\
\hline Serine Protease, CspA & Blocks opsonophagocytosis \\
\hline Fibrinogen receptor, FbsA & Blocks opsonophagocytosis \\
\hline C Protein & Blocks opsonophagocytosis \\
\hline Beta-Hemolysin/cytolysin & Impairment of phagocyte killing \\
\hline Superoxide dismutase & Impairment of oxidative burst killing \\
\hline Carotenoid pigment & Impairment of oxidative burst killing \\
\hline Dlt operon genes & Interferes with antimicrobial peptides \\
\hline Penicillin binding protein Ia & Interferes with antimicrobial peptides \\
\hline \multicolumn{2}{|c|}{ Molecules as inflammatory mediators } \\
\hline Cell wall LTA & Cytokine activation \\
\hline Cell wall peptidoglycan & Cytokine activation \\
\hline Beta Hemolysin/cytolysin & Triggers iNOS and Cytokine release \\
\hline
\end{tabular}

Table 1.

GBS virulence factors and their role in pathogenesis.
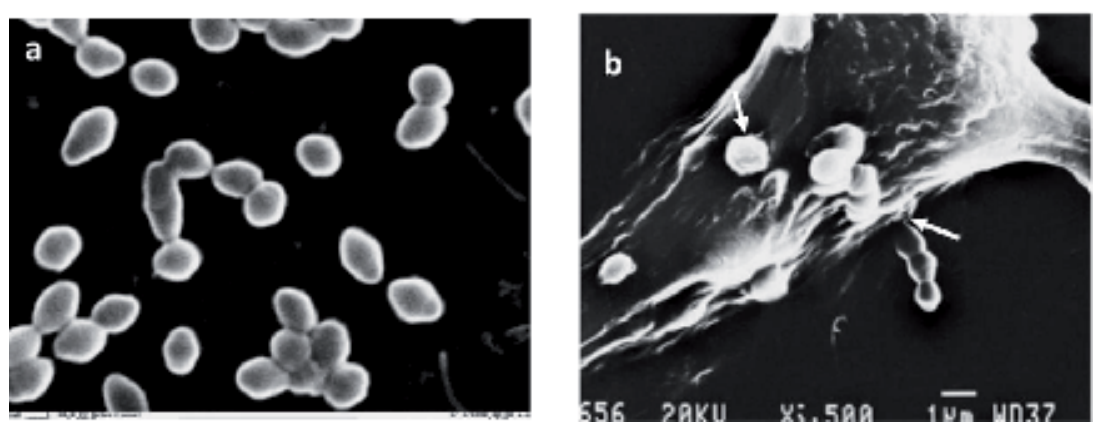

Figure 2.

Scanning electron micrograph (SEM) of (a) GBS, (b) GBS adhering to and invading into A549 cells (courtesy: Ohri et al. [34]).

host phagocytic cells like neutrophils and macrophages leading to bacterial uptake and opsonization by specific antibodies in the presence of complement [42-44]. Primarily sialic acid derivatives i.e. sialylated Group B Streptococcal polysaccharide capsule are the one to confront for opsonization mediated phagocytic killing followed by the other serotype specific epitopes of GBS capsular polysaccharide (CPS). It is also suggested that GBS may be chiefly a taxing human pathogen because its sialylated capsule has undergone selection to resemble host 'self' thus avoiding immune recognition. Surface proteins of GBS have high efficiency to avoid 
opsonophagocytosis along with CPS. C protein or its components resist phagocytic killing and inhibits its interaction with complement or IgG [45]. A cell surface protease CspA, targets host fibrinogen producing adherent fibrin like cleavage products that coat the bacterial surface and interfere with opsonophagocytic clearance [46].

With a big pool of virulence factors encrypted by GBS, it has been confirmed to adhere to a variety of eukaryotic cellular structures. ECM proteins including laminin, fibronectin, fibrinogen, cytokeratin and plasminogen facilitates interaction with host-cell surface integrins thus promoting the entry of GBS into the varied host cells [41]. The initial step of adherence is thought to be mediated by a number of bacterial moieties such as laminin binding proteins, C5a peptidase, glyceraldehyde phosphate dehydrogenase, $\alpha$-enolase and lipoteichoic acid [47]. In addition to adherence facilitating moieties, alpha $\mathrm{C}$ protein and invasion associated gene (iagA) are important molecules in the process of GBS invasion in host cells. Genome-wide phage display technique revealed a fibronectin-binding property associated with the surface-anchored group B streptococcal C5a peptidase, ScpB [48]. This dual functionality of ScpB was confirmed by decreased fibronectin binding of isogenic $\mathrm{ScpB}$ mutants and the direct interaction of recombinant ScpB with solid-phase fibronectin $[48,49]$. Similar targeted mutagenesis studies showed that adherence of GBS to laminin involves a protein adhesin called Lmb [50], repetitive motifs within the surface-anchored protein FbsA mediates attachment to fibrinogen [51], and binding to human keratin 4 is carried out by the serine rich repeat domain protein Srr-1 [52]. Recently, GBS were revealed to express filamentous cell surface appendages known as pili [36]. Pili mediate GBS resistance to AMP's (antimicrobial peptides) and also aid in its attachment to the host cells. Two genetic loci have been found on GBS genome, which are responsible for pilus like structures. Among eight sequenced GBS genomes, not all genomes contain both loci [53]. One of these islands includes genes encoding PilB, an LP(x)TG motif-containing protein that polymerizes to form a pilus backbone and is the major structural component of GBS pili, along with accessory pilus proteins PilA and PilC [53, 54]. Isogenic GBS mutants lacking PilA or PilC showed decreased adherence to epithelial cells, but not mutants lacking the PilB backbone. In addition, the crystal structure of PilC reveals a specific IgG-like fold domain (N2) required for epithelial cell binding [54]. Upon bacterial binding to the host cell receptors, recruitment of host-cell actin to the site of bacterial entry has been observed $[55,56]$. However, there are some studies which have shown that certain bacterial surface proteins like type III CPS and the $\mathrm{N}$-terminal region of the alpha $\mathrm{C}$ protein partially mask the specific components of GBS that are critical for adherence/invasion of eukaryotic cells [29, 57, 58]. Thus decreasing the adherence and invasion efficiency of GBS to host cells. Similarly, Burnham et al., showed prior treatment of the epithelial cells by exogenous addition of phosphoglycerate kinase (PGK, a cell surface and a cytosolic protein of GBS) inhibited GBS internalization [40]. PGK as a major outer surface protein of GBS which showed a similar inhibitory effect using saccharomyces derived PGK in Type V GBS invasion. PGK from other sources like Candida albicans and Schistosoma mansoni has also been used to study host-pathogen interactions specifically invasion and adherence mechanisms [58-60]. Boone et al. [57] showed GBS-PGK released from the bacterial cell binds to plasminogen and actin. These secreted proteins demonstrate an interaction between the bacterial protein and their host cell receptors [61]. However, as reported by Hulse et al. [62] Type III capsular polysaccharide is also reported to attenuate invasion if pre-incubated with the host cells. A similar study was performed with Lactoferrin, an antimicrobial peptide, showing its invasion inhibitory activity on a broad range of organisms including streptococcus [61]. There are many other studies which report that cell surface molecules can also be used to inhibit adherence and invasion in bacteria. A recent published study 
from our lab has reported the role of a cytosolic protein in inhibition of invasion of GBS into eukaryotic epithelial cells [34]. A $39 \mathrm{kDa}$ invasion inhibitory factor (IIF) isolated from cytosol of GBS showed almost 70-80\% reduction in invasion as compared to the crude cytosolic fractions indicating an anti-internalization mechanism. N-terminal sequence showed its homology with a xenobiotic response element(XRE) type transcriptional regulator protein. This family of transcription factors controls various metabolic functions in the bacteria, thus emphasizing on its probable role in pathogenesis as well [63]. Studies like these raise a question as to how an organism can itself contain or manufacture such a factor which can inhibit its own mechanism of pathogenesis thus indicating that bacteria's own components can also play an important role in its adherence and invasion process.

As most pregnant women have low concentrations of type-specific $\operatorname{IgG}$ in their sera, immunization of women during adolescence, before pregnancy, or in late pregnancy (i.e., early third trimester) would be the best approach for immunoprophylaxis [64]. In view of the substantial disease burden in nonpregnant adults, targeted adult immunization (e.g., diabetics or adults "65 years old) also is an attractive prevention strategy. GBS serotypes Ia, III, and V are reported to be most invasive forms to cause disease in infants and adults followed by serotypes Ib and II that account for $75-85 \%$ of infections [65-68]. The production of a trivalent or a pentavalent conjugate vaccine is technically achievable. The cost of developing suitable vaccines, although substantial, is considerably less than the death, disability, and treatment associated with these infections [69, 70]. In 2014, World Health Organization convened the first meeting for consultation on GBS vaccine development, focusing on the GBS maternal immunization program, which was aimed at reducing infections in neonates and young infants worldwide [70].

\section{Conclusion}

Despite the availability of the genome sequence of GBS, advances have been made in deciphering the various facets of molecular mechanisms involved in disease pathogenesis. This has taken our knowledge a step forward in knowing the pivotal role of certain molecular targets which can be explored as target vaccine candidates. Though, GBS being a commensal and an adaptable organism which adjusts its niche according to the environment, it fine tunes its gene expression for its pathogenesis paradigms. Thus, it becomes more imperative to understand how this pathogen responds to its external environment to appropriately express this large repertoire of factors for colonization or invasion of the host tissue targets, which is still under infancy. As it is commonly said 'Prevention is better than Cure', thus to prevent GBS disease the physicians, public health officials, parents, and patients must join hands and campaign for pregnant women, neonates and young infants, and at-risk adults.

\section{Acknowledgements}

Prof. AC is highly acknowledged for the guidance and opportunity given to Dr. MOP for working on GBS cytosolic proteins and writing this brief chapter about GBS. Prof PG and Dr. VSP for critical reading the chapter.

\section{Conflict of interest}

There are no conflicts of interest. 


\section{Author details}

Manju Ohri Pai ${ }^{1 *}$, Venkatesh Srinivasa Pai $^{2}$, Pratima Gupta ${ }^{1}$ and Anuradha Chakraborti ${ }^{3}$

1 Department of Microbiology, All India Institute of Medical Sciences (AIIMS) Rishikesh, Rishikesh, India

2 Department of Medicine, AIIMS Rishikesh, Rishikesh, India

3 Department of Experimental Medicine and Biotechnology, Post Graduate Institute of Medical Education and Research, PGIMER, Chandigarh, India

*Address all correspondence to: manjuohripai@gmail.com

\section{IntechOpen}

(C) 2019 The Author(s). Licensee IntechOpen. This chapter is distributed under the terms of the Creative Commons Attribution License (http://creativecommons.org/licenses/ by/3.0), which permits unrestricted use, distribution, and reproduction in any medium, provided the original work is properly cited. (cc) BY 
Cell Surface and Cytosolic Proteins of Group B Streptococcus Adding New Dimensions... DOI: http://dx.doi.org/10.5772/intechopen.89102

\section{References}

[1] Fry RM. Fatal infections by haemolytic streptococcus group B. Lancet. 1938;1:199-201

[2] Franciosi RA, Knostman JD, Zimmerman RA. Group B streptococcal neonatal and infant infections. The Journal of Pediatrics. 1973;82:707-718

[3] Baker CJ, Barrett FF. Transmission of group B streptococci among parturient women and their neonates. The Journal of Pediatrics. 1973;83:919-925

[4] Howard JB, McCracken GM Jr. The spectrum of group B streptococcal infections in infancy. American Journal of Diseases of Children. 1974;128:815-818

[5] Farley MM, Harvey RC, Studell T, Smith JD, Schuchat A, Wenger JD, et al. A population based assessment of invasive disease due to group B streptococcus in non-pregnant adults. The New England Journal of Medicine. 1993;328:1087-1811

[6] Tettelin H, Masignani V, Cieslewicz MJ, et al. Complete genome sequence and comparative genomic analysis of an emerging human pathogen, serotype V Streptococcus agalactiae. Proceedings of the National Academy of Sciences of the United States of America. 2002;99(19):12391-12396

[7] Glaser P, Rusniok C, Buchrieser C, Chevalier F, Frangeul L, Msadek T, et al. Genome sequence of Streptococcus agalactiae, a pathogen causing invasive neonatal disease. Molecular Microbiology. 2002;45:1499-1513

[8] Deng L, Kasper DL, Krick TP, Wessels MR. Characterization of the linkage between the type III capsular polysaccharide and the bacterial cell wall of group B streptococcus. The Journal of Biological Chemistry. 2000;275:7497-7504
[9] Kasper DL, Baker CJ. Electron microscopic definition of surface antigens of group B streptococcus. The Journal of Infectious Diseases. 1979;139:147-151

[10] Christina VH, Laura P, Luciana T, Simona R, Giovanna A, Laura N, et al. Immunochemistry of capsular type polysaccharide and virulence properties of type VI Streptococcus agalactiae (group B streptococci). Infection and Immunity. 1993;61:1272-1280

[11] Rýc M et al. Immunoelectronmicroscopic demonstration of capsules on group-B streptococci of new serotypes and type candidates. Journal of Medical Microbiology. 1988;25:147-149

[12] Paoletti LC, Ross RA, Johnson KD. Cell growth rate regulates expression of group B streptococcus type III capsular polysaccharide. Infection and Immunity. 1996;64(4):1220-1226

[13] Lauer P, Rinaudo CD, Soriani M, Margarit I, Maoine D. RosiniR et al, genome analysis reveals pili in group $B$ streptococcus. Science. 2005;309:105

[14] Schrag SJ, Zywicki S, Farley MM, Reingold AL, Harrison LH, Lefkowitz LB, et al. Group B streptococcal disease in the era of intrapartum antibiotic prophylaxis. The New England Journal of Medicine. 2000;342:15-20

[15] Ancona RJ, Ferrieri P, Williams PP. Maternal factors that enhance the acquisition of group B streptococci by newborn infants. Journal of Medical Microbiology. 1980;13:273-280

[16] Le Doare K, Heath PT. An overview of global GBS epidemiology. Vaccine. 2013;31(Suppl 4):D7-D12

[17] WHO. World Health Organization Young Infants Study Group. Conclusions 
from the WHO multicenter study of serious infections in young infants. Pediatric Infectious Disease Journal 1999b;18(Suppl.):S32-S34

[18] Gray KJ, Bennett SL, French N, Phiri AJ, Graham SM. Invasive group $B$ streptococcal infection in infants, Malawi. Emerging Infectious Diseases. 2007;13(2):223-229

[19] Delair S, Mukhtar M, Olateju E, et al. Isolates from bacteremic neonates in central Nigeria - a pilot study. In: World Society of Pediatric Infectious Diseases Conference; Cape Town, South Africa; 2013

[20] Sridhar S, Grace R, Nithya PJ, Balaji V, Niranjan T, Manish K, et al. Group B streptococcal infection in a tertiary hospital in India--1998-2010. The Pediatric Infectious Disease Journal. 2014;33(10):1091-1092

[21] Viswanathan R, Singh AK, Basu S, et al. Multi-drug resistant gram negative bacilli causing early neonatal sepsis in India. Archives of Disease in Childhood. Fetal and Neonatal Edition. 2012;97(3):F182-F187

\section{[22] Stoll BJ, Schuchat A. Maternal} carriage of group B streptococci in developing countries. The Pediatric Infectious Disease Journal. 1998;17(6):499-503

[23] CDC. Prevention of perinatal group B streptococcal disease: Revised guidelines from CDC. MMWR August 16, 2002/51(RR11); 1-22

[24] Schuchat A. Epidemiology of group B streptococcal disease in United States: Shifting paradigms. Clinical Microbiology Reviews. 1998;11:497-513

[25] Schuchat A, Wenger JD. Epidemiology of group B streptococcal disease: Risk factors, prevention strategies and vaccine development. Epidemiologic Reviews. 1994;16:372-402
[26] Farley MM. Group B streptococcal disease in non-pregnant adults. Clinical Infectious Diseases. 2001;33:556-561

[27] Tamura GS, Kuypers JM, Smith S, Raff H, Rubens CE. Adherence of group B Sterptococci to cultured epithelial cells: Role of environmental factors and bacterial surface components. Infection and Immunity. 1994;62:2450-2458

[28] Doran KS, Chang CW, Jennifer VM, Eckmann BL, Nizet V. Group B streptococcal beta-hemolysin/ cytolysin promotes invasion of human lung epithelial cells and the release of IL-8. The Journal of Infectious Diseases. 2002;185:196-203

[29] Bolduc GR, Baron MJ, Gravecamp C, Lachenauer CS, Madoff LC. The alpha $\mathrm{C}$ protein mediates internalization of group B streptococcus with human cervical epithelial cells. Cellular Microbiology. 2002;4:751-758

[30] Baker CJ, Edwards MS. In: Remington JS, Klein JO, editors. Group B Streptococcal Infections. Infectious Diseases of the Fetus and Newborn Infant. Philadelphia: W B Saunders; 1995. pp. 980-1054

[31] Harrison LH, Elliot JA, Dwyer DM, et al. Group B streptococcal serotype distribution of isolates from colonized pregnant women at time of delivery in United Arab Emirates. Pediatric Infectious Disease. 1998;17:499-503

[32] Kaur H, Kumar P, Ray P, Chakraborti A. Biofilm formation in clinical isolates of group B streptococci from North India. Microbial Pathogenesis. 2009;46:321-327

[33] Rubens CE, Raff HV, Jackson JC, Chi EY, Bielitzki JT, Hillier SL. Pathophysiology and histopathology of group B streptococcal sepsis in Macaca nemestrina primates induced after intra amniotic inoculation: Evidence for 
bacterial cellular invasion. The Journal of Infectious Diseases. 1991;164:320-330

[34] Ohri M, Parashar S, Pai VS, Ghosh S, Chakraborti A. A cytosol derived factor of group B streptococcus prevent its invasion into human epithelial cells. World Journal of Microbiology and Biotechnology. 2018;34(45):1-14

[35] Rubens CE, Smith S, Hulse M, Chi EY, Belle GV. Respiratory epithelial cell invasion by group B streptococci. Infection and Immunity. 1992;60:5157-5163

[36] Weigand PV, Chattwal GS. Correlation of epithelial cell invasiveness of GBS with clinical source of isolation. Microbial Pathogenesis. 1995;19:83-91

[37] Alenghat E, Esterly JR. Alveolar macrophages in perinatal infants. Pediatrics. 1984;74:221-223

[38] Goldstein E, Lippert W, Warshauer D. Pulmonary alveolar macrophage: Defender against bacterial infection of the lung. The Journal of Clinical Investigation. 1974;54:519-528

[39] Sherman MP, Lehrer RI. Oxidative metabolism of neonatal and adult rabbit lung macrophages stimulated with opsonized group B streptococci. Infection and Immunity. 1992;47:26-30

[40] Burnham CAD, Shokoples SE, Tyrrell GJ. Phosphoglycerate kinase inhibits epithelial cell invasion by group B streptococci. Microbial Pathogenesis. 2005;38:189-200

[41] Shigeoka AO, Hall RT, Hemming VG, Allred CD, Hill HR. Role of antibody and complement in opsonization of group B streptococci. Infection and Immunity. 1978;21(1):34-40

[42] Anderson DC, Hughes BJ, Edwards MS, Buffone GJ, Baker CJ.
Impaired chemotaxigenesis by type III group B streptococci in neonatal sera: Relationship to diminished concentration of specific anticapsular antibody and abnormalities of serum complement. Pediatric Research. 1983;17:496-502

[43] Edwards MS, Nicholson WA, Baker CJ, Casper DL. The role of specific antibody in alternative complement pathway-mediated opsonophagocytosis of type III, group B streptococcus. The Journal of Experimental Medicine. 1980;151:1275-1287

[44] Payne NR, Kim YK, Ferrieri P. Effect of differences in antibody and complement requirements on phagocytic uptake and intracellular killing of "c" protein-positive and -negative strains of type II group B streptococci. Infection and Immunity. 1987;55:1243-1251

[45] Harris TO, Shelver DW, Bohnsack JF, Rubens CE. A novel streptococcal surface protease promotes virulence, resistance to opsonophagocytosis, and cleavage of human fibrinogen. The Journal of Clinical Investigation. 2003;111:61-70

[46] Beckmann C, Waggoner JD, Harris TO, Tamura GS, Rubens CE. Identification of novel adhesins from group B streptococci by use of phage display reveals that C5a peptidase mediates fibronectin binding. Infection and Immunity. 2002;70:2869-2876

[47] Cheng Q, Stafslien D,

Purushothaman SS, Cleary P. The group

$\mathrm{B}$ streptococcal C5a peptidase is

both a specific protease and an invasin. Infection and Immunity. 2002;70(5):2408-2413

[48] Spellerberg B, Rodzinski E, Martin S, Weber Hynemann J, Schnitzler N, et al. Lmb, a protein with similarities to the LraI adhesin family, mediates attachment of Streptococcus agalactiae to human laminin. Infection and Immunity. 1999;67:871-878 
[49] Schubert A, Zakhikany K, Shreiner M, Frank R, Spellerberg B, Eikmann BJ, et al. A fibrinogen receptor from group B streptococcus interacts with fibrinogen by repetitive units with novel ligand binding sites. Molecular Microbiology. 2002;46:557-569

[50] Samen U, Eikmanns BJ, Reinscheid DJ, Borges F. The surface protein Srr-1 of Streptococcus agalactiae binds human keratin 4 and promotes adherence to epithelial HEp-2 cells. Infection and Immunity. 2007;75(11):5405-5414

[51] Rosini R, Rinaudo DC, Soriani M, Lauer P, Mora M, Maione D, et al. Identification of novel genomic islands coding for antigenic piluslike structures in Streptococcus agalactiae. Molecular Microbiology. 2006;61:126-141

[52] Maisey HC, Hensler M, Nizet V, Doran KS. Group B streptococcal pilus proteins contribute to adherence to and invasion of brain microvascular endothelial cells. Journal of Bacteriology. 2006;189(4):1464-1467

[53] Dramsi S et al. Assembly and role of pili in group B streptococci. Molecular Microbiology. 2006;60:1401-1413

[54] Krishnan V et al. An IgG-like domain in the minor pili GBS52 of Streptococcus agalactiae mediates lung epithelial cell adhesion. Structure. 2007;15:893-903

[55] Ozeri V, Rosenshine I, Ben-Ze'ev A, Bokoch GM, Jou T, Heinski E. De novo formation of focal complexes like structures in host cells by invading streptococci. Molecular Microbiology. 2001;41:561-573

[56] Tyrell GJ, Kennedy A, Shokoples SE, Sherburne RK. Binding and invasion of HeLa and MRC- 5 cells by Streptococcus agalactiae. Microbiology. 2002;148:3921-3931
[57] Boone TJ, Burnham CAD, Tyrrell GJ. Binding of group B streptococcal phosphoglycerate kinase to plasminogen and actin. Microbial Pathogenesis. 2011;51:255-261

[58] Alloush HM, Lopze-Ribot JL, Masetn BJ, Chaffin WL.

3-phosphoglycerate kinase: A glycolytic enzyme protein present in cell wall of Candida albicans. Microbiology. 1997;143:321-330

[59] Keung WL, Salaby KA, Thankur A, Medhat AM, Karim AM, Overde PT. Cloning of the gene for phosphoglyceratekinase from Schistosoma mansoni and characterization of its gene products. Molecular and Biochemical Parasitology. 1995;71:221-231

[60] Lee KW, Thakur A, Karim AM, Lo Verde PT. Immune response to Schistosoma mansoni phosphoglycerate kinase during natural and experimental infection: Identification of a schistosome specific B cell epitope. Infection and Immunity. 1995;63:4307-4311

[61] Valenti P, Antonini G. Lactoferrin: An important host defence against microbial and viral attack. Cellular and Molecular Life Sciences. 2005;62:1-12

[62] Hulse ML, Smith S, Chi EY, Pham A, Rubens CE. Effect of type III Group B streptococcal capsular polysaccharide on invasion of respiratory epithelial cells. Infection and Immunity. 1993;61:4835-4841

[63] Vogel CF, Matsumura F. A new cross-talk between the aryl hydrocarbon receptor and RelB, a member of the NF-kappaB family. Biochemical Pharmacology. 2009;77(4):734-745

[64] Baker CJ, Noya FJD. Potential use of intravenous immune globulin for group $B$ streptococcal infection. Reviews of Infectious Diseases. 1990;12:S476-S482 
Cell Surface and Cytosolic Proteins of Group B Streptococcus Adding New Dimensions... DOI: http://dx.doi.org/10.5772/intechopen.89102

[65] Zaleznik DF et al. Invasive disease

due to group B streptococcus in

pregnant women and neonates from

diverse population groups. Clinical

Infectious Diseases. 2000;30:276-281

[66] Weisner AM, Johnson AP,

Lamagni TL, Arnold E, Warner M,

Heath PT, et al. Characterization of group B streptococci recovered from infants with invasive disease in England and Wales. Clinical Infectious Diseases.

2004;38:1203-1208

[67] Baker CJ, Rench MA,

McInnes P. Immunization of pregnant women with group B streptococcal type III capsular polysaccharide-tetanus toxoid conjugate vaccine. Vaccine.

2003;21:3468-3472

[68] Mohle-Boetani JC et al. Comparison of prevention strategies for neonatal group B streptococcal infection: An economic analysis. JAMA. 1993;270:1442-1448

[69] Institute of Medicine (US) Committee to Study Priorities for Vaccine Development; In: Stratton KR, Durch JS, Lawrence RS, editors. Vaccines for the 21st Century: A Tool for Decisionmaking. Washington, DC, USA: National Academies Press; 2000. Appendix 25, Streptococcus, Group B

[70] Lin SM, Zhi Y, Ahn KB, Lim S, Seo HS. Status of group B streptococcal vaccine development. Clinical and Experimental Vaccine Research. 2018;7(1):76-81 

Section 2

Antimicrobial Resistance 



\title{
Chapter 5
}

\section{Nemonoxacin $\left(\right.$ Taigexyn $\left.^{\circledR}\right)$ : A New Non-Fluorinated Quinolone}

\author{
Li-Wen Chang, Ming-Chu Hsu and Ying-Yuan Zhang
}

\begin{abstract}
Nemonoxacin (Taigexyn ${ }^{\circledR}$ ), a novel C-8-methoxy non-fluorinated quinolone, has been approved for use in community-acquired pneumonia (CAP) in Taiwan (2014) and mainland China (2016). The FDA granted nemonoxacin 'qualified infectious disease product' and 'fast-track' designations for CAP and acute bacterial skin and skin structure infection in December 2013. It possesses a broad spectrum of bactericidal activity against typical and atypical respiratory pathogens. In particular, nemonoxacin has activity against resistant Gram-positive cocci, including penicillin-resistant Streptococcus pneumoniae and methicillinresistant Staphylococcus aureus. Oral nemonoxacin was compared with oral levofloxacin for efficacy and safety in three randomized, double-blinded, controlled Phase II-III clinical trials for the treatment of CAP. This article will review the microbiological profile of nemonoxacin against respiratory pathogens including S. pneumoniae and S. aureus, and microbiological outcome data from the three Phase II-III studies.
\end{abstract}

Keywords: community-acquired pneumonia, Gram-positive bacteria, levofloxacin, nemonoxacin, novel antimicrobial, resistant pathogens

\section{Introduction}

Lower respiratory tract infections (LRTIs), which include community-acquired pneumonia (CAP), are the fourth leading cause of death worldwide and the first leading cause of death in low-income countries, causing 3.0 million deaths worldwide in 2016 [1]. CAP is a common condition that causes a significant disease burden for the community, particularly in children younger than 5 years, the elderly and immunocompromised people [2].

Most studies about aetiology show that Streptococcus pneumoniae (S. pneumoniae) remains the most frequently isolated pathogen in CAP patients [3, 4]. The relative frequency of other typical pathogens include Haemophilus influenzae (H. influenzae), Moraxella catarrhalis (M. catarrhalis), and Klebsiella pneumoniae (K. pneumoniae) $[1,4,5]$, as well as atypical organisms include Mycoplasma pneumoniae (M. pneumoniae), Chlamydia pneumoniae (C. pneumoniae), and Legionella pneumophila (L. pneumophila) [6-10]. Recently, methicillin-resistant Staphylococcus aureus (MRSA) is becoming a major pathogen of CAP and causing a rapidly fatal pneumonia characterized as pulmonary haemorrhage and rapid progression to respiratory failure [11-13]. The increasing prevalence of antibiotic resistance in CAP caused by penicillin-intermediate $S$. pneumoniae (PISP) and penicillin-resistant S. pneumoniae (PRSP) are also of great concern [13]. 
All patients with CAP should initially be treated with empirical antibiotic(s) because specific pathogens are typically not identified at the time that antibiotic therapy is initiated. Several retrospective studies have shown that pathogens were not isolated or identified in more than $50 \%$ of patients exhibiting clinical signs and symptoms of pneumonia [14-17]. Furthermore, increasing incidence of antibiotic resistance (major in penicillin, cephalosporin, and macrolide resistance) observed in bacteria causing CAP has resulted in higher treatment failures and poorer medical outcomes for many patients with CAP [15]. A retrospective analysis indicated that the treatment failure of penicillin-based therapy was higher than that of fluoroquinolone-based therapy for CAP in an outpatient clinic basis [18]. The current recommendations for the management of community acquired pneumonia indicated that monotherapy with a respiratory fluoroquinolone as an appropriate empirical treatment for adult CAP inpatients and complicated CAP outpatients with risk factors, more severe disease, or recent use of antibiotics [19].

Nemonoxacin (NEMO), a novel C-8-methoxy non-fluorinated quinolone, exhibits the bactericidal action by inhibition of the topoisomerase II (DNA gyrase) and topoisomerase IV which are required for bacterial DNA replication, repair, transcription, and recombination. The mechanism of action for quinolones, including NEMO, is different from that of aminoglycosides, beta-lactams, macrolides or tetracyclines; therefore, microorganisms resistant to these classes of drugs may be susceptible to NEMO. Resistance to fluoroquinolones occurs majorly by a mutation in DNA gyrase and/or topoisomerase IV genes, altered drug permeation through efflux transporter [20]. Mutations in two quinolone resistance-determining regions (QRDR) of genes encoding DNA gyrase (gyrA and gyrB) and topoisomerase IV (parC and parE) cause resistance to fluoroquinolones [21, 22]. However, bacteria resistance to NEMO only occurred when three different mutations was found in their QRDR genes [23]. Thus, NEMO has a higher barrier for generating resistant pathogens compared to other fluoroquinolones. In vitro resistance to NEMO develops slowly and difficultly via multiple-step mutations [24, 25].

NEMO has shown broad spectrum activity both in vitro and in vivo against Gram-positive and Gram-negative bacteria [25-30], particularly multi-drug resistant Gram-positive bacteria such as PRSP and MRSA. NEMO also exhibits potent antibacterial activity against Gram-negative bacteria and atypical pathogens such as $H$. influenzae, M. catarrhalis, M. pneumoniae, C. pneumoniae, and L. pneumophila in vitro $[26,31]$. Oral NEMO $(500 \mathrm{mg})$ has been approved for treatment of adult CAP patients in Taiwan (2014) and mainland China (2016) [32, 33]. In December 2013, the U.S. Food and Drug Administration (FDA) granted NEMO with 'qualified infectious disease product (QIDP)' and 'fasttrack' designations for CAP and acute bacterial skin and skin structure infection [34]. NEMO (intravenous formulation) also submitted its new drug application (NDA) in May 2017, and granted priority review by the China FDA in February $2018[35,36]$.

An integrated analysis of one Phase III (registration number: NCT01529476) and two Phase II studies (registration numbers: NCT00434291 and NCT01537250) was conducted to compare the commercial dose of oral NEMO $500 \mathrm{mg}$ vs. oral levofloxacin (LEVO) $500 \mathrm{mg}$ for CAP treatment [37-39]. This article will review the integrated efficacy results of NEMO vs. LEVO against the common respiratory pathogens isolated from the three Phase II-III trials. LEVO was chosen as the comparator because it is commonly prescribed worldwide and it is recommended in guidelines for the treatment of CAP. 


\section{Materials and methods}

\subsection{Ethical approval}

One Phase III study was conducted between March 2011 and August 2012 at 53 centres in China and Taiwan [study number: TG-873870-C-4 (study C4)]; one Phase II study was conducted from August 2009 to August 2010 at 26 centres in China [study number: TG-873870-C-3 (study C3)]; the other Phase II study was conducted from December 2006 to September 2007 at 19 centres in the Republic of South Africa and Taiwan [study number: TG-873870-02 (study 02)]. Three studies were conducted in accordance with International Conference on Harmonization Guidelines, the Declaration of Helsinki, and the Good Clinical Practice. The protocols and sample informed consent form were approved by the Institutional Review Board of each participating study site. Written informed consent was provided by all patients or their legally authorized representatives prior to screening/study enrollment.

\subsection{Study design}

All three studies were designed as multicenter, randomized, double-blind, double-dummy, active comparator-controlled trials to assess the non-inferiority of NEMO vs. LEVO for the treatment of CAP in adult patients.

Eligible patients were randomized assigned in a 2:1 ratio to receive either NEMO $500 \mathrm{mg}$ or LEVO $500 \mathrm{mg}$ in the phase III trial, and in a 1:1:1 ratio to receive either NEMO $500 \mathrm{mg}$ or $750 \mathrm{mg}$, or LEVO $500 \mathrm{mg}$ in the two phase II trials. All drugs were orally administered once daily for 7-10 days. To be evaluable, the test-of-cure (TOC) assessments had to occur between 7 and 21 days after administration of the last dose of study medication. This article will review the integrated efficacy results of three Phase II-III trials comparing the commercial dose of NEMO $500 \mathrm{mg}$ vs. LEVO $500 \mathrm{mg}$ for CAP treatment.

\subsection{Eligibility criteria}

Adult subjects were eligible if they had a clinical diagnosis of CAP (defined as fever, elevated white blood cell count, cough, purulent sputum, dyspnoea or tachypnoea, chest pain, pulmonary consolidation, etc.), had a chest radiograph demonstrating new or persistent/progressive infiltrate, and suitable for outpatient therapy with an oral antimicrobial agent.

Patients were excluded if they had any of the following conditions: severe CAP (e.g. requiring invasive endotracheal ventilation or vasoconstrictor due to septic shock), other pneumonia infection (e.g. hospital-acquired pneumonia, viral pneumonia, aspiration pneumonia), history of lung diseases (e.g. active tuberculosis, bronchiectasis, cystic fibrosis, lung abscess, lung cancer, post-obstructive pneumonia), history of hypersensitivity or allergic reactions to any quinolone, history of cardiac diseases (e.g. QTc prolongation, clinically significant abnormality on a 12-lead electrocardiogram at screening), clinically significant renal, hepatic or mental disease, malabsorption syndrome, and received prohibited medications prior enrollment (e.g. other investigational drug, systemic antibacterial agent, chemotherapeutic agents or oncolytics).

Subjects could be withdrawn from the study at any time, for any reason, and without prejudice to further treatment. The criteria for enrollment were to be followed explicitly. If a patient who did not meet enrollment criteria was inadvertently enrolled, that patient was withdrawn from the study. An exception could 
have been granted in rare circumstances where there was a compelling safety or ethical reason to allow the patient to continue. In these rare cases, the Investigator was required to obtain documented approval from Sponsor to allow the subject to continue in the study.

\subsection{Efficacy assessment}

Clinical response at the TOC visit was the primary efficacy endpoint for the three CAP studies. Clinical response was defined as cure (complete resolution or improvement of all pneumonia-related signs and symptoms that existed during enrollment, with chest radiographs improved or not worse, no further antibiotic therapy required, and no new sign and symptoms occurred), failure (persistence or worsening of sign and symptoms of pneumonia, additional treatment with a non-study antibiotic for pneumonia, or progression of chest radiograph abnormalities) or unevaluable (lost to follow-up or withdrew consent which made it lost post-treatment information, failed to complete at least 3 days of treatment, or had an infection other than pneumonia judged by the investigator).

Microbiological response at the TOC visit was the secondary efficacy endpoint for the three CAP studies. Microbiological success was defined as eradication (the baseline pathogen was absent) and presumed eradication (if an adequate source specimen was not available to culture, but the patient was assessed as clinically cured). Microbiological failure was defined as persistence and presumed persistence of the baseline pathogen.

\subsection{Microbiological evaluations}

Baseline bacterial cultures were taken from the primary site of infection (e.g. sputum expectoration), together with 2 sets of blood cultures obtained within $24 \mathrm{~h}$ before patients received the 1 st dose of study drugs.

Sputum samples were collected by expectoration after deep coughing. Fresh specimens collected under the supervision of the investigator were immediately transported to a local laboratory for Gram stain. Cultures were only performed on specimens if the Gram stain revealed $<10$ squamous epithelial cells and $>25$ leukocytes per low-power field. All isolates identified at the local laboratory from such specimens were then sent to the central laboratory for re-identification and susceptibility testing using CLSI methodology. Only the central laboratory microbiology results were utilized in the database. The only exception was if a local laboratory specimen had become unavailable. MICs of NEMO and LEVO were determined for all isolates.

Serology tests for M. pneumoniae, C. pneumoniae, and L. pneumophila were performed at both baseline and TOC visits. Urine samples were also collected to identify L. pneumophila by antigen testing at the baseline visit.

\subsection{Statistics}

Non-inferiority (NI) of NEMO to LEVO was evaluated for clinical response by using 2 -sided $95 \%$ confidence interval (CI) for the true difference in clinical cure rate (NEMO minus LEVO), with clinical cure or failure determined at the TOC visit. NI was concluded if the lower limit of the 2 -sided $95 \%$ CI was not lower than $-10 \%$ for the phase III study (lower limit of $95 \% \mathrm{CI} \geq-10 \%$ ), and not lower than $-15 \%$ for the two phase II studies (lower limit of $95 \%$ CI $\geq-15 \%)$. 


\section{Integrated results}

\subsection{Clinical responses}

The clinical responses at the TOC visit for NEMO $500 \mathrm{mg}$ compared to LEVO $500 \mathrm{mg}$ are outlined in Table 1 . The integrated analysis of clinical cure rate for NEMO was $93.0 \%$ compared with $91.9 \%$ for LEVO.

All three studies met its clinical endpoint by confirming the non-inferiority of NEMO $500 \mathrm{mg}$ compared with LEVO $500 \mathrm{mg}$. In the primary population with evaluable assessment at TOC visit, the clinical cure rates for NEMO and LEVO were 94.3\% (300/318) and 93.5\% (143/153), respectively, in study C4; 93.3\% (56/60) and $88.5 \%(46 / 52)$, respectively, in study C3; and 87.0\% (67/77) and 91.1\% (72/79), respectively, in study 02 . The treatment differences $(95 \% \mathrm{CI})$ between $\mathrm{NEMO}$ and LEVO were $0.9 \%(-3.8 \%, 5.5 \%)$ in study C4, $4.9 \%(-5.9 \%, 15.6 \%)$ in study C3, and $-4.1 \%(-13.9 \%, 5.7 \%)$ in study 02 . Thus, in the three studies, NEMO was found to be non-inferior to LEVO because the lower limit of the $95 \% \mathrm{CI}$ of the treatment difference was $\geq-10 \%$ in the phase III study and $\geq-15 \%$ in both phase II studies. Non-inferiority of NEMO $500 \mathrm{mg}$ to LEVO $500 \mathrm{mg}$ was demonstrated.

\subsection{Microbiological response}

\subsubsection{Overall recovery rate}

The overall recovery rate of pathogens (typical and atypical combined) in all randomized patients was 57.0\% (504/989). This included pathogens identified in

\begin{tabular}{|c|c|c|c|c|}
\hline Population & Clinical response & $\begin{array}{c}\text { NEMO } \\
\text { n (\%) }\end{array}$ & $\begin{array}{l}\text { LEVO } \\
\text { n }(\%)\end{array}$ & $\begin{array}{l}\text { Differences \% } \\
(95 \% \mathrm{CI})\end{array}$ \\
\hline \multicolumn{5}{|l|}{ Integrated analysis } \\
\hline \multirow{3}{*}{$\begin{array}{l}\text { Integrated-primary } \\
\text { population }\end{array}$} & Cure $^{a}$ & $423(93.0 \%)$ & $261(91.9 \%)$ & \multirow[t]{3}{*}{-} \\
\hline & Failure & $32(7.0 \%)$ & $23(8.1 \%)$ & \\
\hline & Unevaluable & $22(-)$ & $18(-)$ & \\
\hline \multicolumn{5}{|l|}{ Phase III Study-C4 } \\
\hline \multirow[t]{3}{*}{ Primary population ${ }^{\mathrm{b}}$} & Cure $^{\mathrm{a}}$ & $300(94.3 \%)$ & $143(93.5 \%)$ & \multirow[t]{3}{*}{$0.9(-3.8,5.5)$} \\
\hline & Failure & $18(5.7 \%)$ & $10(6.5 \%)$ & \\
\hline & Unevaluable & $10(-)$ & $7(-)$ & \\
\hline \multicolumn{5}{|l|}{ Phase II Study-C3 } \\
\hline \multirow[t]{3}{*}{ Primary population ${ }^{\mathrm{b}}$} & Cure $^{\mathrm{a}}$ & $56(93.3 \%)$ & $46(88.5 \%)$ & \multirow[t]{3}{*}{$4.9(-5.9,15.6)$} \\
\hline & Failure & $4(6.7 \%)$ & $6(11.5 \%)$ & \\
\hline & Unevaluable & $0(-)$ & $0(-)$ & \\
\hline \multicolumn{5}{|l|}{ Phase II Study-02 } \\
\hline \multirow[t]{3}{*}{ Primary population ${ }^{\mathrm{b}}$} & Cure $^{\mathrm{a}}$ & $67(87.0 \%)$ & $72(91.1 \%)$ & \multirow[t]{3}{*}{$-4.1(-13.9,5.7)$} \\
\hline & Failure & $10(13.0 \%)$ & $7(8.9 \%)$ & \\
\hline & Unevaluable & $12(-)$ & $11(-)$ & \\
\hline \multicolumn{5}{|c|}{$\begin{array}{l}{ }^{a} \text { Clinical cure rate }=100 \times \text { number of patients with clinical cure/(number of patients with clinical cure }+ \text { number of } \\
\text { patients with clinical failure). Unevaluable response was excluded. } \\
{ }^{b} \text { Primary populations were modified intention-to-treat (mITT), full analysis set (FAS), and intention-to-treat (ITT) } \\
\text { for TG-873870-C4, TG-873870-C3, and TG-873870-02 studies, respectively [35-37]. }\end{array}$} \\
\hline
\end{tabular}

Table 1.

Clinical response at TOC in primary population. 


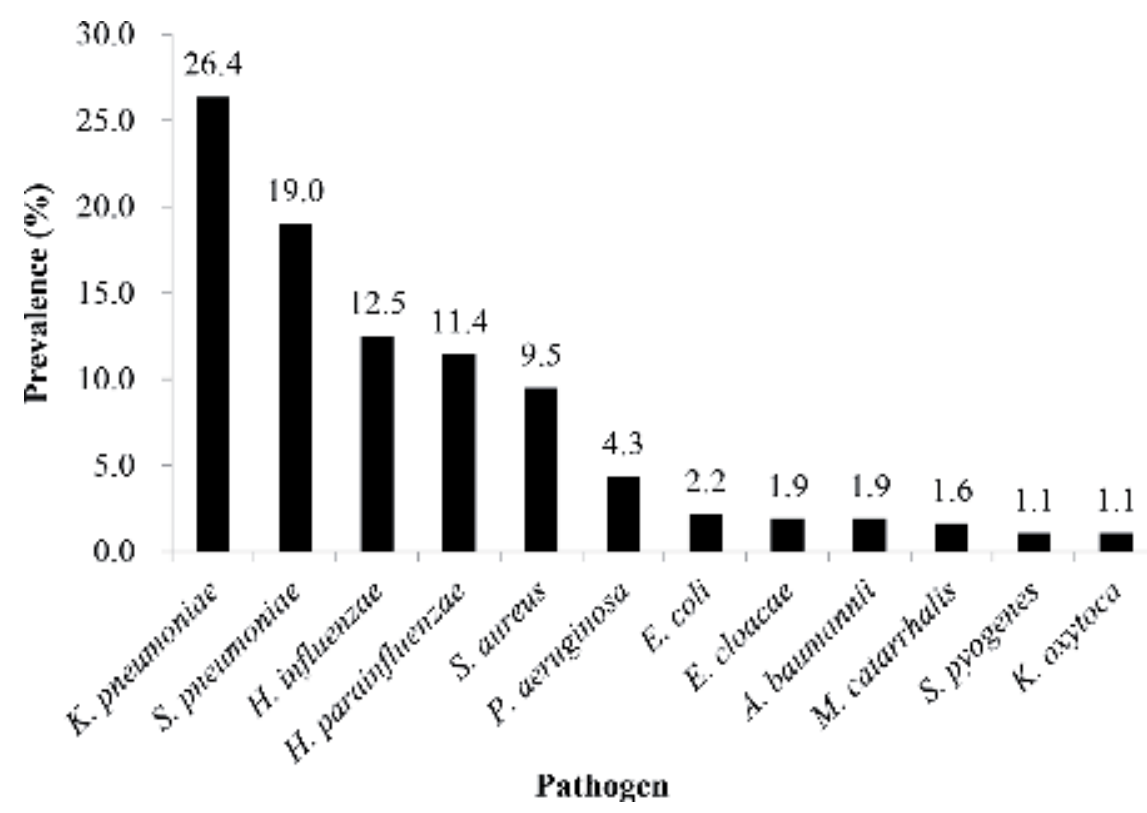

Figure 1.

Identification and prevalence of baseline pathogens in three CAP studies.

appropriate sputum specimen, blood, or other test such as urinary antigen test and atypical pathogen serology testing. The recovery rate for typical pathogens was $29.3 \%$ (290/989). These results were consistent with those observed in other CAP studies [38-42]. The most commonly identified pathogens in all randomized patients were $K$. pneumoniae, S. pneumoniae, Haemophilus species, and S. aureus (Figure 1).

\subsubsection{Microbiological responses to individual pathogens}

The per-pathogen responses of NEMO $500 \mathrm{mg}$ and LEVO $500 \mathrm{mg}$ for the most prevalent pathogens are outlined in Table 2. High clinical and microbiological response rates were achieved against the common CAP pathogens, with similar success rates between the two treatment groups.

The microbiological responses were evaluated in the primary populations who had at least one typical bacterial pathogen identified at baseline from an appropriate specimen. Microbiological eradication and presumed eradication were considered to be success responses. The microbiological success rates for the common baseline CAP pathogens (NEMO vs. LEVO) were $95.6 \%(22 / 23)$ vs. $90.0 \%(18 / 20)$ for S. pneumoniae, $95.2 \%(20 / 21)$ vs. $88.9 \%$ (8/9) for S. aureus, $92.9 \%(39 / 42)$ vs. $86.1 \%$ (31/36) for K. pneumoniae, and $90.7 \%$ (39/43) vs. $91.3 \%$ (21/23) for Haemophilus species.

Among the S. pneumoniae isolates, four were penicillin non-susceptible (PRSP and PISP), with three isolates identified in the NEMO group and one isolate in the LEVO group. The microbiological responses for penicillin non-susceptible $S$. pneumoniae were all success for both groups.

As expected in CAP, the isolation of MRSA was rare, with only 4 isolates identified in the NEMO group. Three out of four patients infected with MRSA had successful responses after receiving NEMO.

Overall, the clinical and microbiological responses for the most commonly identified pathogens were almost concordant. High clinical cure rates were achieved 
Nemonoxacin $\left(\right.$ Taigexyn $\left.^{\circledR}\right)$ : A New Non-Fluorinated Quinolone

DOI: $h$ ttp://dx.doi.org/10.5772/intechopen.88455

\begin{tabular}{|c|c|c|c|c|}
\hline \multirow[t]{2}{*}{ Baseline pathogen } & \multicolumn{2}{|c|}{ Clinical cure rate $^{a}$} & \multicolumn{2}{|c|}{ Microbiological success rate ${ }^{b}$} \\
\hline & $\begin{array}{c}\text { NEMO } \\
\text { n1/n2 (\%) }\end{array}$ & $\begin{array}{c}\text { LEVO } \\
\text { n1/n2(\%) }\end{array}$ & $\begin{array}{c}\text { NEMO } \\
\text { n1/n2 (\%) }\end{array}$ & $\begin{array}{c}\text { LEVO } \\
\text { n1/n2(\%) }\end{array}$ \\
\hline \multicolumn{5}{|l|}{ Gram-positive bacteria } \\
\hline Streptococcus pneumoniae & $22 / 24(91.7 \%)$ & $19 / 20(95.0 \%)$ & $22 / 23(95.6 \%)$ & $18 / 20(90.0 \%)$ \\
\hline PRSP & $1(100.0 \%)$ & $1(100.0 \%)$ & $1(100.0 \%)$ & $1(100.0 \%)$ \\
\hline PISP & $2(100.0 \%)$ & - & $2(100.0 \%)$ & - \\
\hline Staphylococcus aureus & $20 / 21(95.2 \%)$ & $8 / 9(88.9 \%)$ & $20 / 21(95.2 \%)$ & $8 / 9(88.9 \%)$ \\
\hline MRSA & $3 / 4(75.0 \%)$ & - & $3 / 4(75.0 \%)$ & - \\
\hline \multicolumn{5}{|l|}{ Gram-negative bacteria } \\
\hline Klebsiella pneumoniae & $40 / 42(95.2 \%)$ & $32 / 36(88.9 \%)$ & $39 / 42(92.9 \%)$ & $31 / 36(86.1 \%)$ \\
\hline Haemophilus species & $39 / 43(90.7 \%)$ & $21 / 23(91.3 \%)$ & $39 / 43(90.7 \%)$ & $21 / 23(91.3 \%)$ \\
\hline Escherichia coli & $5 / 5(100.0 \%)$ & 1/1 (100.0\%) & $5 / 5(100.0 \%)$ & $1 / 1(100.0 \%)$ \\
\hline Moraxella catarrhalis & $2 / 2(100.0 \%)$ & $3 / 3(100.0 \%)$ & $2 / 2(100.0 \%)$ & $3 / 3(100.0 \%)$ \\
\hline Pseudomonas aeruginosa & $6 / 7(85.7 \%)$ & $5 / 5(100.0 \%)$ & $6 / 7(85.7 \%)$ & $4 / 5(80.0 \%)$ \\
\hline Acinetobacter baumannii & $5 / 5(100.0 \%)$ & $1 / 1(100.0 \%)$ & $5 / 5(100.0 \%)$ & 1/1 (100.0\%) \\
\hline \multicolumn{5}{|l|}{ Atypical pathogens } \\
\hline Mycoplasma pneumoniae & $90 / 97(92.8 \%)$ & $63 / 66(95.5 \%)$ & - & - \\
\hline Chlamydia pneumoniae & $22 / 23(95.7 \%)$ & $16 / 16(100.0 \%)$ & - & - \\
\hline Legionella pneumophila & 19/21 (90.5\%) & $8 / 8(100.0 \%)$ & - & - \\
\hline \multicolumn{5}{|c|}{$\begin{array}{l}{ }^{a} \text { Clinical cure rate }=100 \times \text { number of patients with clinical cure } /(\text { number of patients with clinical cure }+ \text { number of } \\
\text { patients with clinical failure). Unevaluable response was excluded. } \\
b \text { Microbiological success rate }=100 \times \text { number of patients with success response/(number of patients with success } \\
\text { response }+ \text { number of patients with failure response). Unevaluable response was excluded. }\end{array}$} \\
\hline
\end{tabular}

Table 2.

Per-pathogen clinical and microbiological response at TOC in the integrated-primary population.

against not only typical bacteria but also atypical pathogens after NEMO treatment, with 92.8\% (90/97), 95.7\% (22/23), and 90.5\% (19/21) for M. pneumoniae, C. pneumoniae, and L. pneumophila, respectively.

\subsubsection{Antimicrobial susceptibility}

The susceptibility of baseline pathogens isolated from the three CAP studies are outlined in Table 3. All isolates of S. pneumoniae, including PRSP and LEVOresistant strains, were inhibited by NEMO at concentrations of $\leq 1 \mathrm{mg} / \mathrm{L}$. The $\mathrm{MIC}_{90}$ for $S$. pneumoniae were $0.125 \mathrm{mg} / \mathrm{L}$ for NEMO and $1 \mathrm{mg} / \mathrm{L}$ for LEVO.

NEMO was active against $S$. aureus, with $\mathrm{MIC}_{90}$ of $0.25 \mathrm{mg} / \mathrm{L}$ compared with an $\mathrm{MIC}_{90}$ of $2 \mathrm{mg} / \mathrm{L}$ for LEVO. Among the $S$. aureus, 5 isolates were MRSA, with MIC ranges of $0.03-1 \mathrm{mg} / \mathrm{L}$ for NEMO and $0.12-32 \mathrm{mg} / \mathrm{L}$ for LEVO. All isolates of $S$. aureus, including MRSA, were inhibited by NEMO at concentrations of $\leq 1 \mathrm{mg} / \mathrm{L}$.

The in vitro activity of NEMO was comparable to that of LEVO against Gramnegative bacteria. But for Gram-positive bacteria including MRSA, the $\mathrm{MIC}_{\mathrm{s}}$ of NEMO were 8-fold lower than that of LEVO, supporting its utility in the treatment of patients with CAP. 


\begin{tabular}{|c|c|c|c|c|c|c|}
\hline \multirow{2}{*}{$\begin{array}{l}\text { Baseline pathogen } \\
\text { (number of isolates) }\end{array}$} & \multicolumn{3}{|c|}{$\operatorname{NEMO}(\mathrm{mg} / \mathrm{L})$} & \multicolumn{3}{|c|}{ LEVO (mg/L) } \\
\hline & $\mathrm{MIC}_{50}$ & $\mathrm{MIC}_{90}$ & Range & $\mathrm{MIC}_{50}$ & $\mathrm{MIC}_{90}$ & Range \\
\hline \multicolumn{7}{|l|}{ Gram-positive bacteria } \\
\hline S. pneumoniae (70) & 0.12 & 0.12 & $\leq 0.015-1$ & 1 & 1 & $0.03-8$ \\
\hline PRSP (2) & - & - & $0.12-1$ & & - & 1 \\
\hline LEVO-resistant (1) & - & - & 0.5 & - & - & 8 \\
\hline S. aureus (35) & 0.03 & 0.25 & $\leq 0.015-1$ & 0.25 & 2 & $0.12-32$ \\
\hline MRSA (5) & 0.25 & - & $0.03-1$ & 2 & - & $0.12-32$ \\
\hline \multicolumn{7}{|l|}{ Gram-negative bacteria } \\
\hline K. pneumoniae (97) & 0.25 & 8 & $\leq 0.06->32$ & 0.06 & 4 & $\leq 0.03->32$ \\
\hline H. influenzae (46) & 0.03 & 0.12 & $\leq 0.008-1$ & 0.015 & 0.06 & $\leq 0.008-1$ \\
\hline H. parainfluenzae (42) & 0.12 & 2 & $\leq 0.008-4$ & 0.06 & 1 & $\leq 0.008-8$ \\
\hline E. coli (8) & 1 & - & $\leq 0.06->32$ & 0.5 & - & $\leq 0.03-32$ \\
\hline M. catarrhalis (6) & 0.06 & - & $0.015-0.06$ & 0.06 & - & $\leq 0.008-0.06$ \\
\hline P. aeruginosa (16) & 1 & 8 & $0.25-16$ & 0.5 & 16 & $0.12->32$ \\
\hline A. baumannii (7) & 0.25 & - & $0.12-1$ & 0.12 & - & $\leq 0.06-1$ \\
\hline
\end{tabular}

Table 3.

In vitro activity of NEMO and LEVO against baseline isolates from patients enrolled in the three CAP studies.

\section{Conclusion}

Efficacy data reported herein from the individual and integrated analyses of the three CAP trials demonstrate that oral NEMO $500 \mathrm{mg}$ administered once daily for 7-10 days is an efficacious treatment for adult CAP. Non-inferiority of NEMO $500 \mathrm{mg}$ to LEVO $500 \mathrm{mg}$, a widely used agent in the clinical setting, was demonstrated in the three CAP studies. NEMO was effective in eradicating the typical pathogens associated with CAP, including high cure rates for atypical pathogens. Furthermore, the in vitro activity of NEMO against bacterial pathogens isolated from patients enrolled in the CAP clinical trials demonstrated a susceptibility profile that supports its utility in the treatment of patients with CAP.

\section{Acknowledgements}

We thank the following investigator groups of TG-873870-C-4, TG-873870-C-3, and TG-873870-02 studies for their valuable involvement: Biwen Mo (Affiliated Hospital of Guilin Medical University, Guangxi, China), Zhuang Ma and Ping Chen (The General Hospital of Shenyang Military Area Command, Liaoning, China), Yuan Lv (Peking University First Hospital, Beijing, China), Shihlung Cheng (Far Eastern Memorial Hospital, New Taipei City, Taiwan), Yanping Yang (Central Hospital of Jinan, Jinan, China), Zhaohui Tong (Beijing Chao-Yang Hospital, Capital Medical University, Beijing, China), Renguang Wu (Cheng-Ching General Hospital, Taichung, Taiwan), Shenghua Sun (The Third Xiangya Hospital, Central South University, Hunan, China), Zhaolong Cao (Peking University People’s Hospital, Beijing, China), Li Zhao (Shengjing Hospital, China Medical University, Liaoning, China), Xiongbiao Wang (Putuo Hospital Affiliated to Shanghai 
University of Traditional Chinese Medicine, Shanghai, China), Xuefen Wang (The First Affiliated Hospital, Zhejiang University, Zhejiang, China), Dexi Wang (Guangzhou Red Cross Hospital, Guangdong, China), Xiangyang Li (Huadong Hospital, Fudan University, Shanghai, China), Yiqiang Peng (Central Hospital of Changsha, Hunan, China), Yongjie Liang (East Hospital, Tongji University, Shanghai, China), Hua Liu (Gansu Provincial People's Hospital, Lanzhou, China), Zuke Xiao (Jiangxi Provincial People's Hospital, Jiangxi, China), Xiaoju Lv (West China Hospital, Sichuan University, Chengdu, China), Shiman Wu (The First Affiliated Hospital, Shanxi Medical University, Shanxi, China), Yuanrong Dai (The Second Affiliated Hospital, Wenzhou Medical University, Zhejiang, China), Yijiang Huang (Hainan Provincial People's Hospital, Hainan, China), Zhenghong $\mathrm{Hu}$ (Wuhan General Hospital of Guangzhou Command, Wuhan, China), Chen Qiu (People's Hospital of Shenzhen, Guangdong, China), Xi Li (Affiliated Hospital of Hainan Medical University, Hainan, China), Suiyang Zhang (The Second Artillery General Hospital, Beijing, China), Wenpu Li (Hunan Provincial People's Hospital, Hunan, China), Shuang Liu (Beijing Anzhen Hospital, Capital Medical University, Beijing, China), Yi Shi (Nanjing General Hospital, Nanjing, China), Chang Xiong (Taihe Hospital, Hubei University of Medicine, Shiyan, Hubei, China), Jiulong Kuang (The Second Affiliated Hospital, Nanchang University, Jiangxi, China), Qingyu Xiu (Changzheng Hospital, Shanghai, China), Shehuai Cui (Daping Hospital, the Third Military Medical University, Chongqing, China), Jianguo Li (The Second Affiliated Hospital, Zhongshan University, Guangdong, China), Qichang Lin (The First Affiliated Hospital, Fujian medical University, Fujian, China), Wenxiang Huang (The First Affiliated Hospital of Chongqing Medical University, Chongqing, China), Yixin Wan (The Second Affiliated Hospital, Lanzhou University, Lanzhou, China), Qimanguli (The First Affiliated Hospital, Xinjiang Medical University, Xinjiang, China), Ce Shen (Shanghai Jiao Tong University Affiliated Sixth People's Hospital, Shanghai, China), Yi Xiao (Peking Union Medical College Hospital, Beijing, China), Xiaoju Wu (People's Hospital of Wuhan University, Wuhan, China), Yin-Ching Chuang, (Chi Mei Medical Center, Tainan, Taiwan), Wann-Cherng Perng (Tri-Service General Hospital, Taipei, Taiwan), Shih-Ming Tsao (Chung Shan Medical University Hospital, Taichung, Taiwan), Jeng-Yuan Hsu and Kai-Ming Chang (Taichung Veterans General Hospital, Taichung, Taiwan), Chin-Chou Wang (Kaohsiung Chang Gung Memorial Hospital, Kaohsiung, Taiwan), Jen-Hsien Wang (China Medical University Hospital, Taipei, Taiwan), Pen-Fang Yeh (Cheng Hsin General Hospital, Taipei, Taiwan), His-Hsun Lin (E-Da Hospital, Kaohsiung City, Taiwan), PH Kuo (National Taiwan University Hospital, Taipei, Taiwan), Ming-Shian Lin (Ditmanson Medical Foundation Chia-Yi Christian Hospital, Chiayi, Taiwan), WeiJuin Su and Reury-Perng Perng (Taipei Veterans General Hospital, Taipei, Taiwan), Zhenyi Ren (Hangzhou First People's Hospital, Zhejiang, China), Changzheng Wang (Xinqiao Hospital, The Third Military Medical University, Chongqing, China), Heping Yang (Southwest Hospital, The Third Military Medical University, Chongqing, China), Chengping Hu (Xiangya Hospital, Central South University, Hunan, China), Dirkie J.J. van Rensburg (Park Medical Center, Witbank, Mpumalanga, South Africa), Ismail H. Mitha (Benmed/Pentagon Hospital, Benoni, South Africa), Andrè J. Bester (Jubilee Hospital, Temba, South Africa), Joseph Kasumba (Josha Research, Bloemfontien, South Africa), Ming-Lin Ho (Changhua Christian Hospital, Changhua, Taiwan), Christiaan De Villiers (De Villiers Clinical Trials, South Africa), M. Fulat (Eastmed Medical Centre, South Africa), Mashra Gani (Mercantile Hospital, South Africa), J.C.J. Jurgens (DJW Navorsing, South Africa), Horng-Chyuan Lin (Chang Gung Memorial Hospital, Linko, Taiwan), Grant Nieuwoudt (Langeberg Medical Centre, South Africa) and C. van Rensburg (South Africa). 
We also thank all study participants for their cooperation and the laboratory technicians for their assistance in performing the antimicrobial susceptibility tests.

TG-873870-C-4 study was supported by the Major Research and Development Project of Innovative Drugs under the auspices of the Ministry of Science and Technology in Beijing, China (Nos. 2008ZX09312-010 and 2012ZX09303004-001).

TG-873870-02 study was partially supported by a MOEA grant from the Government of Taiwan.

\section{Conflict of interest}

Li-Wen Chang and Ming-Chu Hsu are employees of TaiGen Biotechnology Co., Ltd.

\section{Author details}

Li-Wen Chang ${ }^{1}$, Ming-Chu $\mathrm{Hsu}^{1}$ and Ying-Yuan Zhang ${ }^{2,3 *}$

1 TaiGen Biotechnology Co., Ltd., Taipei, Taiwan

2 Institute of Antibiotics, Huashan Hospital, Fudan University, Shanghai, China

3 China Key Laboratory of Clinical Pharmacology of Antibiotics, Ministry of Health, Shanghai, China

*Address all correspondence to: yyzhang39@hotmail.com

\section{IntechOpen}

(C) 2019 The Author(s). Licensee IntechOpen. This chapter is distributed under the terms of the Creative Commons Attribution License (http://creativecommons.org/licenses/ by/3.0), which permits unrestricted use, distribution, and reproduction in any medium, provided the original work is properly cited. (cc) BY 


\section{References}

[1] The top 10 causes of death: World Health Organization [Internet]. Available from: https://www.who.int/news-room/ fact-sheets/detail/the-top-10-causes-ofdeath [Accessed: 24 May 2018]

[2] Pakhale S, Mulpuru S, Verheij TJ, Kochen MM, Rohde GG, Bjerre LM. Antibiotics for communityacquired pneumonia in adult outpatients. Cochrane Database of Systematic Reviews. 2014;30(11):2927-2932. DOI: $10.1007 / \mathrm{s} 11274-014-1720-2$

[3] Drijkoningen JJ, Rohde GG. Pneumococcal infection in adults: Burden of disease. Clinical Microbiology and Infection. 2014;20(Suppl 5):45-51. DOI: 10.1111/1469-0691.12461

[4] Welte T, Torres A, Nathwani D. Clinical and economic burden of communityacquired pneumonia among adults in Europe. Thorax. 2012;67(1):71-79. DOI: 10.1136/thx.2009.129502

[5] Ariza-Prota MA, Pando-Sandoval A, García-Clemente M, Fole-Vázquez D, Casan P. Community-acquired Moraxella catarrhalis bacteremic pneumonia: Two case reports and review of the literature. Case Reports in Pulmonology. 2016;2016:5134969. DOI: $10.1155 / 2016 / 5134969$

[6] Al-Aydie SN, Obeidat NM, Al-Younes HM. Role of Chlamydia pneumoniae in community-acquired pneumonia in hospitalized Jordanian adults. Journal of Infection in Developing Countries. 2016;10(3): 227-236. DOI: $10.3855 /$ jidc.6590

[7] Dumke R, Schnee C, Pletz MW, Rupp J, Jacobs E, Sachse K, et al. Capnetz Study Group.Mycoplasma pneumoniae and Chlamydia spp. infection in community-acquired pneumonia, Germany. Emerging Infectious Diseases. 2015;21(3):426-434. DOI: 10.3201/eid2103.140927
[8] Arancibia F, Cortes CP, Valdés M, Cerda J, Hernández A, Soto L, et al. Importance of Legionella pneumophila in the etiology of severe communityacquired pneumonia in Santiago, Chile. Chest. 2014;145(2):290-296. DOI: 10.1378/chest.13-0162

[9] von Baum H, Welte T, Marre R, Suttorp N, Lück C, Mint ES. Mycoplasma pneumoniae pneumonia revisited within the German Competence Network for Communityacquired pneumonia (CAPNETZ). BMC Infectious Diseases. 2009;9:62. DOI: $10.1186 / 1471-2334-9-62$

[10] von Baum H, Ewig S, Marre R, Suttorp N, Gonschior S, Welte T, et al. Community-acquired Legionella pneumonia: New insights from the German competence network for community acquired pneumonia. Clinical Infectious Diseases. 2008;46(9):13561364. DOI: $10.1086 / 586741$

[11] Quan TP, Fawcett NJ, Wrightson JM, Finney J, Wyllie D, Jeffery K, et al. Increasing burden of communityacquired pneumonia leading to hospitalisation, 1998-2014. Thorax. Infections in Oxfordshire Research Database (IORD). 2016;71(6):535-542. DOI: 10.1136/thoraxjnl-2015-207688

[12] Mandell LA, Wunderink RG, Anzueto A, Bartlett JG, Campbell GD, Dean NC, et al. Infectious Diseases Society of America; American Thoracic Society. Infectious diseases society of America/American thoracic society consensus guidelines on the management of community-acquired pneumonia in adults. Clinical Infectious Diseases. 2007; 44(Suppl 2):S27-S72

[13] Ho PL, Cheng VC, $\mathrm{Chu}$ CM. Antibiotic resistance in community-acquired pneumonia caused by Streptococcus pneumoniae, 
methicillin-resistant Staphylococcus aureus, and Acinetobacter baumannii. Chest. 2009;136(4):1119-1127. DOI: 10.1378/chest.09-0285

[14] Kaysin A, Mint VAJ. Communityacquired pneumonia in adults:

Diagnosis and management. American Family Physician. 2016;94(9):698-706

[15] Tanaseanu C, Bergallo C, Teglia O, Jasovich A, Oliva ME, Dukart G, et al. 308 Study Group; 313 Study Group. Integrated results of 2 phase 3 studies comparing tigecycline and levofloxacin in community-acquired pneumonia. Diagnostic Microbiology and Infectious Disease. 2008;61(3):329-338. DOI: 10.1016/j.diagmicrobio.2008.04.009

[16] Peto L, Nadjm B, Horby P, Ngan TT, van Doorn R, Van Kinh N, et al. The bacterial aetiology of adult communityacquired pneumonia in Asia: A systematic review. Transactions of the Royal Society of Tropical Medicine and Hygiene. 2014;108(6):326-337. DOI: 10.1093/trstmh/tru058

[17] Woodhead M, Blasi F, Ewig S, Garau J, Huchon G, Ieven M, et al. Joint Taskforce of the European Respiratory ociety and European Society for Clinical Microbiology and Infectious Diseases. Guidelines for the management of adult lower respiratory tract infections. Clinical Microbiology and Infection. 2011;17(Suppl 6):E1-E59. DOI: 10.1111/j.1469-0691.2011.03672.x

[18] Wang CC, Lin CH, Lin KY, Chuang YC, Sheng WH. Comparative outcome analysis of penicillin-based versus fluoroquinolone-based antibiotic therapy for community-acquired pneumonia: A nationwide populationbased cohort study. Medicine (Baltimore). 2016;95(6):e2763. DOI: 10.1097/MD.0000000000002763

[19] Corrêa RA, Costa AN, Lundgren F, Michelin L, Figueiredo MR, Holanda M, et al. 2018 recommendations for the management of community acquired pneumonia. Jornal Brasileiro de Pneumologia. 2018;44(5):405-423. DOI: 10.1590/S1806-37562018000000130

[20] Bearden DT, Danziger LH. Mechanism of action of and resistance to quinolones. Pharmacotherapy. 2001;21(10 Pt 2):224S-232S

[21] Pan XS, Ambler J, Mehtar S, Fisher LM. Involvement of topoisomerase IV and DNA gyrase as ciprofloxacin targets in Streptococcus pneumoniae. Antimicrobial Agents and Chemotherapy. 1996;40(10):2321-2326

[22] Minarini LA, Darini AL. Mutations in the quinolone resistance-determining regions of gyrA and parC in Enterobacteriaceae isolates from Brazil. Brazilian Journal of Microbiology. 2012;43(4):1309-1314. DOI: $10.1590 /$ S1517-838220120004000010

[23] Qin X, Huang H. Review of nemonoxacin with special focus on clinical development. Drug Design, Development and Therapy. 2014;8: 765-774. DOI: 10.2147/DDDT.S63581. eCollection 2014

[24] Roychoudhury S, Makin K, Twinem T, Leunk R, Hsu MC. In vitro resistance development to nemonoxacin in Streptococcus pneumoniae: A unique profile for a novel nonfluorinated quinolone. Microbial Drug Resistance. 2016;22(7):578-584

[25] Chen YH, Liu CY, Ko WC, Liao CH, Lu PL, Huang CH, et al. Trends in the susceptibility of methicillinresistant Staphylococcus aureus to nine antimicrobial agents, including ceftobiprole, nemonoxacin, and tyrothricin: Results from the Tigecycline in vitro Surveillance in Taiwan (TIST) study, 2006-2010. European Journal of Clinical Microbiology \& Infectious Diseases. 2014;33(2):233-239. DOI: 10.1007/s10096-013-1949-y 
[26] Chotikanatis K, Kohlhoff SA, Hammerschlag MR. In vitro activity of nemonoxacin, a novel nonfluorinated quinolone antibiotic, against

Chlamydia trachomatis and Chlamydia pneumoniae. Antimicrobial Agents and Chemotherapy. 2014;58(3):1800-1801. DOI: 10.1128/AAC.02263-13

[27] Li CR, Li Y, Li GQ, Yang XY, Zhang WX, Lou RH, et al. In vivo antibacterial activity of nemonoxacin, a novel non-fluorinated quinolone. The Journal of Antimicrobial Chemotherapy. 2010;65(11):2411-2415. DOI: 10.1093/ jac/dkq341

[28] Lauderdale TL, Shiau YR, Lai JF, Chen HC, King CH. Comparative in vitro activities of nemonoxacin (TG873870), a novel nonfluorinated quinolone, and other quinolones against clinical isolates. Antimicrobial Agents and Chemotherapy. 2010;54(3): 1338-1342. DOI: 10.1128/AAC.01197-09

[29] Chen YH, Liu CY, Lu JJ, King $\mathrm{CH}$, Hsueh PR. In vitro activity of nemonoxacin (TG-873870), a novel non-fluorinated quinolone, against clinical isolates of Staphylococcus aureus, enterococci and Streptococcus pneumoniae with various resistance phenotypes in Taiwant. The Journal of Antimicrobial Chemotherapy. 2009;64(6):1226-1229. DOI: 10.1093/ jac/dkp370

[30] Adam HJ, Laing NM, King CR, Lulashnyk B, Hoban DJ, Zhanel GG. In vitro activity of nemonoxacin, a novel nonfluorinated quinolone, against 2,440 clinical isolates. Antimicrobial Agents and Chemotherapy. 2009;53(11):4915-4920. DOI: $10.1128 /$ AAC.00078-09

[31] Zhu DM, Wu PC, Hu FP, Wu S, Ye XY, Zhang YY. Activities of nemonoxacin against clinical isolates from Shanghai, China. Chinese Journal of Infection and Chemotherapy. 2015;15:97-112
[32] TaiGen Biotechnology Co Ltd. TaiGen Biotechnology receives marketing approval from the Taiwan Food and Drug Administration for Taigexyn ${ }^{\circledR}$ (nemonoxacin) in Taiwan [media release]. Available from: https:// www.taigenbiotech.com.tw/ [Accessed: 13 March 2014]

[33] TaiGen Biotechnology Co Ltd. TaiGen Biotechnology receives market approval from the China Food and Drug Administration for Taigexyn (nemonoxacin) [media release]. Available from: https://www.taigenbiotech.com.tw/ [Accessed: 13 June 2016]

[34] TaiGen Biotechnology Co Ltd. TaiGen Biotechnology receives qualified infectious disease product and fast track designations from the U.S. Food and Drug Administration for nemonoxacin (Taigexyn $(\mathrm{Rm})$ ) [media release]. Available from: https://www. taigenbiotech.com.tw/ [Accessed: 23 December 2013]

[35] TaiGen Biotechnology Co Ltd. TaiGen Biotechnology announces submission of new drug application for nemonoxacin intravenous formulation in to the China Food and Drug Administration [media release]. Availabe from: https://www. taigenbiotech.com.tw/ [Accessed: 30 May 2017]

[36] TaiGen Biotechnology Co Ltd. TaiGen Biotechnology announces that nemonoxacin (intravenous formulation) was granted priority review by the China Food and Drug Administration [media release]. Available from: https:// www.taigenbiotech.com.tw/ [Accessed: 05 February 2018]

[37] Yuan J, Mo B, Ma Z, Lv Y, Cheng SL, Yang Y, et al. Safety and efficacy of oral nemonoxacin versus levofloxacin in treatment of community-acquired pneumonia: A phase 3, multicenter, randomized, double-blind, double-dummy, 
active-controlled, non-inferiority

trial. Journal of Microbiology,

Immunology, and Infection 2017; pii:

S1684-1182(17)30151-2. DOI: 10.1016/j. jmii.2017.07.011

[38] Liu Y, Zhang Y, Wu J, Zhu D, Sun S, Zhao L, et al. A randomized, double-blind, multicenter phase II study comparing the efficacy and safety of oral nemonoxacin with oral levofloxacin in the treatment of community-acquired pneumonia. Journal of Microbiology, Immunology, and Infection. 2017;50(6):

811-820. DOI: 10.1016/j.jmii.2015.09.005

[39] van Rensburg DJ, Perng RP, Mitha IH, Bester AJ, Kasumba J, Wu RG, et al. Efficacy and safety of nemonoxacin versus levofloxacin for community-acquired pneumonia. Antimicrobial Agents and Chemotherapy. 2010;54(10):4098-4106. DOI: 10.1128/AAC.00295-10

[40] File TM Jr, Low DE, Eckburg PB, Talbot GH, Friedland HD, Lee J, et al. Integrated analysis of FOCUS 1 and FOCUS 2: Randomized, doubledblinded, multicenter phase 3 studies of the efficacy and safety of ceftaroline fosamil versus ceftriaxone in patients with community-acquired pneumonia. Clinical Infectious Diseases. 2010;51(12):1395-1405. DOI: $10.1086 / 657313$

[41] Critchley IA, Eckburg PB, Jandourek A, Biek D, Friedland HD, Thye DA. Review of ceftaroline fosamil microbiology: Integrated FOCUS studies. The Journal of Antimicrobial Chemotherapy. 2011;66(Suppl 3): iii45-iii51. DOI: 10.1093/jac/dkr098

[42] File TM Jr, Rewerska B, Vucinic-Mihailovic V, Gonong JRV, Das AF, Keedy K, et al. SOLITAIRE-IV: A randomized, bouble-blind, multicenter study comparing the efficacy and safety of intravenous-to-oral solithromycin to intravenous-to-oral moxifloxacin for treatment of community-acquired bacterial pneumonia. Clinical Infectious Diseases. 2016;63(8):1007-1016. DOI: 10.1093/cid/ciw490 


\title{
Staphylococcus aureus in the Meat Supply Chain: Detection Methods, Antimicrobial Resistance, and Virulence Factors
}

\author{
Valeria Velasco, Mario Quezada-Aguiluz \\ and Helia Bello-Toledo
}

\begin{abstract}
Staphylococcus aureus (S. aureus) can cause a wide variety of infections in humans, such as skin and soft tissue infections, bacteremia, pneumonia, and food poisoning. This pathogen could be carried on the nares, skin, and hair of animals and humans, representing a serious problem at the hospital and the community level as well as in the food industry. The pathogenicity of $S$. aureus is given by bacterial structures and extracellular products, among which are toxins, which could cause staphylococcal diseases transmitted by food (SFD). S. aureus has the ability to develop resistance to antimicrobials (AMR), highlighting methicillinresistant strains (MRSA), which have resistance to all beta-lactam antibiotics, except to the fifth-generation cephalosporins. Methicillin resistance is primarily mediated by three mechanisms: production of an altered penicillin-binding protein PBP2' (or PBP2a), encoded by the mecA gene; high production of $\beta$-lactamase in borderline oxacillin-resistant Staphylococcus aureus (BORSA); and mutations in the native PBPs, called modified S. aureus (MODSA). Emerging strains have been isolated from meat-producing animals and retail meat, such as MRSA, MRSA ST398 (associated with livestock), multidrug-resistant (MDR) S. aureus, and enterotoxinproducing $S$. aureus. Therefore, there is a risk of contamination of meat and meat products during the different processing stages of the meat supply chain.
\end{abstract}

Keywords: meat-producing animals, raw meat, antimicrobial resistance (AMR), methicillin-resistant $S$. aureus (MRSA), livestock-associated methicillin-resistant $S$. aureus (LA-MRSA), multidrug-resistant (MDR), enterotoxins, mec $A$ gene

\section{Introduction}

In animal production, the emergence and the spread of antimicrobial-resistant pathogens have been associated with the misuse or overuse of antibiotics [1]. Those pathogens or the genes associated with antimicrobial resistance (AMR) could enter into the food supply chain through the food-producing animals and food handlers [2] and be transmitted to humans, threatening the effective treatments of infectious diseases [3].

Staphylococcus aureus has the ability to develop resistance to many commonly used antimicrobials. The first resistant $S$. aureus strains were isolated 2 years after 
the introduction of penicillin; in this case the mechanism of resistance was the production of the enzyme $\beta$-lactamase. Subsequently, in 1959, the antibiotic methicillin was introduced, and the first strain of methicillin-resistant $S$. aureus (MRSA) was clinically identified in 1960 [4]. These strains are resistant to penicillins, cephalosporins, and all $\beta$-lactam antibiotics, except ceftaroline and ceftobiprol.

Methicillin resistance is caused primarily by three mechanisms. The classical mechanism implies the production of an altered penicillin-binding protein, PBP2' (also called PBP2a), which is encoded by the mecA gene. This protein has a lower affinity for $\beta$-lactam antibiotics, resulting in normal cross-linking of peptidoglycan strands during bacterial cell wall synthesis [5]. Currently, new mecA gene homologs have been described, such as $m e c B, m e c C$, and $m e c D$, which may not be detected by conventional methods [6-8]. The borderline oxacillin-resistant S. aureus: (BORSA) is other mechanism in which the resistance to oxacillin is mediated by an increase of the $\beta$-lactamase production. The third mechanism is exhibited by modified S. aureus (MODSA), in which the resistance to methicillin is a consequence of modifications in their native PBPs, apparently by accumulation of mutations in the transpeptidase domains [9].

Different clones of MRSA have been recognized, such as health care-associated MRSA (HA-MRSA) [10], community-associated MRSA (CA-MRSA) [11], and livestock-associated MRSA (LA-MRSA) [12].

This pathogen can cause different diseases, such as skin and soft tissue infections, bacteremia, pneumonia, and food poisoning $[13,14]$.

Staphylococcus aureus can colonize the nares, skin, and hair of animals and humans [15]. The transmission can occur either through direct contact with infected animals or humans or with asymptomatic carriers [16]. In addition, MRSA strains have been isolated from different animals, such as pigs, cattle, and poultry $[1,17,18]$ and from retail raw meat $[19,20]$. In recent years, raw meat has been considered as an important means by which people who have no contact with livestock can be colonized with $S$. aureus from animals, therefore, act as a vehicle of transmission of this bacteria [21].

Moreover, multidrug-resistant (MDR) S. aureus strains have been detected in animals and meat [20, 22, 23], and MRSA serotype (ST) 398 has been detected primarily in pigs associated also with infections in humans [12, 24].

The food poisoning is caused by eating foods contaminated with heat-stable enterotoxins produced by Staphylococcus aureus. Enterotoxin-producing S. aureus strains have been isolated from different food samples $[23,25,26]$.

Therefore, the ability of $S$. aureus to colonize humans and animals and the detection of MRSA, MDR, enterotoxin-producing, and other emerging S. aureus strains in meat-producing animals and retail meat have increased the concern about the spread of those strains into the food supply chain [23, 26, 27]. At present, the international trade of products of animal origin is an important aspect to consider in the global dissemination of this pathogen. Thus, the countries have different regulations that tend to achieve a high level of food safety, in order to protect the health of consumers [28].

The aim of this chapter is to provide information about the detection, prevalence, characteristics, molecular typing, antimicrobial susceptibility, and the mechanisms of antimicrobial resistance of Staphylococcus aureus strains isolated from the meat supply chain.

\section{Methods of detection and identification of Staphylococcus aureus and methicillin-resistant Staphylococcus aureus (MRSA) in animals and meat}

Different culture methods have been used to detect $S$. aureus, and although conventional microbiological procedures are laborious, they are still considered standard methods for the detection and confirmation of the presence of $S$. aureus. 
The test $A P I^{\circledR}$ Staph has been shown to be a reliable method for phenotypic characterization, as other methods have had a lower precision [29]. In addition, the biochemical identification of $S$. aureus using the Sensititre ${ }^{\mathrm{TM}}$ automated system had a $100 \%$ agreement with the PCR technique by the detection of the 16S rRNA-encoding gene [20], using two selective enrichment steps preceding plating in selective agars, which seems to enhance the detection rate of MRSA [27].

According to Kateete et al. [30], there is no only phenotypic test (including the coagulase test) that can guarantee reliable results in the identification of Staphylococcus aureus.

In the past decades, methodologies, such as phage typing and genotyping were used. However, these techniques have disadvantages since they are time-consuming and can only be performed in specialized laboratories by trained professionals. Nowadays, more simple and precise techniques are being used, such as the detection by PCR technique, which has been used as the "gold standard" method to identify pathogens. Staphylococcus aureus could be confirmed by the detection of the nuc gene, which encodes a species-specific extracellular thermostable nuclease protein of $S$. aureus. Brakstad et al. [31] demonstrated that the detection of the nuc gene allows the identification of $100 \%$ of the isolates of S. aureus, using less than $0.69 \mathrm{pg}$. of chromosomal DNA or 10 bacterial CFU cells. In the study carried out by Velasco et al. [23], an agreement of $75 \%$ between the biochemical test API® Staph and the PCR technique (detection of $n u c$ gene) was determined in confirmation of $S$. aureus. A higher agreement could be reached considering a criterion of a higher probability of detection in API® Staph test.

In relation to the detection and identification of MRSA, there are different methods that have been used, mainly, in clinical laboratories. Among these tests one can mention the determination of minimum inhibitory concentrations (MIC) (dilution in agar or dilution in broth and Etest), oxacillin detection agar (OSA) [32-34], and detection of the protein PBP2' by the latex agglutination test $[32,35,36]$. This last test has an accuracy as high as the PCR method and greater than susceptibility testing method to confirm MRSA [37]. Currently, cefoxitin, a potent inducer of the mec $A$ gene regulatory system, is used for the detection of heterogeneous MRSA populations [38]. Rostami et al. [39] compared the sensitivity and specificity of phenotypic reactions with the molecular detection of methicillin resistance. For the cefoxitin disk diffusion test, $100 \%$ sensitivity and specificity was obtained. In contrast, the disk oxacillin was 91.7 and $92.8 \%$, respectively. The authors conclude that in the absence of molecular techniques, the cefoxitin disk is the best detector of MRSA, in accordance with the recommendation given by the CLSI [38].

The isolation and identification of $S$. aureus and MRSA, including selective enrichment and plating, followed by confirmation using biochemical testing and/ or PCR assays, require 3-7 days approximately [20, 27, 40]. Therefore, the development of a rapid method for detection has become an important need in the microbiological analysis of samples especially when there is a potential risk of exposure for humans.

Real-time PCR technology has been used as an alternative to culture methods for the rapid detection of $S$. aureus and MRSA. However, most studies have been applied in clinical samples, and a few studies have used real-time PCR for the detection of MRSA in animals [35, 41] and meat [27, 36, 42].

The real-time PCR assay carried out by Velasco et al. [43] used a primary and a secondary enrichment of samples from meat-producing animals and retail raw meat in order to detect $S$. aureus and MRSA.

Table 1 shows the agreement between the detection of $S$. aureus obtained by real-time PCR using primary and secondary enrichments compared with a conventional culture/PCR method. 


\begin{tabular}{|c|c|c|c|c|c|c|}
\hline \multirow{2}{*}{$\begin{array}{l}\text { Comparison } \\
\text { within each } \\
\text { sample type }\end{array}$} & \multirow{2}{*}{$\begin{array}{c}\text { No. } \\
\text { samples }\end{array}$} & \multirow{2}{*}{$\begin{array}{l}\text { No. positive } \\
\text { by culture/ } \\
\text { PCR method }\end{array}$} & \multicolumn{3}{|c|}{ No. (\%) of samples* } & \multirow{2}{*}{$\begin{array}{c}\text { kappa } \\
\text { statistic }\end{array}$} \\
\hline & & & $\begin{array}{l}\text { Positive } \\
\text { agreement } \\
\text { (sensitivity) }\end{array}$ & $\begin{array}{l}\text { Negative } \\
\text { agreement } \\
\text { (specificity) }\end{array}$ & $\begin{array}{c}\text { Total } \\
\text { agreement }\end{array}$ & \\
\hline \multicolumn{7}{|c|}{ Real-time PCR first enrichment } \\
\hline Animals & 77 & 32 & $32(100.0)$ & $34(75.6)$ & $66(85.7)$ & 0.72 \\
\hline Meat & 112 & 58 & $52(89.7)$ & $42(77.8)$ & $94(83.9)$ & 0.68 \\
\hline Deli meat & 45 & 5 & $4(80.0)$ & $40(100.0)$ & $44(97.8)$ & 0.88 \\
\hline \multicolumn{7}{|c|}{ Real-time PCR second enrichment } \\
\hline Animals & 77 & 32 & $32(100.0)$ & $36(80.0)$ & $68(88.3)$ & 0.77 \\
\hline Meat & 112 & 58 & $52(89.7)$ & $46(85.2)$ & $98(87.5)$ & 0.75 \\
\hline Deli meat & 45 & 5 & $5(100.0)$ & $26(65.0)$ & $31(68.9)$ & 0.29 \\
\hline \multicolumn{7}{|c|}{$\begin{array}{l}\text { "Positive agreement: number positive as the denominator. Negative agreement: number negative as the denominator. Total } \\
\text { agreement: the sum of the positive and negative agreement divided by the total sample size within each sample type } \\
\text { Data from Velasco et al. [43]. }\end{array}$} \\
\hline
\end{tabular}

Table 1.

Raw agreement indices among conventional culture/PCR method and real-time PCR assay, with two-step enrichment procedure for the detection of $S$. aureus from animals and retail meat.

The kappa statistic for detection of $S$. aureus using the primary enrichment in real-time PCR was 0.68-0.88 (Table 1), which indicates a good agreement (substantial to almost perfect agreement) with the conventional culture/PCR method. Using the secondary enrichment and real-time PCR, the kappa statistic for detection of $S$. aureus was $0.29-0.77$, resulting in a fair agreement when deli meat was tested. This is due to the significantly higher recovery of $S$. aureus from the secondary enrichment samples by real-time PCR. This observation suggests that small concentration of $S$. aureus could be missed when the primary enrichment alone is used in real-time PCR and that the recovery of potentially injured or nonviable strains appears to be enhanced when a secondary enrichment is used. Therefore, including a secondary selective enrichment step could improve the odds of detection of $S$. aureus.

The total agreement on the detection of the mecA gene between the real-time PCR using primary and secondary enrichment compared with a conventional culture/ PCR method ranged from 86.7 to $98.7 \%$. The kappa statistic for both enrichments in real-time PCR was $0-0.49$. The $\mathrm{k}=0$ indicates no agreement beyond that expected by chance, because the real-time PCR assay detected the mec $A$ gene probably from bacteria other than $S$. aureus. This may be due to the fact that either coagulase-negative staphylococci or non-S. aureus species can also carry the mec $A$ gene [44-46]. In this study, the DNA extraction was carried out from selective enrichments, which could contain DNA from other species that may carry the mecA gene.

The real-time PCR assay can decrease the total time for detection of $S$. aureus and the presence of the $m e c A$ gene in animal and meat samples. Using the two-step selective enrichment, the total time was $<2$ days by the real-time PCR method, compared with a total time of 6-7 days using the conventional/culture method. However, the presence of MRSA should be confirmed by a phenotypic and genetic method.

\subsection{Prevalence of Staphylococcus aureus strains in the meat supply chain}

Figure 1 shows the prevalence of $S$. aureus in the pork meat supply in a study carried out in Chile [23]. The overall prevalence of S. aureus was 33.9\%, with a higher prevalence on carcasses $(56.5 \%)$ than pigs and pork meat $(\mathrm{P} \leq 0.05)$. 
Staphylococcus aureus in the Meat Supply Chain: Detection Methods, Antimicrobial Resistance... DOI: http://dx.doi.org/10.5772/intechopen.85620

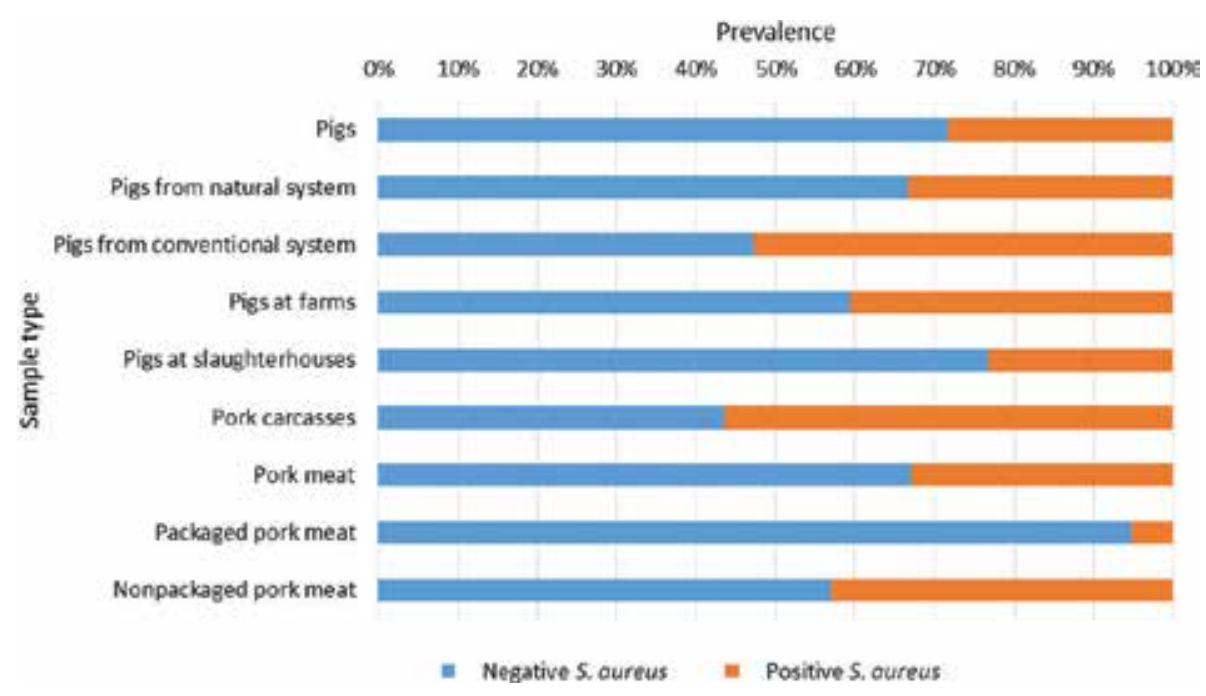

Figure 1.

Prevalence of S. aureus in the meat supply chain in Chile. Data from Velasco et al. [23].

The type of production system, natural or conventional, did not affect the prevalence $(\mathrm{P}>0.05)$. A higher prevalence of $S$. aureus might be expected in conventional pig production system than natural pig-farming system, due to a higher risk of spread of microorganisms between pigs by direct contact when animals are confined in a limited indoor area [47]. In addition, naturally raised pigs spend time outdoor and have access to larger pen areas, which can reduce infection intensity [48].

A higher prevalence of $S$. aureus was found in pigs sampled at farms (40.6\%) than in pigs sampled at slaughterhouses $(23.3 \%)(\mathrm{P} \leq 0.05)$. It might be thought that the prevalence of $S$. aureus in animals could be higher in slaughterhouses due to the risk of transmission during transportation or in resting pens, where animals from different herds could have contact $[1,49,50]$. In this study, nasal and skin swabs were taken after the stunning; however, live animals were rinsed by shower to remove external solid waste before the entrance to the process, which could reduce the impurities in the skin.

As expected, non-packaged meat was more contaminated (43.1\%) than packaged meat $(5.3 \%)(\mathrm{P} \leq 0.05)$, since non-packaged meat is more exposed to bacterial contamination, during processing and commercialization in meat counter at supermarkets and retail stores.

A higher prevalence of $S$. aureus in pigs and pork meat has been determined in other studies, with values ranging from 45 to $65 \%[20,51,52]$. However, Tanih et al. [53] detected a prevalence of $S$. aureus in carcasses around $13.0 \%$, which is much lower than the prevalence found in this study.

In addition, the mec $A$ gene and the protein PBP2' were not detected in any sample from the pork meat supply. However, three mecA-negative $S$. aureus strains exhibited resistance to oxacillin and/or cefoxitin and were also negative for the mec $C$ gene. Those strains were isolated from a skin, a carcass, and a packaged meat sample.

In a study carried out in Fargo, ND, USA [20], the overall prevalence of $S$. aureus was $37.2 \%$. A prevalence of $34.7 \%$ was obtained in animals, with the highest proportion in pigs $(50.0 \%)$ and sheep $(40.6 \%)(\mathrm{P} \leq 0.05)$. A total of $47.6 \%$ of raw meat samples were contaminated with $S$. aureus, with the highest prevalence in chicken $(67.6 \%)$ and pork $(49.3 \%)(\mathrm{P} \leq 0.05)$. In deli meat, a prevalence of $13.0 \%$ of $S$. aureus was determined (Figure 2$)$. Five pork samples $(7.0 \%)$ were positive for MRSA. 


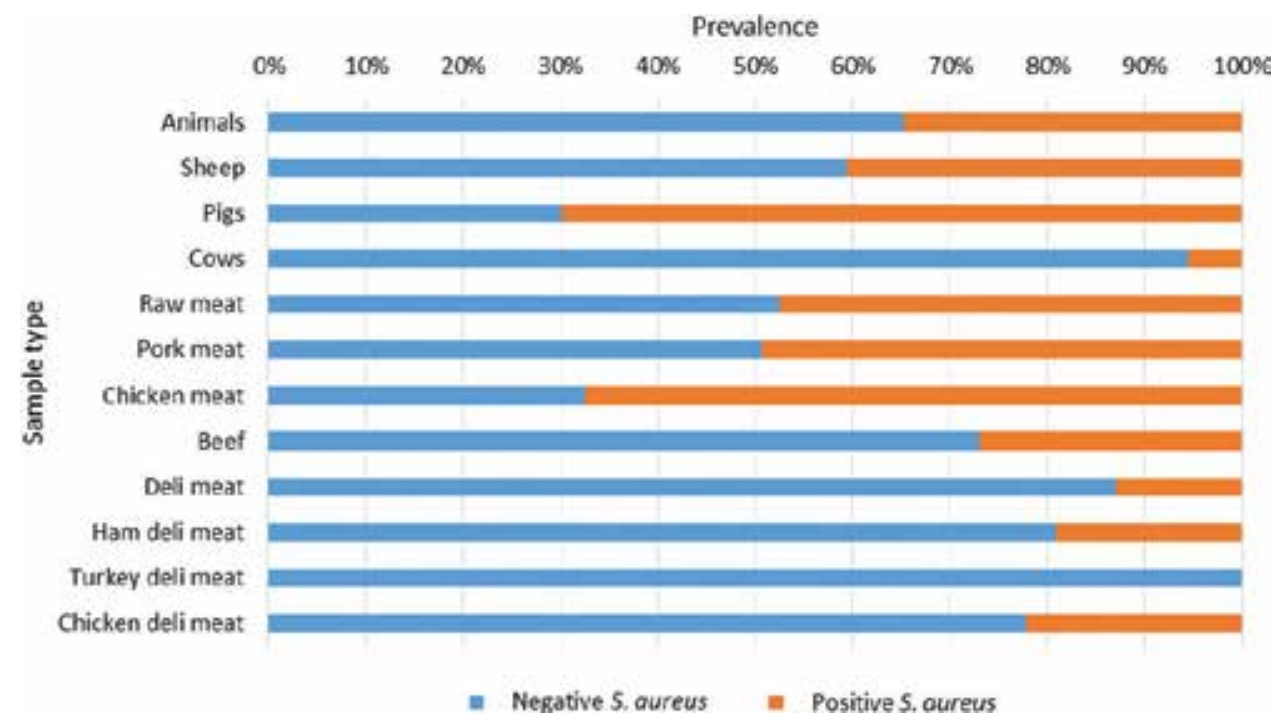

Figure 2.

Prevalence of S. aureus in the meat-producing animals and retail raw meat in North Dakota. Data from Buyukcangaz et al. [20].

Other studies have detected a higher prevalence of $S$. aureus in sheep (57\%) and cattle (14\%) [54]; however, the prevalence in pigs has been reported to vary widely $(6-57 \%)[55,56]$. The recovery of $S$. aureus in meat in this study was higher than previous studies (39.2 and 14.4\%) [26, 51]. The prevalence of S. aureus in ham was $19 \%$, which was considerably lower than the prevalence reported by Atanassova et al. [57].

In this study, MRSA was not detected in animals; however, a prevalence of MRSA in swine ranging from 6 to $71 \%$ has been detected previously $[55,58]$. In pork meat, the prevalence of MRSA has also been reported to be less than $10 \%$ in other studies $[27,51,52]$.

\section{Characterization of Staphylococcus aureus isolated from the meat supply chain}

\subsection{Molecular characterization of Staphylococcus aureus strains in meat-producing animals and retail meat}

Different molecular techniques have been used for typing $S$. aureus strains, such as pulsed-field gel electrophoresis (PFGE) based on macro-restriction patterns of genomic DNA, multilocus sequence typing (MLST) that determines the allelic profile of seven housekeeping genes, and spa typing based on the sequencing of the polymorphic $\mathrm{X}$ region of the gene encoding the protein A. A greater discriminatory power has been found with PFGE than MLST, spa typing, and SCCmec typing [59]. However, a combination of two typing methods may be most accurate for strain differentiation [60]. Conversely, it is not possible to obtain a macro-restriction pattern for ST398 strains by PFGE using the restriction enzyme SmaI, since the DNA of those strains cannot be digested with SmaI, maybe due to the methylation of the SmaI-recognition site caused by a methylation enzyme [61]. There is a Cfr9I PFGE, a new tool for studying non-typeable ST398 strains, which use Cfr9I: a neoschizomer of the SmaI enzyme [62] and specific PCRs for detection of S. aureus ST398 [63]. Restriction patterns with the same number of bands represent the same strain, patterns that differ up to three fragments represent strains that are closely 
related, and isolates that differ at four to six bands may have the same genetic lineage [64]. Nonetheless, BioNumerics software (applied maths) allows restriction patterns of PFGE images to be normalized and to be compared within and between local laboratories with high reproducibility. The band position tolerance and optimization must be set at 1.0 and $0.5 \%$, respectively, and a similarity coefficient of $80 \%$ to define the clusters [65].

Different clones of methicillin-susceptible S. aureus (MSSA) and MRSA have been detected in humans, animals, and meat. The most common clones that cause CA-MRSA infections have been identified as USA300 and USA400 and those causing HA-MRSA infections as USA100 and USA200 [66]. Some sequence types (ST) of S. aureus strains have been determined, such as ST5, ST8, ST22, ST36, and ST45, among others, associated to HA-MRSA [67], ST30 and ST80 associated to CA-MRSA [68], and ST398 linked with animals [69, 70].

The SCCmec typing is based on the genetic characteristics of a mobile genetic element called staphylococcal cassette chromosome mec (SCCmec) that carries the $m e c A$ gene. The emergence of MRSA is due to the acquisition of the SCCmec element into the chromosome of MSSA strains. SCCmec elements are highly diverse and have been classified into types and subtypes as shown in Table $2[4,71,72]$.

The SmaI macro-restriction fragment profiles of some $S$. aureus strains isolated from the pork chain supply in Chile are shown in Figure 3. The $S$. aureus strains were genetically diverse, identifying only two clusters: ST1 from meat and carcass and ST433 from natural raised pigs. Genetic diversity among S. aureus strains of swine origin could suggest different source of contamination at different stages of the pork chain supply.

In the study carried out by Buyukcangaz et al. [20], five pork samples were positive for MRSA, of which three were ST398 and two were ST5. The most common clones in sheep were ST398 and ST133, in pigs and pork both ST398 and ST9, and in chicken ST5. The clustering of isolates obtained by PFGE agreed well with the MLST types, i.e., the identical restriction patterns or patterns that differed at two to six bands had an identical ST. A total of 34 S. aureus isolated from animals

\begin{tabular}{|c|c|c|c|c|}
\hline $\begin{array}{l}\text { SCCmec } \\
\text { type }\end{array}$ & $\begin{array}{l}\text { mec gene } \\
\text { complex }\end{array}$ & $\begin{array}{l}\text { Structure of } m e c \text { gene } \\
\text { complex }\end{array}$ & $\begin{array}{l}\text { ccr gene } \\
\text { complex }\end{array}$ & ccr genes \\
\hline I & Class B & IS1272- $\triangle$ mecR1-mecA-IS431 & Type 1 & $\operatorname{ccr} A 1, \operatorname{ccr} B 1$ \\
\hline II & Class A & mecI-mecR1-mecA-IS431 & Type 2 & $\operatorname{ccr} A 2, \operatorname{cr} B 2$ \\
\hline III & Class A & mecI-mecR1-mecA-IS431 & Type 3 & $\operatorname{ccr} A 3, \operatorname{ccrB} 3$ \\
\hline IV & Class B & IS1272- $\triangle$ mесR1-тесA-IS431 & Type 2 & $\operatorname{ccr} A 2, \operatorname{ccr} B 2$ \\
\hline V & Class C2 & IS431-mecA- $\triangle$ mecR1-IS431 & Type 5 & $\operatorname{ccrC1}$ \\
\hline VI & Class B & IS1272- $\triangle$ mecR1-mecA-IS431 & Type 4 & $\operatorname{ccr} A 4, \operatorname{ccrB} 4$ \\
\hline VII & Class C1 & IS431-mecA- $\triangle$ mecR1-IS431 & Type 5 & $\operatorname{ccrC1}$ \\
\hline VIII & Class A & mecI-mecR1-mecA-IS431 & Type 4 & $\operatorname{ccrA4}, \operatorname{ccrB} 4$ \\
\hline IX & Class C2 & IS431-mесA- $\triangle$ mесR1-IS431 & Type 1 & ccrA1, ccrB1 \\
\hline $\mathrm{X}$ & Class C1 & IS431-mecA- $\triangle$ mecR1-IS431 & Type 7 & ccrA1, $\operatorname{ccrB6}$ \\
\hline $\mathrm{XI}$ & Class E & blaZ-mecA-mecR1-mecI & Type 8 & ccrA1, $\operatorname{ccrB3}$ \\
\hline XII & Class C2 & IS431-mecA- $\triangle$ mecR1-IS431 & Type 9 & ccrA1, $\operatorname{ccr} C 2$ \\
\hline XIII & Class A & IS431-mecI-mecR1-mecA-IS431 & Type 9 & $\operatorname{ccrC} 2$ \\
\hline
\end{tabular}

Table 2.

Genetic structure of the different SCCmec types described in Staphylococcus aureus. 


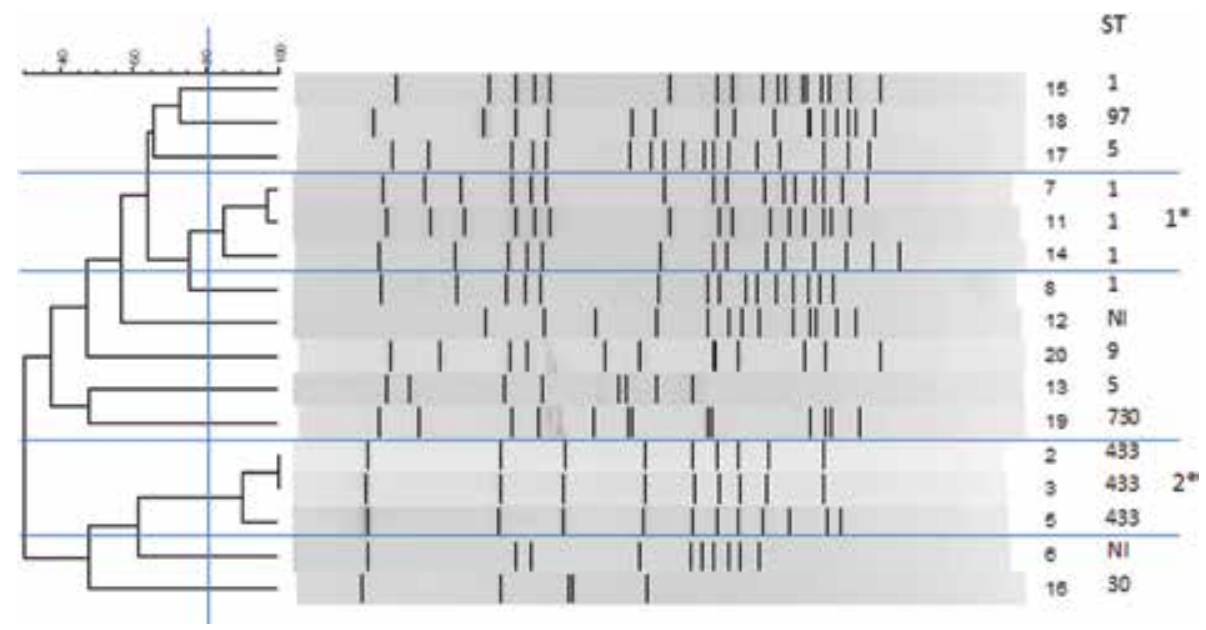

Figure 3.

Dendrogram showing the genetic similarity and sequence types (ST) of S. aureus isolates from pork production chain in Chile.

(sheep and pigs) and from pork meat, which were ST398, could not be restricted with SmaI or XmaI during PFGE analysis. The high prevalence of ST398 indicates a potential risk for humans to acquire this emerging sequence type which has potential for causing infection. The MRSA isolates had the same MLST allelic profile and indistinguishable PFGE patterns than two MSSA strains, all obtained from pork. The close genetic similarity of the MRSA and MSSA isolates may be due to the acquisition of $m e c A$ gene by horizontal transfer of SCCmec from MRSA strains to MSSA lineages [1, 22, 73, 74].

In addition, contamination of meat with $S$. aureus strains from animals and humans could occur during slaughtering or processing. In fact, the genetic relatedness between $S$. aureus strains ST9 from pigs and pork meat may suggest the possible contamination of meat during slaughtering [20], and the genetic similarity between clones isolated from humans and meat suggests the spread of $S$. aureus into the food chain supply [75].

\subsection{Antimicrobial resistance in Staphylococcus aureus from meat-producing animals and meat}

Methicillin and other $\beta$-lactam antibiotics affect the cell wall synthesis in gram-positive bacteria inhibiting the last stage of the peptidoglycan synthesis called transpeptidation. During the transpeptidation the linkage between $\mathrm{N}$-acetylmuramic acid and the cell wall takes place, catalyzed by transpeptidases and carboxypeptidases, called penicillin-binding proteins (PBPs). These proteins are able to bind penicillin in their active sites through a covalent bond between a serine and the $\beta$-lactam ring, resulting in the inhibition of the transpeptidation [76].

Methicillin resistance in $S$. aureus is primarily mediated by the production of an altered penicillin-binding protein, PBP2' (also called PBP2a), encoded by the mecA gene, which is carried on the staphylococcal cassette chromosome mec (SCCmec). This protein has a lower affinity for $\beta$-lactam antibiotics, resulting in a normal cross-linking of peptidoglycan strands during cell wall synthesis [77].

Some studies have isolated $S$. aureus strains from humans and livestock that are phenotypically resistant to methicillin, but they do not harbor the mec $A$ gene. The phenotypic methicillin resistance has been associated with variations of the mec $A$ gene, such as the $m e c A_{L G A 251}$ renamed as $m e c C[7,78]$, the $m e c B$ gene [6], and others 
Staphylococcus aureus in the Meat Supply Chain: Detection Methods, Antimicrobial Resistance... DOI: $h$ ttp://dx.doi.org/10.5772/intechopen.85620

that are not as well-known [75]. The mecC gene is located on the staphylococcal cassette chromosome mec type XI (SSCmec XI) and exhibits 70\% sequence homology with the mecA gene $[7,79,80]$. Additionally, MRSA lacking the mec genes (MRLM) may have uncommon phenotypes, such as the $\beta$-lactamase hyperproduction (BHP), which partially hydrolyzes the $\beta$-lactam ring, usually known as borderline oxacillinresistant $S$. aureus (BORSA), with an intermediate resistance level to oxacillin [81]. Different nucleotide mutations in $p b p$ genes, the pbp4 promoter, and genes involved in penicillin-binding protein 4 overproduction have also been associated with MRLM, called as modified S. aureus (MODSA) [9, 81, 82].

In March 2017, Schwendener et al. [83] reported a new mec gene called mecD, which confers resistance to all $\beta$-lactams antibiotics, including anti-MRSA cephalosporins, ceftobiprole, and ceftaroline. The gene was found in strains of Macrococcus caseolyticus isolated from bovines and canines. Alarmingly, the mecD gene was in an island of resistance associated with a site-specific integrase, which implies a risk of transmission by horizontal gene transfer to other species.

Other $S$. aureus strains with significant importance have also been detected in the meat supply chain, such as multidrug-resistant (MDR) S. aureus, which exhibit resistance to at least three classes of antibiotics [22].

Another mechanism of resistance to $\beta$-lactam antibiotics is the production of the enzyme $\beta$-lactamase, which hydrolyses the $\beta$-lactam ring resulting in the inactivation of the antibiotic. This enzyme is encoded by blaZ gene located in a transposon element within a plasmid [84].

Table 3 shows the resistance profiles of $S$. aureus strains isolated from the pork meat supply chain in Chile. A total of 16 profiles were observed, including 8 profiles

\begin{tabular}{|c|c|c|c|c|}
\hline \multirow[t]{2}{*}{$\begin{array}{l}\text { Antimicrobial resistance } \\
\text { profile* }^{*}\end{array}$} & \multirow[t]{2}{*}{$\begin{array}{l}\text { No. of subclasses } \\
\text { resistant to }\end{array}$} & \multicolumn{3}{|c|}{$\begin{array}{l}\text { No. (\%) of all S. aureus isolates with the specific } \\
\text { profile }\end{array}$} \\
\hline & & Animal $N=28$ & Carcass N = 12 & Meat $\mathrm{N}=15$ \\
\hline PEN-KAN-ERY-CIP-TET & 5 & $3(10.7)$ & & \\
\hline PEN-CEF-KAN-ERY-TET & 4 & $1(3.6)$ & & \\
\hline PEN-KAN-ERY-TET & 4 & $1(3.6)$ & $1(8.3)$ & \\
\hline PEN-ERY-CIP-TET & 4 & $10(35.7)$ & $1(8.3)$ & \\
\hline PEN-KAN-ERY & 3 & $1(3.6)$ & & \\
\hline PEN-ERY-CIP & 3 & $1(3.6)$ & & \\
\hline PEN-GEN-QDA & 3 & & $1(8.3)$ & \\
\hline PEN-ERY-QDA & 3 & & & $1(6.7)$ \\
\hline OXA-PEN-CEF-GEN-KAN & 2 & & & $1(6.7)$ \\
\hline PEN-ERY & 2 & $1(3.6)$ & & $2(13.3)$ \\
\hline PEN-CIP & 2 & $1(3.6)$ & & $1(6.7)$ \\
\hline PEN-QDA & 2 & & & $1(6.7)$ \\
\hline PEN-TET & 2 & $1(3.6)$ & & \\
\hline KAN-ERY & 2 & & & $1(6.7)$ \\
\hline OXA-PEN-CEF & 1 & & $1(8.3)$ & \\
\hline PEN & 1 & $1(3.6)$ & $7(58.3)$ & $7(46.6)$ \\
\hline Susceptible to all tested & 0 & $7(25.0)$ & $1(8.3)$ & $1(6.7)$ \\
\hline $\begin{array}{l}{ }^{*} \text { OXA, oxacillin; PEN, penic } \\
\text { ciprofloxacin; } Q U I / D A L, \text { quin }\end{array}$ & $\begin{array}{l}\text { EF, cefoxitin; } G 1 \\
\text { n/dalfopristin; } T\end{array}$ & $\begin{array}{l}\text { tamicin; KAN } \\
\text { acycline [38]. }\end{array}$ & mycin; ERY, & mycin; CIP, \\
\hline
\end{tabular}

Table 3.

Antimicrobial resistance profiles of Staphylococcus aureus strains isolated from the meat chain supply in Chile. 
of MDR (resistance to at least three classes of antibiotics) [26]. The most MDR S. aureus strains were isolated from pigs. Rubin et al. [85] determined a significant higher resistance to penicillin, erythromycin, and tetracycline in S. aureus of swine origin than other type of animals.

The less effective antibiotic was penicillin. The low effectiveness of penicillin could be due to the enzyme penicillinase that hydrolyzes the $\beta$-lactam ring and inactivates the drug [5].

Two $S$. aureus strains were both oxacillin- and cefoxitin-resistant, and one $S$. aureus strain exhibited only cefoxitin resistance. However, those strains were $m e c A$ - and PBP2'-negative. Currently, the cefoxitin disk diffusion method is used to detect methicillin resistance [38]; it is easier to interpret and has a higher sensitivity

\begin{tabular}{|c|c|c|c|c|}
\hline \multirow[t]{2}{*}{ Antimicrobial resistance profile* } & \multirow[t]{2}{*}{$\begin{array}{l}\text { No. of subclasses } \\
\text { resistant to }\end{array}$} & \multicolumn{3}{|c|}{$\begin{array}{l}\text { No. }(\%) \text { of all } S \text {. aureus isolates with the } \\
\text { specific profile }\end{array}$} \\
\hline & & $\begin{array}{l}\text { Animal } \\
(n=58)\end{array}$ & $\begin{array}{l}\text { Raw meat } \\
(n=69)\end{array}$ & $\begin{array}{l}\text { Deli meat } \\
(n=6)\end{array}$ \\
\hline $\begin{array}{l}\text { ERY-PEN-TET-LINC- } \\
\text { CHL-GEN-CIP-QUI/ } \\
\text { DAL }\end{array}$ & 8 & & $1(1.4)$ & \\
\hline $\begin{array}{l}\text { ERY-PEN-TET-LINC- } \\
\text { CHL-CIP-QUI/ } \\
\text { DAL }\end{array}$ & 7 & & $1(1.4)$ & \\
\hline ERY-PEN-TET-LINC-CHL-STR & 6 & $2(3.4)$ & & \\
\hline ERY-PEN-TET-LINC-KAN & 5 & & $1(1.4)$ & \\
\hline PEN-TET-LINC-CHL-STR & 5 & $1(1.7)$ & & \\
\hline PEN-TET-LINC-GEN & 4 & $1(1.7)$ & & \\
\hline PEN-TET-LINC-KAN & 4 & & $1(1.4)$ & \\
\hline PEN-TET-LINC-STR & 4 & $2(3.4)$ & & \\
\hline ERY-PEN-TET-LINC & 4 & $1(1.7)$ & $13(18.8)$ & \\
\hline PEN-TET-LINC & 3 & $22(37.9)$ & $1(1.4)$ & \\
\hline PEN-LINC-STR & 3 & $1(1.7)$ & & \\
\hline ERY-PEN-LINC & 3 & & $2(2.9)$ & \\
\hline ERYTET-LINC & 3 & & $5(7.2)$ & \\
\hline PEN-LINC & 2 & $4(6.9)$ & $1(1.4)$ & $1(16.7)$ \\
\hline PEN-TET & 2 & $12(20.7)$ & $2(2.9)$ & \\
\hline TET-LINC & 2 & $3(5.2)$ & & \\
\hline ERY-LINC & 2 & & $3(4.3)$ & \\
\hline ERY-PEN & 2 & & $2(2.9)$ & \\
\hline LINC & 1 & $1(1.7)$ & & \\
\hline PEN & 1 & $3(5.2)$ & $10(14.5)$ & $1(16.7)$ \\
\hline TET & 1 & $3(5.2)$ & $4(5.8)$ & \\
\hline ERY & 1 & & & $1(16.7)$ \\
\hline Susceptible to all tested & 0 & $2(3.4)$ & $22(31.9)$ & $3(50.0)$ \\
\hline $\begin{array}{l}\text { IP, ciprofloxacin; CHL, chloramphe } \\
\text { comycin; QUI/DAL, quinupristin/dal } \\
\text { yukcangaz et al. [20]. }\end{array}$ & LKY, en & $E N$ & $\begin{array}{l}\text { KAN, } \\
\text { ET, tetr }\end{array}$ & $\begin{array}{l}\text { in; LINC, } \\
\text { Data from }\end{array}$ \\
\hline
\end{tabular}

Table 4.

Antimicrobial resistance (AR) profiles of Staphylococcus aureus and methicillin-resistant S. aureus (MRSA) isolates from animals and retail meat. 
[86]. Those strains did not harbor the $m e c C$ gene; therefore, they could carry other variations of the mecA gene that are not as well-known $[75,78,82]$ or could present uncommon phenotypes such as BORSA [81, 87]. Therefore, the whole genome sequencing is always necessary to understand the mechanism of resistance.

The use of antimicrobial agents in pigs is an important risk factor for increasing the prevalence of MRSA, promoting the selective pressure, and enhancing the emerging and the spread of MRSA [88]. In Holland, a high prevalence of MRSA was detected in pigs, with a resistance to different antibiotics, suggesting the spread of MRSA strains within animals in the slaughterhouses [1].

Table 4 shows the antimicrobial resistance profiles of the 133 S. aureus strains isolated from animals and retail meat in the study of Buyukcangaz et al. [20]. The most common resistance profiles in isolates were penicillin-tetracycline and penicillin-tetracycline-erythromycin, in animals and raw meat, respectively. Most of the $S$. aureus strains isolated from animals exhibited resistance to the same antimicrobials reported by other authors $[89,90]$. Other authors have also determined a higher occurrence of resistance to penicillin, tetracycline, and erythromycin in $S$. aureus strains isolated from retail meat and different food samples $[26,91]$. Penicillin resistance has been reported to spread rapidly among $S$. aureus strains being facilitated by plasmids and is the most frequently reported resistance detected in foodborne $S$. aureus [26].

The rate of MDR strains was $41.4 \%$, in animals was $51.7 \%$, and in meat $36.2 \%$ $(\mathrm{n}=25)$. The MDR isolates were found in pigs, pork, and sheep. MDR isolates from pork were mainly ST398 (60\%) and ST9 (30\%). All MDR strains from sheep were ST398.

Five pork samples that were MRSA (three ST398 and two ST5) exhibited penicillin resistance and four MDR. In addition, most of the $S$. aureus isolates susceptible to all antimicrobial agents were obtained from chicken, of which $76 \%$ were ST5.

The AMR bacteria in animals have increased over time due to the frequent use of antimicrobial agents at the farm level $[1,89]$. Therefore, controlling the use of antibiotics in farming could limit the risk of transmission of AMR pathogens among animals and to humans [90].

\subsection{Characteristics of pathogenicity of Staphylococcus aureus strains in meat-producing animals and meat}

S. aureus produces different virulence factors, including bacterial structures such as capsules and adhesins, and extracellular products, such as enzymes, with activity of coagulase, catalase, hyaluronidase, and toxins such as toxin $\alpha$, toxin $\beta$, toxin leucocidin, enterotoxin, exfoliative toxin, and toxic shock syndrome toxin. These virulence factors contribute to different stages of infection from adhesion of the pathogen to the surface, to invasion, causing toxic effects, tissue damage, and distal disease. The synthesis of these virulence factors is a highly regulated process, which contributes to the production of the different human or animal diseases $[92,93]$.

The main regulator of virulence gene expression is the agr operon, which functions through a quorum sensing mechanism. The locus is autocatalytic, controlled in a manner dependent on cell density through the production and detection of selfinducing peptides (AIP). The agr locus has two divergent transcription units, RNAII and RNAIII, controlled by their promoters, P2 and P3, respectively [94]. This locus exerts a negative regulation on the adhesin molecules in the colonization stage of the host during the stationary phase. However, when a high load of the autoinducer peptide (agrD protein) is reached in the post-exponential growth stage, RNAIII is activated and inhibits the expression of adhesion proteins, activating the expression 
of extracellular enzymes and toxins ( $\alpha-\beta$ hemolysins, lipases, proteases, etc.), virulence factors related to nutrient acquisition, survival and bacterial dissemination $[95,96]$.

In dairy, one of the main virulence factors is the formation of biofilms, which are structured consortia of bacterial cells that are immersed in a polymeric matrix consisting of polysaccharides, proteins, extracellular DNA (eDNA), lipids, and other macromolecules. The biofilms allow bacteria to adhere to inert or living surfaces, increasing their growth rate and survival in a hostile environment [97].

Enterotoxin-producing $S$. aureus strains may cause gastroenteritis and have a significant importance due to its detection in the meat supply chain. Five classical enterotoxins have been found in $S$. aureus, which are known as SE types (SEA to SEE) encoded by the se genes. However, in recent years, new SEs and SE-like toxins have been detected [26]. Since enterotoxins can resist heat treatment and low $\mathrm{pH}$ conditions that can easily destroy the bacteria, it is important to highlight the impact of the expression of enterotoxins by $S$. aureus on human health [25]. In the study carried out by Velasco et al. [23], only $1 S$. aureus strain of a total of 23 strains isolated from pork meat samples was positive for enterotoxin B (SEB) determined by the reversed passive latex agglutination test and for the seb gene detected by PCR method. The SEB-producing $S$. aureus strain was isolated from a meat sample obtained from a butcher store and was non-packaged. Therefore, contamination of meat with foodborne $S$. aureus may occur in the meat supply chain, primarily in more exposed food, such as non-packaged meat.

\section{Conclusions}

Staphylococcus aureus is present in the meat supply chain, and some emerging strains, such as MRSA, MRSA ST398, MRLM, MDR, and enterotoxin-producing $S$. aureus, have been detected in animals, meat, and humans.

The genetic similarity between $S$. aureus strains isolated from humans, animals, and meat suggests the potential risk of contamination of meat during processing or handling, the spread of emerging $S$. aureus strains into the food chain, and the potential transmission to humans.

Further research is needed to expand the knowledge and comprehension of the molecular characterization and the different mechanisms of AMR in S. aureus.

\section{Acknowledgements}

The results of the studies showed in this book chapter were supported by the Research Project Fondecyt No. 11140379 (Chile) and the Dean's Office, College of Agriculture, Food Systems and Natural Resources College, North Dakota State University (Fargo, ND, USA).

\section{Conflict of interest}

The authors declare that there is no conflict of interest regarding the publication of this book chapter. 


\section{Author details}

Valeria Velasco $^{1 *}$, Mario Quezada-Aguiluz ${ }^{2,3,4}$ and Helia Bello-Toledo ${ }^{2}$

1 Department of Animal Sciences, Agronomy School, University of Concepción, Chillán, Chile

2 Laboratory of Antibacterial Agents Research, Department of Microbiology, Biological Sciences School, University of Concepción, Concepción, Chile

3 Department of Internal Medicine, Medicine School, University of Concepción, Concepción, Chile

4 Millennium Nucleus on Interdisciplinary Approach to Antimicrobial Resistance (MICROB-R), Chile

*Address all correspondence to: vvelasco@udec.cl

\section{IntechOpen}

(C) 2019 The Author(s). Licensee IntechOpen. This chapter is distributed under the terms of the Creative Commons Attribution License (http://creativecommons.org/licenses/ by/3.0), which permits unrestricted use, distribution, and reproduction in any medium, provided the original work is properly cited. (cc) BY 


\section{References}

[1] de Neeling AJ, van den Broek MJM, Spalburg EC, van Santen-Verheuvel MG, Dam-Deisz WDC, Boshuizen HC, et al. High prevalence of methicillin resistant Staphylococcus aureus in pigs. Veterinary Microbiology. 2007;122:366-372

[2] Sáenz Y, Zarazaga M, Brias L, Lantero M, Ruiz-Larrea F, Torres C. Antibiotic resistance in Escherichia coli isolates obtained from animals, foods and humans in Spain. International Journal of Antimicrobial Agents. 2001;18:353-358

[3] Smith DL, Harris AD, Johnson JA, Silbergeld EK, Morris JG. Animal antibiotic use has an early but important impact on the emergence of antibiotic resistance in human commensal bacteria. Proceedings of the National Academy of Sciences. 2002;99(9):6434-6439

[4] Aguayo-Reyes A, Quezada-Aguiluz M, Mella S, Riedel G, Opazo-Capurro A, Bello-Toledo $\mathrm{H}$, et al. Bases moleculares de la resistencia a meticilina en Staphylococcus aureus. Revista chilena de infectología. 2018;35(1):7-14

[5] Peacock SJ, Paterson GK.

Mechanisms of methicillin resistance in Staphylococcus aureus. Annual Review of Biochemistry. 2015;84:577-601

[6] Tsubakishita S, Kuwahara-Arai K, Baba T, Hiramatsu K. Staphylococcal cassette chromosome mec-like element in Macrococcus caseolyticus. Antimicrobial Agents and Chemotherapy. 2010;54(4):1469-1475

[7] García-Álvarez L, Holden MTG, Lindsay $\mathrm{H}$, Webb CR, Brown DFJ, Curran MD, et al. Meticillin-resistant Staphylococcus aureus with a novel mecA homologue in human and bovine populations in the UK and Denmark: A descriptive study. The Lancet Infectious Diseases. 2011;11(8):595-603
[8] MacFadyen AC, Fisher EA, Costa B, Cullen C, Paterson GK. Genome analysis of methicillin resistance in Macrococcus caseolyticus from dairy cattle in England and Wales. Microbial Genomics.

2018;4:1-8

[9] Angeles Argudín M, Roisin S, Nienhaus L, Dodémont M, De Mendonça R, Nonhoff C, et al. Genetic diversity among Staphylococcus aureus isolates showing oxacillin and/or cefoxitin resistance not linked to the presence of mec genes. Antimicrobial Agents and Chemotherapy. 2018;62(7):1-6

[10] Tiemersma EW, Bronzwaer SLAM, Lyytikäinen O, Degener JE, Schrijnemakers P, Bruinsma N, et al. Methicillin-resistant Staphylococcus aureus in Europe, 1999-2002. Emerging Infectious Diseases. 2004;10:1627-1634

[11] Kennedy AD, Otto M, Braughton KR, Whitney AR, Chen L, Mathema B, et al. Epidemic community-associated methicillin-resistant Staphylococcus aureus: Recent clonal expansion and diversification. Proceedings of the National Academy of Sciences. 2008;105:1327-1332

[12] Golding GR, Campbell JL, Spreitzer DJ, Veyhl J, Surynicz K, Simor A, et al. A preliminary guideline for the assignment of methicillin-resistant Staphylococcus aureus to a Canadian pulsed-field gel electrophoresis epidemic type using spa typing. Canadian Journal of Infectious Diseases and Medical Microbiology. 2008;19:273-281

[13] Tong SYC, Davis JS, Eichenberger E, Holland TL, Fowler VG. Staphylococcus aureus infections: Epidemiology, pathophysiology, clinical manifestations, and management. Clinical Microbiology Reviews. 2015;28:603-661 
[14] Argudín MÁ, Mendoza MC, Rodicio MR. Food poisoning and Staphylococcus aureus enterotoxins. Toxins. 2010;2:1751-1773

[15] Voss A, Loeffen F, Bakker J, Klaassen C, Wulf M. Methicillinresistant Staphylococcus aureus in pig farming. Emerging Infectious Diseases. 2005;11(12):1965-1966

[16] (CFSPH) C for FS and PH. Methicillin-Resistant Staphylococcus Aureus MRSA. Iowa State University; 2011. pp. 1-25

[17] Friese A, Schulz J, Zimmermann K, Tenhagen BA, Fetsch A, Hartung J, et al. Occurrence of livestock-associated methicillin-resistant Staphylococcus aureus in Turkey and broiler barns and contamination of air and soil surfaces in their vicinity. Applied and Environmental Microbiology. 2013;79:2759-2766

[18] Nemeghaire S, Argudín MA, Haesebrouck F, Butaye P. Epidemiology and molecular characterization of methicillin-resistant Staphylococcus aureus nasal carriage isolates from bovines. BMC Veterinary Research. 2014;10:153

[19] Hanson BM, Dressler AE, Harper AL, Scheibel RP, Wardyn SE, Roberts LK, et al. Prevalence of Staphylococcus aureus and methicillin-resistant Staphylococcus aureus (MRSA) on retail meat in Iowa. Journal of Infection and Public Health. 2011;4:169-174

[20] Buyukcangaz E, Velasco V, Sherwood JS, Stepan RM, Koslofsky RJ, Logue CM. Molecular typing of Staphylococcus aureus and methicillinresistant $S$. aureus (MRSA) isolated from animals and retail meat in North Dakota, United States. Foodborne Pathogens and Disease. 2013;10:608-617

[21] Carrel M, Zhao C, Thapaliya D, Bitterman P, Kates AE, Hanson BM, et al. Assessing the potential for raw meat to influence human colonization with Staphylococcus aureus. Scientific Reports. 2017;7:1-10

[22] Guardabassi L, O’Donoghue M, Moodley A, Ho J, Boost M. Novel lineage of methicillin-resistant Staphylococcus aureus, Hong Kong. Emerging Infectious Diseases. 2009;15:1998-2000

[23] Velasco V, Vergara JL, Bonilla AM, Muñoz J, Mallea A, Vallejos D, et al. Prevalence and characterization of Staphylococcus aureus strains in the pork chain supply in Chile. Foodborne Pathogens and Disease. 2018;15(5):262-268

[24] Pan A, Battisti A, Zoncada A, Bernieri F, Boldini M, Franco A, et al. Community-acquired methicillinresistant Staphylococcus aureus ST398 infection, Italy. Emerging Infectious Diseases. 2009;15(5):845-846

[25] Le Loir Y, Baron F, Gautier M. Staphylococcus aureus and food poisoning. Genetics and Molecular Research. 2003;2(1):63-72

[26] Aydin A, Muratoglu K, Sudagidan M, Bostan K, Okuklu B, Harsa S.

Prevalence and antibiotic resistance of foodborne Staphylococcus aureus isolates in Turkey. Foodborne Pathogens and Disease. 2011;8:63-69

[27] De Boer E, Zwartkruis-Nahuis JTM, Wit B, Huijsdens XW, De Neeling AJ, Bosch T, et al. Prevalence of MRSA in meat. International Journal of Food Microbiology. 2009;134:52-56

[28] Müller A, Seinige D, Jansen W, Klein G, Ehricht R, Monecke S, et al. Variety of antimicrobial resistances and virulence factors in Staphylococcus aureus isolates from meat products legally and illegally introduced to Germany. PLoS One. 2016;11(12):e0167864

[29] Heikens E, Fleer A, Paauw A, Florijn A, Fluit AC. Comparison of 
genotypic and phenotypic methods for species-level identification of clinical isolates of coagulase-negative staphylococci. Journal of Clinical Microbiology. 2005;43:2286-2290

[30] Kateete DP, Kimani CN, Katabazi FA, Okeng A, Okee MS, Nanteza A, et al. Identification of Staphylococcus aureus: DNase and mannitol salt agar improve the efficiency of the tube coagulase test. Annals of Clinical Microbiology and Antimicrobials. 2010;9:23

[31] Brakstad OG, Aasbakk K, Maeland JA. Detection of Staphylococcus aureus by polymerase chain reaction amplification of the nuc gene. Journal of Clinical Microbiology. 1992;30:1654-1660

[32] Danial J, Noel M, Templeton KE, Cameron F, Mathewson F, Smith M, et al. Real-time evaluation of an optimized real-time PCR assay versus brilliance chromogenic MRSA agar for the detection of meticillinresistant Staphylococcus aureus from clinical specimens. Journal of Medical Microbiology. 2011;60:323-328

[33] Kim MH, Lee WI, Kang SY. Detection of methicillin-resistant Staphylococcus aureus in healthcare workers using real-time polymerase chain reaction. Yonsei Medical Journal. 2013;54(5):1282-1284

[34] Nimmo GR, Bergh H, Nakos J, Whiley D, Marquess J, Huygens F, et al. Replacement of healthcare-associated MRSA by community-associated MRSA in Queensland: Confirmation by genotyping. The Journal of Infection. 2013;67:439-447

[35] Anderson MEC, Weese JS. Evaluation of a real-time polymerase chain reaction assay for rapid identification of methicillin-resistant Staphylococcus aureus directly from nasal swabs in horses. Veterinary Microbiology. 2007;122:185-189

[36] Weese JS, Avery BP, Reid-Smith RJ. Detection and quantification of methicillin-resistant Staphylococcus aureus (MRSA) clones in retail meat products. Letters in Applied Microbiology. 2010;51:338-342

[37] Sakoulas G, Gold HS, Venkataraman L, Degirolami PC, Eliopoulos GM, Qian Q. Methicillin-resistant Staphylococcus aureus: Comparison of susceptibility testing methods and analysis of mecA-positive susceptible strains. Journal of Clinical Microbiology. 2001;39:3946-3951

[38] CLSI. Performance Standards for Antimicrobial Susceptibility Testing. M100 CS. 28th ed. Wayne, PA; 2018

[39] Rostami S, Moosavian M, Shoja S, Torabipour M, Farshadzadeh Z.

Comparison of mecA gene-based PCR with CLSI cefoxitin and oxacillin disc diffusion methods for detecting methicillin resistance in Staphylococcus aureus clinical isolates. African Journal of Microbiology Research. 2013;7(21):2438-2441

[40] Zhang W, Hao Z, Wang Y, Cao X, Logue CM, Wang B, et al. Molecular characterization of methicillin-resistant Staphylococcus aureus strains from pet animals and veterinary staff in China. Veterinary Journal. 2011;190:e125-e129

[41] Morcillo A, Castro B, RodríguezÁlvarez C, González JC, Sierra A, Montesinos MI, et al. Prevalence and characteristics of methicillinresistant Staphylococcus aureus in pigs and pig workers in Tenerife, Spain. Foodborne Pathogens and Disease. 2012;9(3):207-210

[42] Waters AE, Contente-Cuomo T, Buchhagen J, Liu CM, Watson L, Pearce $\mathrm{K}$, et al. Multidrug-resistant Staphylococcus aureus in US meat and poultry. Clinical Infectious Diseases. 2011;52:1-4

[43] Velasco V, Sherwood JS, Rojas-García PP, Logue CM. Multiplex real-time PCR for detection of Staphylococcus aureus, 
mecA and panton-valentine leukocidin (PVL) genes from selective enrichments from animals and retail meat. PLoS One. 2014;9(5):e97617

[44] Thomas LC, Gidding HF, Ginn AN, Olma T, Iredell J. Development of a realtime Staphylococcus aureus and MRSA (SAM-) PCR for routine blood culture. Journal of Microbiological Methods. 2007;68:296-302

[45] Ryffel C, Tesch W, Birch-Machin I, Reynolds PE, Barberis-Maino L, Kayser $\mathrm{FH}$, et al. Sequence comparison of mecA genes isolated from methicillin-resistant Staphylococcus aureus and Staphylococcus epidermidis. Gene. 1990;94:137-138

[46] Higashide M, Kuroda M, Ohkawa S, Ohta T. Evaluation of a cefoxitin disk diffusion test for the detection of mecA-positive methicillinresistant Staphylococcus saprophyticus. International Journal of Antimicrobial Agents. 2006;27:500-504

[47] Crombé F, Angeles Argudfn M, Vanderhaeghen W, Hermans K, Haesebrouck F, Butaye P. Transmission dynamics of methicillin-resistant Staphylococcus aureus in pigs. Frontiers in Microbiology. 2013;4:1-21

[48] Edwards SA. Product quality attributes associated with outdoor pig production. Livestock Production Science. 2005;94:5-14

[49] Agerso Y, Vigre H, Cavaco LM, Josefsen MH. Comparison of air samples, nasal swabs, ear-skin swabs and environmental dust samples for detection of methicillin-resistant Staphylococcus aureus (MRSA) in pig herds. Epidemiology and Infection. 2014;142:1727-1736

[50] O'Connor AM, Gailey J, McKean JD, Hurd HS. Quantity and distribution of salmonella recovered from three swine lairage pens. Journal of Food Protection. 2006;69:1717-1719
[51] Pu S, Han F, Ge B. Isolation and characterization of methicillinresistant Staphylococcus aureus strains from louisiana retail meats. Applied and Environmental Microbiology. 2009;75:265-267

[52] O'Brien AM, Hanson BM, Farina SA, Wu JY, Simmering JE, Wardyn SE, et al. MRSA in conventional and alternative retail pork products. PLoS One. 2012;7:e30092

[53] Tanih NF, Sekwadi E, Ndip RN, Bessong PO. Detection of pathogenic Escherichia coli and Staphylococcus aureus from cattle and pigs slaughtered in abattoirs in Vhembe District, South Africa. Scientific World Journal. 2015;2015:1-8

[54] Mørk T, Kvitle B, Jørgensen HJ. Reservoirs of Staphylococcus aureus in meat sheep and dairy cattle. Veterinary Microbiology. 2012;155:81-87

[55] Khalid KA, Zakaria Z, Ooi PT, McOrist S. Low levels of meticillinresistant Staphylococcus aureus in pigs in Malaysia. The Veterinary Record. 2009;164:626-627

[56] Lowe BA, Marsh TL, IsaacsCosgrove N, Kirkwood RN, Kiupel M, Mulks MH. Microbial communities in the tonsils of healthy pigs. Veterinary Microbiology. 2011;147:346-357

[57] Atanassova V, Meindl A, Ring C. Prevalence of Staphylococcus aureus and staphylococcal enterotoxins in raw pork and uncooked smoked ham-A comparison of classical culturing detection and RFLP-PCR. International Journal of Food Microbiology. 2001;68:105-113

[58] van de Vijver LPL, Tulinski P, Bondt N, Mevius D, Verwer C.

Prevalence and molecular characteristics of methicillin-resistant Staphylococcus aureus (MRSA) in organic pig herds in the Netherlands. Zoonoses and Public Health. 2014;61:338-345 
[59] Rasschaert G, Vanderhaeghen W, Dewaele I, Janež N, Huijsdens X, Butaye P, et al. Comparison of fingerprinting methods for typing methicillin-resistant Staphylococcus aureus sequence type 398. Journal of Clinical Microbiology. 2009;47(10):3313-3322

[60] Tenover FC, Arbeit R, Archer G, Biddle J, Byrne S, Goering R, et al. Comparison of traditional and molecular methods of typing isolates of Staphylococcus aureus. Journal of Clinical Microbiology. 1994;32(2):407-415

[61] Bens CCPM, Voss A, Klaassen CHW. Presence of a novel DNA methylation enzyme in methicillin-resistant Staphylococcus aureus isolates associated with pig farming leads to uninterpretable results in standard pulsed-field gel electrophoresis analysis. Journal of Clinical Microbiology. 2006;44(5):1875-1876

[62] Argudín MA, Rodicio MR, Guerra B. The emerging methicillin-resistant Staphylococcus aureus ST398 clone can easily be typed using the Cfr9I SmaI-neoschizomer. Letters in Applied Microbiology. 2010;50(1):127-130

[63] Van Wamel WJB, Hansenová Maňásková S, Fluit AC, Verbrugh $\mathrm{H}$, De Neeling AJ, Van Duijkeren E, et al. Short term micro-evolution and PCRdetection of methicillin- resistant and -susceptible Staphylococcus aureus sequence type 398. European Journal of Clinical Microbiology \& Infectious Diseases. 2010;29(1):119-122

[64] Tenover FC, Arbeit RD, Goering RV, Mickelsen PA, Murray BE, Persing DH, et al. Interpreting chromosomal DNA restriction patterns produced by pulsedfield gel electrophoresis: Criteria for bacterial strain typing. Journal of Clinical Microbiology. 1995;33(9):2233-2239

[65] Murchan S, Kaufmann ME, Deplano A, De Ryck R, Struelens M, Zinn CE, et al. Harmonization of pulsedfield gel electrophoresis protocols for epidemiological typing of strains of methicillin-resistant Staphylococcus aureus: A single approach developed by consensus in 10 European laboratories and its application for tracing the spre. Journal of Clinical Microbiology. 2003;41(4):1574-1585

[66] McDougal LK, Steward CD, Killgore GE, Chaitram JM, McAllister SK, Tenover FC. Pulsed-field gel electrophoresis typing of oxacillinresistant Staphylococcus aureus isolates from the United States: Establishing a National Database. Journal of Clinical Microbiology. 2003;41(11):5113-5120

[67] Deurenberg RH, Vink C, Kalenic S, Friedrich AW, Bruggeman CA, Stobberingh EE. The molecular evolution of methicillin-resistant Staphylococcus aureus. Clinical Microbiology and Infection. 2007;13:222-235

[68] Stenhem M, Örtqvist Å, Ringberg H, Larsson L, Olsson-Liljequist B, Hæggman S, et al. Imported methicillinresistant Staphylococcus aureus, Sweden. Emerging Infectious Diseases. 2010;16(2):189-196

[69] Krziwanek K, Metz-Gercek S, Mittermayer H. Methicillin-resistant Staphylococcus aureus ST398 from human patients, upper Austria. Emerging Infectious Diseases. 2009;15(5):766-769

[70] van Belkum A, Melles DC, Peeters JK, van Leeuwen $W B$, van Duijkeren $A$, Huijsdens XW, et al. Methicillinresistant and -susceptible Staphylococcus aureus sequence type 398 in pigs and humans. Emerging Infectious Diseases. 2008;14(3):479-483

[71] Wu Z, Li F, Liu D, Xue H, Zhao X. Novel type XII staphylococcal cassette chromosome mec harboring a new cassette chromosome recombinase, CcrC2. Antimicrobial Agents and Chemotherapy. 2015;59(12):7597-7601 
[72] Baig S, Johannesen TB, OverballePetersen S, Larsen J, Larsen AR, Stegger M. Novel SCCmec type XIII (9A) identified in an ST152 methicillinresistant Staphylococcus aureus. Infection, Genetics and Evolution. 2018;61:74-76

[73] Enright MC, Day NPJ, Davies CE, Peacock SJ, Spratt BG. Multilocus sequence typing for characterization of methicillin-resistant and methicillinsusceptible clones of Staphylococcus aureus. Journal of Clinical Microbiology. 2000;38(3):1008-1015

[74] Wielders CLC, Vriens MR, Brisse S, De Graaf-Miltenburg LAM, Troelstra A, Fleer A, et al. Evidence for in-vivo transfer of mecA DNA between strains of Staphylococcus aureus. Lancet. 2001;357:1674-1675

[75] Velasco V, Buyukcangaz E, Sherwood JS, Stepan RM, Koslofsky RJ, Logue CM. Characterization of Staphylococcus aureus from humans and a comparison with isolates of animal origin, in North Dakota, United States. PLoS One. 2015;10(10):e0140497

[76] Stapleton PD, Taylor PW. Methicillin resistance in Staphylococcus aureus: Mechanisms and modulation. Science Progress. 2002;85:57-72

[77] Alipour F, Ahmadi M, Javadi S. Evaluation of different methods to detect methicillin resistance in Staphylococcus aureus (MRSA). Journal of Infection and Public Health. 2014;7:186-191

[78] Stegger M, Andersen PS, Kearns A, Pichon B, Holmes MA, Edwards G, et al. Rapid detection, differentiation and typing of methicillin-resistant Staphylococcus aureus harbouring either mecA or the new mecA homologue mecALGA251. Clinical Microbiology and Infection. 2012;18:395-400

[79] Ito T, Hiramatsu K, Tomasz A, De Lencastre H, Perreten V, Holden MTG, et al. Guidelines for reporting novel mecA gene homologues. Antimicrobial Agents and Chemotherapy. 2012;56(10):4997-4999

[80] Petersen A, Stegger M, Heltberg O, Christensen J, Zeuthen A, Knudsen LK, et al. Epidemiology of methicillin-resistant Staphylococcus aureus carrying the novel mecC gene in Denmark corroborates a zoonotic reservoir with transmission to humans. Clinical Microbiology and Infection. 2013;19:E16-E22

[81] Nadarajah J, Lee MJS, Louie L, Jacob L, Simor AE, Louie M, et al. Identification of different clonal complexes and diverse amino acid substitutions in penicillinbinding protein 2 (PBP2) associated with borderline oxacillin resistance in Canadian Staphylococcus aureus isolates. Journal of Medical Microbiology. 2006;55:1675-1683

[82] Banerjee R, Gretes M, Harlem C, Basuino L, Chambers HF. A mecAnegative strain of methicillin-resistant Staphylococcus aureus with highlevel ??-lactam resistance contains mutations in three genes. Antimicrobial Agents and Chemotherapy.

2010;54(11):4900-4902

[83] Schwendener S, Cotting K, Perreten V. Novel methicillin resistance gene mecD in clinical Macrococcus caseolyticus strains from bovine and canine sources. Scientific Reports. 2017;7(43797):1-11

[84] Lowy FD. Antimicrobial resistance: The example of Staphylococcus aureus. The Journal of Clinical Investigation. 2003;111(9):1265-1273

[85] Rubin JE, Ball KR, Chirino-Trejo M. Antimicrobial susceptibility of Staphylococcus aureus and Staphylococcus pseudintermedius isolated from various animals. The Canadian Veterinary Journal. 2011;52(2):153-157

[86] Broekema NM, Van Tam T, Monson TA, Marshall SA, Warshauer DM. 
Comparison of cefoxitin and oxacillin disk diffusion methods for detection of mecA-mediated resistance in Staphylococcus aureus in a large-scale study. Journal of Clinical Microbiology. 2009;47(1):217-219

[87] Stefani S, Chung DR, Lindsay JA, Friedrich AW, Kearns AM, Westh H, et al. Meticillin-resistant Staphylococcus aureus (MRSA): Global epidemiology and harmonisation of typing methods. International Journal of Antimicrobial Agents. 2012;39:273-282

[88] van Duijkeren E, Ikawaty R, Broekhuizen-Stins MJ, Jansen MD, Spalburg EC, de Neeling AJ, et al. Transmission of methicillin-resistant Staphylococcus aureus strains between different kinds of pig farms. Veterinary Microbiology. 2008;126(4):383-389

[89] Nemati M, Hermans K, Lipinska U, Denis O, Deplano A, Struelens M, et al. Antimicrobial resistance of old and recent Staphylococcus aureus isolates from poultry: First detection of livestock-associated methicillinresistant strain ST398. Antimicrobial Agents and Chemotherapy. 2008;52(10):3817-3819

[90] Huber H, Koller S, Giezendanner N, Stephan R, Zweifel C. Prevalence and characteristics of meticillin-resistant Staphylococcus aureus in humans in contact with farm animals, in livestock, and in food of animal origin, Switzerland, 2009. Eurosurveillance. 2010;15(16):1-4

[91] Pu S, Wang F, Ge B.

Characterization of toxin genes and antimicrobial susceptibility of Staphylococcus aureus isolates from louisiana retail meats. Foodborne Pathogens and Disease. 2011;8(2):299-306

[92] Lowy FD. Staphylococcus aureus infections. The New England Journal of Medicine. 1998;339(8):520-532
[93] Foster TJ, Geoghegan JA, Ganesh VK, Höök M. Adhesion, invasion and evasion: The many functions of the surface proteins of Staphylococcus aureus. Nature Reviews Microbiology. 2014;12:49-62

[94] Gomes-Fernandes M, Laabei M, Pagan N, Hidalgo J, Molinos S, Villar Hernandez R, et al. Accessory gene regulator (Agr) functionality in Staphylococcus aureus derived from lower respiratory tract infections. PLoS One. 2017;12(4):e0175552

[95] Robinson DA, Monk AB, Cooper JE, Feil EJ, Enright MC. Evolutionary genetics of the accessory gene regulator (agr) locus in Staphylococcus aureus. Journal of Bacteriology.

2005;187(24):8312-8321

[96] Wright JS, Traber KE, Corrigan R, Benson SA, Musser JM, Novick RP. The agr radiation: An early event in the evolution of staphylococci. Journal of Bacteriology. 2005;187(16):5585-5594

[97] Costerton JW, Stewart PS, Greenberg EP. Bacterial biofilms: A common cause of persistent infections. Science. 1999;49:1318-1322 


\title{
An Emerging Multidrug-Resistant Pathogen: Streptococcus pneumoniae
}

\author{
Khalid I. Alqumaizi and Razique Anwer
}

\begin{abstract}
Streptococcus pneumoniae (S. pneumoniae) has a multifaceted bond with its human host and causing several diseases in children and adults when host flexible immunity and bacterial acquisition factors allow them to invade essentially sterile spots, such as the middle ear spaces (causes otitis media), lungs (causes pneumonia), bloodstream (causes sepsis) and meninges (causes meningitis). In the early 1940s, management of pneumococcal infections used to be somewhat straightforward, and penicillin commonly was the antibiotic of choice. Soon after mainstreaming antibiotic usage, worldwide emergence of antibiotic resistance among S. pneumoniae isolates has changed this approach. Multiple factors, like prior antibiotic use, inappropriate usage of antibiotics especially in young age, and day care attendance are the most commonly identified risk features for the spread of penicillin resistance and other multiple-antibiotic resistance. Basic fundamental mechanisms of most pneumococcal resistances have been identified, several organizations like WHO, CDC, BSAC, EUCAST started campaigns for appropriate antibiotic use and also the introduction of pneumococcal conjugate vaccines have been recommended to limit the further emergence and spread of pneumococcal resistant.
\end{abstract}

Keywords: drug-resistant $S$. pneumoniae, World Health Organization, upper respiratory tract, $\beta$-lactam antibiotics, penicillin-binding proteins

\section{Background}

According to WHO, bacterial resistance to antibiotic drugs are now one of the most global events that threaten humanity; due to new resistant mechanisms acquired by bacteria that help them to evade both natural and chemical elimination systems that are, immune system and antibiotic drugs [1]. With the ability to acquire resistance, simple infections can create major clinical problems for different patients, leading to serious events that include death. Unfortunately, although warnings about the aimless use of antibiotic drugs have been made by medical experts since the 1940s, the expenditure of antibiotic drugs are still increasing [2]. This issue is not only related to certain countries like India and South Africa where antibiotics are available without prescriptions, but also worldwide [2]. This implies that restricted guidelines must be made by specialized health sectors in both hospitals and pharmacies. Not only that but also generating a public awareness forum 
where people around the world are educated about the dangerousness of misusing antibiotic drugs. However, if increased consumption of antibiotics continues, doors for bacteria are going to be open, permitting them to enter an adaptive phase where mutations and among other things can take place; leading to deleterious consequences [3]. Indeed, the world today must reform the way antibiotics are being prescribed and utilized; not doing so, will impose a fast-rising threat which can be slowed down if certain behavior changes like a simple hand washing are applied [1]. Nevertheless, researchers in this field are facing a wide range of challenges which led to a major decrease in the discovery and development of new antibiotics; due to the widespread use of these drugs which have led to difficult new resistant bacteria families to appear [4]. This can be illustrated by looking back in time, for instance, approximately 47 new antibiotics were developed collectively in the period from 1983 to 2002, while from 2003 to 2012 almost seven new drugs only were developed [4]. This shows how close we are to reaching a post-antibiotic era where fear and trepidation from the simplest injuries and common infections are once again established. Therefore, the science community must come together and set up a focused system where only life-threatening resistant bacterium is targeted in order to safe major resources and develop better outcomes.

On one hand, we should also not forget to monitor and adjust the public behavior towards this topic, as it is the major fuel to this crisis. On the other hand, if this threat is left without a serious action, an estimation of nearly 10 million people will die every year in 2050 due to antimicrobial resistance, not to mention the huge cost burden with over 100 trillion USD [5]. In this chapter, we aim to establish a comprehensive understanding of defense mechanism of certain worrying and lifethreatening bacteria (Streptococcus spp.) that have mastered new maneuvers to evade the immune system and antibiotic drugs; causing multiple of diseases that are hard to treat, and to investigate its impact on patients clinically. Not only that but also to scrutinize the general defects that allowed pathogens like bacteria to survive and conquer the human body, and to explore the drugs that used to fight such bacteria but eventually failed to do so. Under these circumstances, doors of opportunities are going to be open for researchers to grasp the most important knowledge that they need in order to innovate new ideas, to create new treatments and methods to minimize the risks of this crisis. For this reason, the scope of this chapter is going to be mainly focused on the problem of certain worrying bacteria that were categorized and prioritized by WHO.

\section{Insights into antimicrobial emergence}

It is well-known to scientists that bacteria are one of cleverest creatures that can not only generate new methods continuously to evade the immune system and antibiotic drugs, but also adapt to various situations to ensure its survival and growth. By knowing that, it is important to explore their mechanism in an attempt to have a better understanding of how they work and function. However, it would make sense to direct all efforts to certain worrying bacteria that are resistant by prioritizing it according to certain criteria. To do so, WHO has published a global priority list of resistant bacteria to antibiotic drugs in order to facilitate a path that will guide researchers all around the world where the urgency of finding new treatments is vital [6]. With the help of expert opinion and evidence-based data WHO-global priority pathogens list developed a multi-criteria decision analysis (MCDA) technique for prioritizing the research and development of new and effective antibiotic treatments. Following steps has been taken to set prioritization: (1) selection of antibiotic-resistant bacteria to be prioritized; (2) selection of criteria 
for prioritization; (3) data extraction and synthesis; (4) scoring of alternatives and weighting of criteria by experts; and (5) finalization of the ranking of pathogens. This list was created with the help of specialists all around the world and contains 12 most dangerous resistant bacteria families organized based on where exigency of new treatments is needed. The first three were sat as a critical priority, and those are Acinetobacter baumannii, CR, Pseudomonas aeruginosa CR and Enterobacteriaceae 3GCR [6]. The second six were sat as high priority, and those are Enterococcus faecium VR, Staphylococcus aureus MR\&VR, Helicobacter pylori ClaR, Campylobacter FQR, Salmonella spp. FQR and Neisseria gonorrhoeae FQR [6]. The last three were sat as medium priority, and include S. pneumoniae PNS, Haemophilus influenzae AmpR and Shigella spp. FQR [6]. It is important to say that WHO has clearly pinpointed that Mycobacterium tuberculosis was excluded from the list because it has been reported worldwide as a priority and other initiatives are already devoted to finding new treatments for Mycobacterium tuberculosis [7]. In spite of that, those bacteria were selected based on 10 criteria, and those include "mortality, healthcare and community burden, a prevalence of resistance, a 10-year trend of resistance, transmissibility, preventability in the hospital and community settings, treatability and current pipeline" [8]. Each criterion was chosen by experts who have previous experience and knowledge, and evidence for those criteria was taken from various reliable sources; such as, systematic reviews of published literature and so much more. In the light of this, a one must bear in mind that sometimes establishing priorities have its drawbacks, which a large public forum like WHO should seek to abstain to avoid any wrongness that would rather cause a disaster; however, it is indeed an appreciated and understandable move as sometimes "the simplest messages are usually the most effective," and it will eventually help in addressing bacteria in a proper manner [9]. Nonetheless, the goal here is not only to create new treatments, but rather bring multiple sectors like governments, pharmaceutical companies, and experts together to ensure a successful procedure to face this great challenge both by raising awareness of communities and encouraging research $[10,11]$.

Furthermore, to face a great challenge like bacterial resistance a one must have a tremendous knowledge about their defense mechanism and the way they behave towards facing obstacles that are immune system and antibiotic drugs, and we attempt to review the accessible evidence and asses the relative importance of pathogens, and the status of drug-resistance $S$. pneumoniae, and their mechanisms and evolution of resistance to the various antibiotics.

\section{Streptococcus pneumoniae}

\subsection{Classification, transmission, colonization and invasion}

S. pneumoniae, is an important facultatively anaerobic Gram-positive coccalshaped bacterium that occur in pairs or chains and surrounded by a polysaccharide capsule, belongs to Firmicutes phylum. Traditionally, classification based on their three distinctive patterns appear on blood agar, which are termed alpha (partial), beta (complete) and gamma (none) hemolysis. According to Rebecca Lancefield classification, the beta-hemolytic streptococci (BHS) species can be further classified by the cell wall carbohydrate [12]. Most of the BHS species are associated with human diseases, and are categorized under Lancefield Groups A, B, C and G. Group $A$ and Group B are characterized by presence of antigen on particular species while Group $\mathrm{C}$ and $\mathrm{G}$ antigen occur on a small number of closely related species (collectively as termed "Group C/G") [13] (Figure 1). S. pneumoniae (also known as 


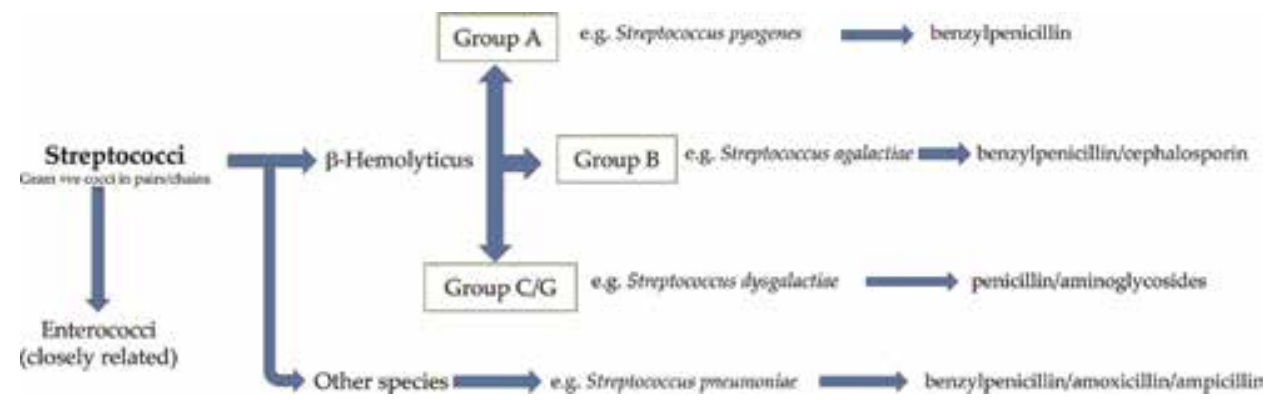

Figure 1.

Classification of Streptococcus spp. and drug of choice for causative agents.

pneumococcus) is an opportunistic pathogen that colonizes the mucosal surfaces of the human upper respiratory tract (URT) and group in other species of streptococci. This microorganism survives and multiply in wet environments, colonize in respiratory tract, bloodstream, pleural fluid, peritoneum, surgical wounds and oropharynx secretions of infected individuals. It has also been shown to colonize the normally sterile site results in invasive infection. Despite the diversity of host sites of S. pneumoniae can survive for long periods on both dry and moist surfaces. Carriage of pneumococci in the nasopharynx is more common in young children. Carriage is generally asymptomatic; but it serves as the main source for invasive pneumococcal infections and also plays a role in transmission from person-toperson. Adherence is the main features that facilitate colonization in the host cells and tissues. Prerequisite factors (including influenza A virus and other bacteria) are required for $S$. pneumoniae to colonize and persist on the mucosal surface, after attaining of incubation duration sufficient transmission to occur. Nasal inflammatory response due to influenza A virus, that regulates the expression of proinflammatory chemokines, also upregulation of target epithelial receptors and damaged respiratory epithelium used for $S$. pneumoniae adherence and disintegrate the epithelium and that helps in providing nutrient. These combined effects of viral co-infection increase the susceptibility of the host to colonization of S. pneumoniae [14]. S. pneumoniae basically produced two enzymes, peptidoglycan- $N$ acetylglucosamine deacetylase and attenuator of drug resistance, that helps in the modification of their peptidoglycan and promote it resistant to the lytic effects of lysozyme, which are abundant on the mucosal surface of the upper respiratory tract [15]. Negatively charged capsular polysaccharides also aided S. pneumoniae access and attach to the surface of epithelial cells and avoiding entrapment in the nasal mucus [16]. S. pneumoniae also uses several surface components for binding, like virulence protein $A \& B$, enolase, phosphorylcholine moieties on cell wall teichoic acid $[17,18]$. The successful colonization of $S$. pneumoniae depends on their relationship with normal microbiota, which are very complex mechanism. Symbiotic relation with microbiota of nasopharynx is depends on competition or coordination in nature [19]. S. pneumoniae produces numbers of bacteriocins (pneumocins) and other related microbial peptides which helps in inhibit the growth of another microbiota [20].

\subsection{Identified risk features of $S$. pneumoniae}

Over the last 15 years, S. pneumoniae, designated as a "red-alert" human pathogen, primarily because of its exceptional ability to survive in the community environment and remarkable ability to upregulate or acquire resistance to antibiotics. S. pneumoniae imposes a huge disease burden as the leading cause of wide 
range of infections, including community-acquired pneumonia, meningitis and sepsis in children and adults and causes otitis media in infants and young children. As all of these diseases are "dead ends" in the life cycle of the organism, the bacterial factors that cause invasive diseases must also be adaptive for colonization and/or transmission. S. pneumoniae is an opportunistic pathogen that colonizes the mucosal surfaces of the human upper respiratory tract. Up to $27-65 \%$ of children and $<10 \%$ of adults are carriers of $S$. pneumoniae and carriage involves a commensal relationship between the bacterium and the host [21]. Dissemination of this microorganism through local spread, aspiration or seeding to the bloodstream results in many invasive diseases (Figure 2). Globally, pneumonia considered as leading cause of death in younger child whose age is $<5$ years, and it attributed 1.6 million deaths annually. According to the World Health Organization, pneumococcal disease continues to cause the most deaths among vaccine-preventable diseases [22]. Persons at higher risk for invasive pneumococcal disease include children below 2 years of age, adults above 65 years of age, those with underlying chronic conditions (cardiovascular or pulmonary diseases, etc.), and also who are immunocompromised like, congenital immunodeficiency, human immunodeficiency virus infection, leukemia, or systemic corticosteroid use, etc. [23].

\subsection{Mechanisms of antimicrobial resistance}

An organism is considered resistant when its growth in vitro is not inhibited by an antimicrobial agent. The causative agents for resistance differ greatly but often linked to empirical antimicrobial therapy, that's include inappropriate

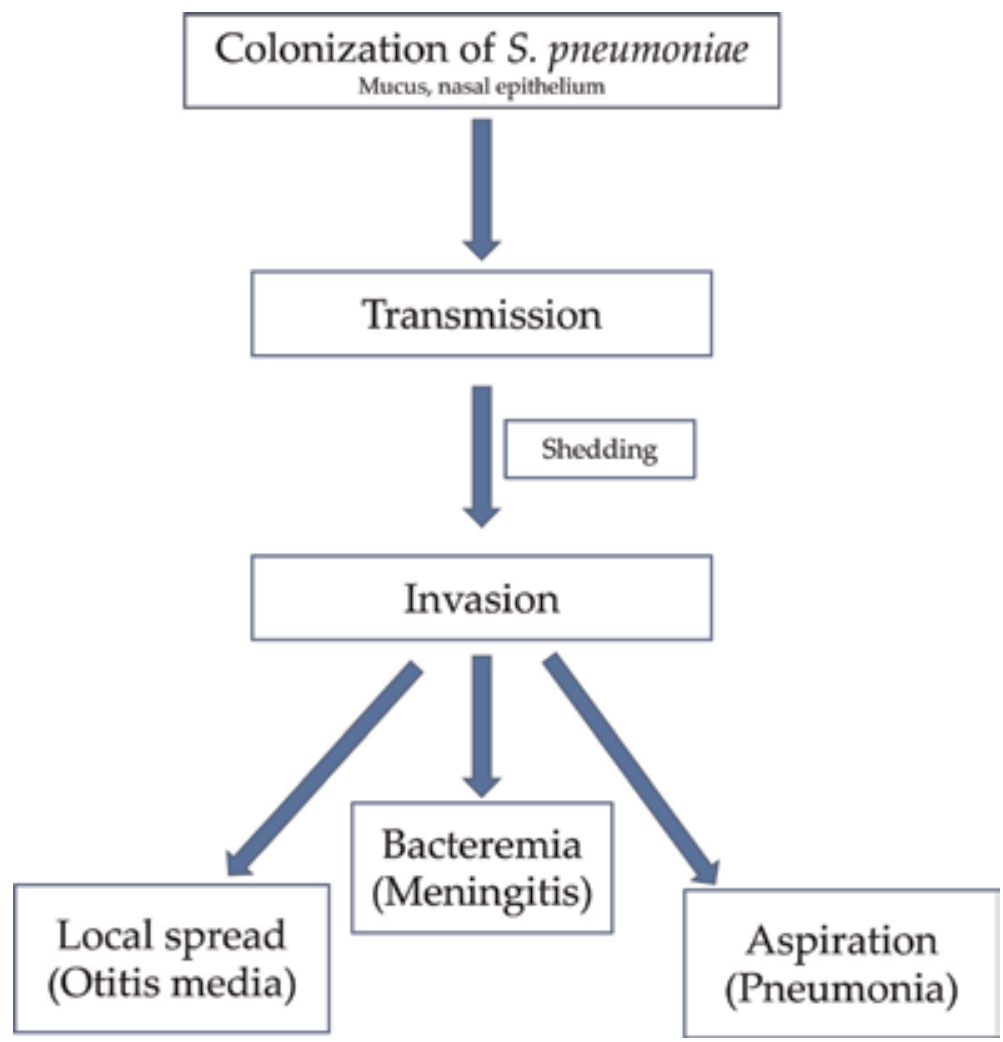

Figure 2.

Pathophysiology of Streptococcus pneumoniae. 
administration of subtherapeutic doses of antimicrobial agents, drug overuse or interrupted courses, and poor tissue-intake of the antimicrobial agent [24].

Antimicrobial resistance probably originated from horizontal resistance gene between bacterial species. These genes are acquired rapidly by the mechanism of plasmid promoted-conjugation, transformation or virus-induced transduction process, that all process contribute to the development of antimicrobial resistance. Due to these mechanisms some of the genes are inherited, some change to random DNA mutations in bacteria, and others are imported from related or distant bacteria [25] (Figure 3). Repeatedly use of antibiotic has been shown to be the strongest risk factor for the carriage and spread of resistant pneumococci, at both the individual and the community levels [26]. Evidence showed that antimicrobial resistance developed in S. pneumoniae may indication of transmission of the organism among patients and may be predictive of an impending outbreak of S. pneumoniae infections.

S. pneumoniae modify its genome through the uptake and incorporation of exogenous DNA from other pneumococci or closely related oral streptococci has facilitated the spread of antibiotic resistance and evasion of vaccine-induced immunity. Identification of resistant pneumococci based upon genetic features, culture-based phenotypic susceptibility methods are the gold-standard approach in clinical laboratories. Interpretations to evaluate antibiotic resistance in $S$. pneumoniae have been established by several organizations, such as WHO, CDC, Clinical and Laboratory Standards Institute (CLSI), the (BSAC), British Society for Antimicrobial Chemotherapy (BSAC), and the European Committee on Antimicrobial Susceptibility Testing (EUCAST). Culture of clinical specimens and subsequent antibiotic susceptibility testing to suggest treatment options are helps in recognition of antibiotic resistance in S. pneumoniae. The microbial identification and diagnosis of the infecting microorganisms are prerequisites for efficient treatment and hospital/community infection control and helps in control the spreading antibiotic resistance strains. These procedures are time consuming, laborious, and require well-trained technicians for correct interpretation of results. However, effective, immunological microbial identification methods have been developed for only a small number of bacterial species [27]. Molecular-based methods such as ribosomal RNA sequencing and MALDI-TOF are available and considered as powerful tool to

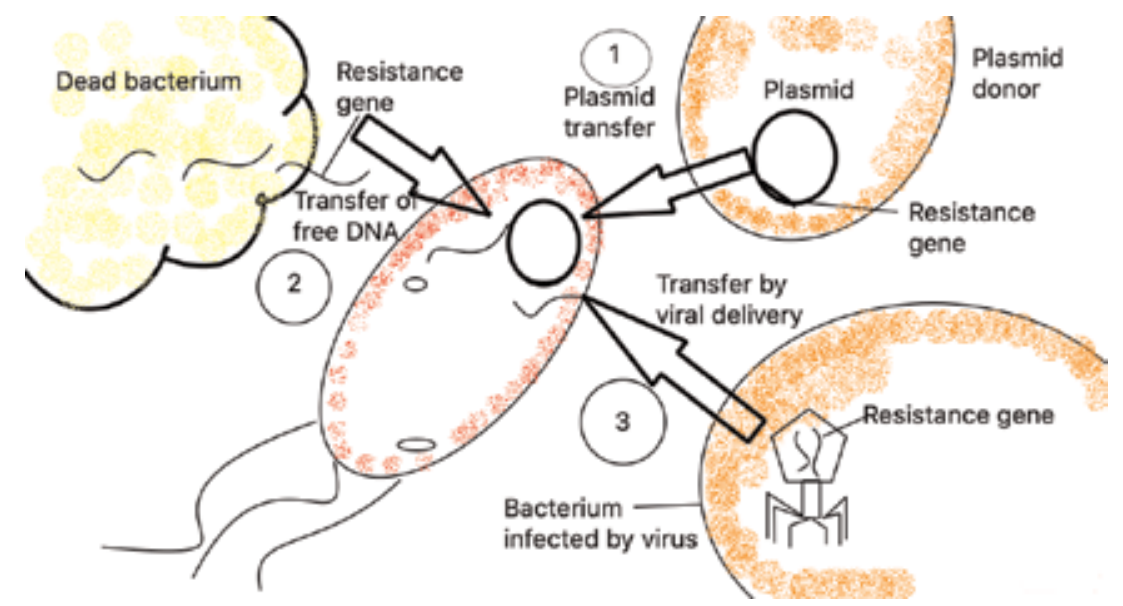

Figure 3.

Bacterial acquiring resistance genes. Three major methods for resistant gene acquisition: (1) donor cells transfer plasmid containing one or more genes into another bacteria, (2) bacteria integrate gene through transformation process and, (3) a virus acquires a resistance gene from a bacterium and injects it into a different bacterial cell. 
improve detection from clinical specimens $[28,29]$. Biomolecular factors for antibiotics resistance have also led to the development of a variety of molecular assays to detect the presence of resistance genes in pneumococcal isolates (PCR) and also directly from clinical specimens (MALDI-TOF) [30, 31]. According to Metcalf et al., they developed a promising whole-genome sequencing (WGS) based "typing pipeline" for rapid automated predictions of pneumococcal serotypes, MICs, genotypes, and additional features [32]. Enhanced bioinformatic tools such as ARGANNOT (antibiotic resistance gene annotation) for querying WGS data greatly expand the depth of laboratory-based strain surveillance efforts and provides a periodically updated database for known accessory resistance genes to screen bacterial whole-genome sequence data [33].

Antibiotics have been a basis of pneumococcal disease treatment and either by decreasing or eradicating the bacterial load from host body [34]. As production of penicillin started in the mid-1940s, after that treatment of pneumococcal infections has relied heavily upon penicillin and other $\beta$-lactam antibiotics, which showed most effective antibiotics against this bacterium. In 1912, a first antimicrobialresistant pneumococcal infections were documented when optochin resistance in experimental mice was described [35]. Five years later acquired optochin resistance was seen in humans [36]. In 1967, the first clinical isolate in a pediatric patient in Australia reported with reduced penicillin susceptibility [37]. During the period of 1970-1980, pneumococci resistant to penicillin, erythromycin, and trimethoprimsulfamethoxazole (TMP-SMX) spread rapidly globally, including many developed nations [38]. Tetracycline, chloramphenicol and fluoroquinolone resistances were also documented at relatively low levels compared to those for the abovementioned antibiotics [39]. More than $40 \%$ of isolates are penicillin resistant in several countries that lack significant conjugate vaccine coverage [40, 41]. Only few studies have been conducted on the acquisition of multidrug resistance however, these studies have found that extremes of age (i.e., $<5$ years and more than 65 years of age), previous use of $\beta$-lactam antibiotics by patients with noninvasive disease, antibiotic use in the last month by patients with nasopharyngeal colonization, population density, geographic location, and pneumococcal seven-valent conjugate vaccine (PCV7) serotype are all independent risk factors [42].

Typical therapy for the treatment of pneumococci disease (including invasive) are $\beta$-lactam antibiotics (benzylpenicillin, amoxicillin or ampicillin). Soon after mainstreaming antibiotic usage, multi-resistant pneumococcal clones emerged and disseminated worldwide. Penicillin resistant S. pneumoniae strains emerged globally, including macrolide and tetracycline, that elucidates the potential of this microorganism to respond selectively in environmental changes. Regulated mechanisms of innate resistance or acquisition of foreign determinants that have also brought $S$. pneumoniae as one of the organisms threatening the current antibiotic era. Nearly, 90 serotypes of $S$. pneumoniae have been identified like 6B, 9V, 14, 19F, or $23 \mathrm{~F}$ were high level resistant to $\beta$-lactam, were first reported in children via nosocomial transmission [43]. In European Union countries, multidrug resistance was observed among isolates of serotypes 19A, 14, 1, 19F, and 23F [44]. In the United States, serotypes of 15A, 15B, 15C, 6C, 23A and 35B showed less multidrug resistance if the person had conjugate vaccine, taken 14 years ago. Multi-resistant serotype 19A isolates still showed the highest MICs for $\beta$-lactams, macrolides, lincosamides, tetracycline, and co-trimoxazole [45].

Another cause of $\beta$-lactam resistance is due to phenotypic expression of penicillin resistance alterations that results in modification of penicillin-binding proteins (PBPs), consequently reducing peptidoglycan synthesis. This loose affinity causes cell lysis and bacterial cell death [46]. As peptidoglycan serves important roles in maintenance of cell integrity, cell expansion, cell division, cellular diffusion and 
surface anchoring. Gram positive bacterium pneumococcal peptidoglycan is composed of alternating glucosamine and $N$-acetylmuramic acid residues, directly cross-linked by transpeptidases between two $N$-acetylmuramic acid residues via short pentapeptides (L-Ala- $\gamma$-D-Glu-L-Lys-D-Ala-D-Ala) between the L-Lys and the last D-Ala of an adjacent loop. Structural similarity of the $\beta$-lactam binds to the D-Ala-D-Ala terminus of the peptidoglycan stem peptide, that causes $\beta$-lactams irreversibly bind transpeptidases at their active site. Binding of $\beta$-lactams to the transpeptidase active site of these penicillin-binding proteins (PBPs) thus blocks cross-linking of muropeptide chains to prevent cell wall synthesis [47]. Pneumococcal strain reveals reflective changes in corresponding key PBP genes, and a very wide range of "resistant" PBP gene alleles [48]. It has never been observed within pneumococcal strains how $\beta$-lactamases, introduced either mobile genetic elements or expressed from the core genome. Structural alterations that causes prevention of binding to analogs ( $\beta$-lactams) of their normal substrates is expressed from the core genome serve their essential biosynthesis for resistant PBP [49].

Six PBPs genes have been described in $S$. pneumoniae. Three PBP alterations (PBP1a, 2x, and 2b) strongly associated with $\beta$-lactam resistance. All three of these PBPs share a penicillin-sensitive $\mathrm{N}$-terminal transpeptidase domain that contains three conserved motifs: SerXXLys, containing the active-site serine that is bound (acylated) by PBPs; SerXAsn; and LysSer(or Thr)Gly [50]. In contrast to PBP2b and PBP2x, PBP2a has been associated with decreased susceptibility and higher MICs which causes $\beta$-lactam resistance [51]. PBP gene substitutions that appear to affect the polarity, charge distribution, and flexibility of the region neighboring the active site to decrease PBP-binding affinities for penicillin and/or other $\beta$-lactam classes in non-susceptible pneumococci [52].

As discussed earlier, PBP genes ( $P B P 1 a, P B P 2 b$, and $P B P 2 x)$ have been clearly demonstrated to be required for high-level $\beta$-lactam resistance in clinical isolates. In some instances, low-level resistance is also dependent upon proteins that are not directly targeted by $\beta$-lactams. Sometime due to different PBP allele combinations shows different $\beta$-lactam resistance phenotypes, and this complication leads to PBP genes from certain strains were not transform wild-type strains to the same high level of resistance [53]. One study showed that strains exhibiting identical PBP transpeptidase domain sequences exhibited penicillin MICs ranging from 0.25 to $2.0 \mu \mathrm{g} / \mathrm{ml}$ [54]. Another cause for resistivity is due to unaltered murM genes. murM gene inactivation, effects in the lack of branching activity, subsequently the synthesis of peptidoglycan consisting of only linear muropeptides. The finding suggested that MurM aminoacyl ligase appears to be required for penicillin resistance, that appeared a direct role of aminoacyl ligase branching activity in penicillin resistance [55]. One study also showed another type of resistant mechanism, peptidoglycan $O$-acetyltransferase encoded by the $a d r$ gene, attenuates PBP variant causes penicillin resistance [56]. Though, recent studies showed that most penicillin-resistant pneumococci are effectively treated by high doses of parenteral $\beta$-lactams.

\section{Conclusion}

With the advent of more advanced laboratory techniques, including wholegenome sequencing, and continued, high-quality surveillance of antimicrobial resistance, we can continue to further expand our understanding of this area. Special program and campaigns run by various organization like, WHO, CDC, BSAC, EUCAST should continue to be in all countries to decrease not only the burden of disease but also antimicrobial-resistant pneumococci. Also more focus 
An Emerging Multidrug-Resistant Pathogen: Streptococcus pneumoniae DOI: http://dx.doi.org/10.5772/intechopen.88524

on pneumococcal conjugate-vaccines because the new conjugate vaccines target these resistant serotypes, the implementation of use of these vaccines is expected to have an important role in limiting the spread of antibiotics-resistant

S. pneumoniae strains.

\section{Conflict of interest}

The author declares that there is no conflict of interest.

\section{Author details}

Khalid I. Alqumaizi ${ }^{1}$ and Razique Anwer ${ }^{2 *}$

1 Department of Family Medicine, College of Medicine, Imam Mohammad Ibn Saud Islamic University (IMSIU), Riyadh, Saudi Arabia

2 Department of Pathology, College of Medicine, Imam Mohammad Ibn Saud Islamic University (IMSIU), Riyadh, Saudi Arabia

*Address all correspondence to: razainuddin@imamu.edu.sa

\section{IntechOpen}

(C) 2019 The Author(s). Licensee IntechOpen. This chapter is distributed under the terms of the Creative Commons Attribution License (http://creativecommons.org/licenses/ by/3.0), which permits unrestricted use, distribution, and reproduction in any medium, provided the original work is properly cited. (c) BY 


\section{References}

[1] WHO. Antimicrobial Resistance: Global Report on Surveillance 2014. Geneva: World Health Organization; 2014. Available from: http://apps.who. int/iris/bitstream/10665/112642/1/ 9789241564748_eng.pdf?ua=1

[2] Honigsbaum M. Superbugs and us. Lancet. 2018;391(10119):420. DOI: 10.1016/S0140-6736(18)30110-7

[3] Giedraitienè A, Vitkauskienè A, Naginienė R, Pavilonis A. Antibiotic resistance mechanisms of clinically important bacteria. Medicina. 2011; 47(3):137-146

[4] Li B, Webster TJ. Bacteria antibiotic resistance: New challenges and opportunities for implant-associated orthopaedic infections. Journal of Orthopaedic Research. 2018;36(1): 22-32. DOI: $10.1002 /$ jor.23656

[5] O’Neill J. Antimicrobial Resistance: Tackling a Crisis for the Health and Wealth of Nations. Review on Antimicrobial Resistance. 2014. Available from: https://amr-review.org/ sites/default/files/AMR\%20Review\% 20Paper\%20-\%20Tackling\%20a\%20 crisis $\% 20$ for $\% 20$ the $\% 20$ health\%20and $\% 20$ wealth\%20of\%20nations_1.pdf

[6] Tacconelli E, Carrara E, Savoldi A, Harbarth S, Mendelson M, Monnet DL, et al. Discovery, research, and development of new antibiotics: The WHO priority list of antibiotic-resistant bacteria and tuberculosis. The Lancet Infectious Diseases. 2018;18(3): 318-327

[7] WHO. Publications on TB Drug Resistance. Available from: http://www. who.int/tb/publications/drug-resistance/ en/ [Accessed: 18 December 2017]

[8] Luepke KH, Suda KJ, Boucher H, et al. Past, present, and future of antibacterial economics: Increasing bacterial resistance, limited antibiotic pipeline, and societal implications. Pharmacotherapy: The Journal of Human Pharmacology and Drug Therapy. 2017;37:71-84

[9] The Pew Charitable Trusts. Antibiotics Currently in Clinical Development. 2017. Available from: http://www.pewtrusts.org/ /media/ assets/2017/05/antibiotics-currently-inclinical-development-03-2017.Pdf?la=en [Accessed: 2 June 2017]

[10] The Wellcome Trust. What We Do. Available from: https://wellcome.ac. uk/what-we-do [Accessed: 17 May 2017]

[11] BARDA. Biomedical Advanced Research and Development Authority. Available from: https://www.phe.gov/ about/BARDA/Pages/default.aspx [Accessed: 17 May 2017]

[12] Lancefield RC. A serological differentiation of human and other groups of hemolytic streptococci. Journal of Experimental Medicine. 1933; 57:571-595

[13] Facklam R. What happened to the streptococci: Over-view of taxonomic and nomenclature changes. Clinical Microbiology Reviews. 2002;15:613-630

[14] McCullers JA, Rehg JE. Lethal synergism between influenza virus and Streptococcus pneumoniae: Characterization of a mouse model and the role of plateletactivating factor receptor. The Journal of Infectious Diseases. 2002;186:341-350

[15] Davis K, Akinbi H, Standish A, Weiser J. Resistance to mucosal lysozyme compensates for the fitness deficit of peptidoglycan modifications by Streptococcus pneumoniae. PLoS Pathogens. 2008;4:e1000241

[16] Nelson AL et al. Capsule enhances pneumococcal colonization by limiting 
mucus-mediated clearance. Infection and Immunity. 2007;75:83-90

[17] Jensch I et al. PavB is a surfaceexposed adhesin of Streptococcus pneumoniae contributing to nasopharyngeal colonization and airways infections. Molecular Microbiology. 2010;77:22-43

[18] Cundell DR, Gerard NP, Gerard C, Idanpaan-Heikkila I, Tuomanen EI. Streptococcus pneumoniae anchor to activated human cells by the receptor for platelet-activating factor. Nature. 1995;377:435-438

[19] Shak JR, Vidal JE, Klugman KP. Influence of bacterial interactions on pneumococcal colonization of the nasopharynx. Trends in Microbiology. 2013;21:129-135

[20] Bogaardt C, van Tonder AJ, Brueggemann AB. Genomic analyses of pneumococci reveal a wide diversity of bacteriocins-Including pneumocyclicin, a novel circular bacteriocin. BMC Genomics. 2015; 16:554

[21] Bogaert D, De Groot R, Hermans PW. Streptococcus pneumoniae colonisation: The key to pneumococcal disease. The Lancet Infectious Diseases. 2004;4:144-154

[22] WHO Global Immunization Data 2014. Geneva, Switzerland: World Health Organization; Available from: http://www.who.int/immunization/ monitoring_surveillance/global_ immunization_data.pdf?ua1

[23] Robinson KA, Baughman W, Rothrock G, Barrett NL, Pass M, Lexau $\mathrm{C}$, et al. Active bacterial core surveillance/emerging infections program network. Epidemiology of invasive Streptococcus pneumoniae infections in the United States, 1995-1998: Opportunities for prevention in the conjugate vaccine era. JAMA.
2001;285:1729-1735. DOI: 10.1001/ jama.285.13.1729

[24] Livermore DM. Bacterial resistance: Origins, epidemiology, and impact. Clinical Infectious Diseases. 2003;36 (Suppl 1):S11-S23

[25] Mah MW, Memish ZA, Cunningham $\mathrm{G}$, Bannatyne RM. Outbreak of Acinetobacter baumannii in an intensive care unit associated with tracheostomy. American Journal of Infection Control. 2001;29(5):284-288

[26] Dowell SF, Schwartz B. Resistant pneumococci: Protecting patients through judicious use of antibiotics. American Family Physician. 1997;55: 1647-1648

[27] Gray LD, Fedorko DP. Laboratory diagnosis of bacterial meningitis. Clinical Microbiology Reviews. 1992;5: 130-145

[28] Avni T, Mansur N, Leibovici L, Paul M. PCR using blood for diagnosis of invasive pneumococcal disease: Systematic review and meta-analysis. Journal of Clinical Microbiology. 2010; 48:489-496

[29] Cherkaoui A, Hibbs J, Emonet $S$, Tangomo M, Girard M, Francois P, et al. Comparison of two matrix-assisted laser desorption ionization-time of flight mass spectrometry methods with conventional phenotypic identification for routine identification of bacteria to the species level. Journal of Clinical Microbiology. 2010;48(4):1169-1175. DOI: 10.1128/JCM.01881-09

[30] Fukushima KY, Yanagihara K, Hirakata Y, Sugahara K, Morinaga Y, Kohno S, et al. Rapid identification of penicillin and macrolide resistance genes and simultaneous quantification of Streptococcus pneumoniae in purulent sputum samples by use of a novel realtime multiplex PCR assay. Journal of 
Clinical Microbiology. 2008;46:

2384-2388. DOI: 10.1128/JCM.00051-08

[31] Seng P, Drancourt M, Gouriet F, La Scola B, Fournier PE, Rolain JM, et al. Ongoing revolution in bacteriology: Routine identification of bacteria by matrix-assisted laser desorption ionization time-of-flight mass spectrometry. Clinical Infectious Diseases. 2009;49(4):543-551. DOI: 10.1086/600885

[32] Metcalf BJ, Gertz RE, Gladstone RA, Walker H, Sherwood LK, Jackson D, et al. Strain features and distributions in pneumococci from children with invasive disease before and after 13-valent conjugate vaccine implementation in the USA. Clinical Microbiology and Infection. 2016;22:60.e9-60.e29. DOI: 10.1016/j.cmi.2015.08.027

\section{[33] Gupta SK, Padmanabhan BR,} Diene SM, Lopez-Rojas R, Kempf M, et al. ARG-ANNOT, a new

bioinformatic tool to discover antibiotic resistance genes in bacterial genomes. Antimicrobial Agents and Chemotherapy. 2014;58:212-220. DOI: 10.1128/AAC.01310-13

[34] Jacobs MR, Koornhof HJ, RobinsBrowne RM, Stevenson CM, Ver-Maak ZA, Freiman I. Emergence of multiply resistant pneumococci. The New England Journal of Medicine. 1978;299: 735-740. DOI: $10.1056 /$ NEJM197810052991402

[35] Moore HF, Chesney AM. A study of ethylhydrocuprein (optochin) in the treatment of acute lobar pneumonia. Archives of Internal Medicine. 1917;19:611

[36] Ross RW. Acquired tolerance of pneumococcus to M. \& B. 693. Lancet. 1939;1:1207-1208

[37] Hansman D, Bullen MM. A resistant penumococcus. Lancet. 1967;2:264-265
[38] Klugman KP, Koornhof HJ, Kuhnle V. Clinical and nasopharyngeal isolates of unusual multiply resistant pneumococci. American Journal of Diseases of Children. 1986;140: 1186-1190

[39] Jones RN, Sader HS, Mendes RE, Flamm RK. Update on antimicrobial susceptibility trends among Streptococcus pneumoniae in the United States: Report of ceftaroline activity from the SENTRY antimicrobial surveillance program (1998-2011). Diagnostic Microbiology and Infectious Disease. 2013;75:107-109. DOI: 10.1016/ j.diagmicrobio.2012.08.024

[40] Doern GV, Pfaller MA, Kugler K, Freeman J, Jones RN. Prevalence of antimicrobial resistance among respiratory tract isolates of Streptococcus pneumoniae in North America: 1997 results from the SENTRY antimicrobial surveillance program. Clinical Infectious Diseases. 1998;27:764-770. DOI: $10.1086 / 514953$

[41] Song JH, Lee NY, Ichiyama S, Yoshida R, Hirakata Y, Fu W. Spread of drug-resistant Streptococcus pneumoniae in Asian countries: Asian network for surveillance of resistant pathogens (ANSORP) study. Clinical Infectious Diseases. 1999;28:1206-1211. DOI: $10.1086 / 514783$

[42] Brandileone MC, Casagrande ST, Guerra ML, Zanella RC, Andrade AL, Di Fabio J. Increase in numbers of $\beta$-lactam-resistant invasive Streptococcus pneumoniae in Brazil and the impact of conjugate vaccine coverage. Journal of Medical Microbiology. 2006;55:567-574. DOI: 10.1099/jmm.0.46387-0

[43] Jacobs MR. Clinical significance of antimicrobial resistance in Streptococcus pneumoniae. South African Medical Journal. 2007;97:1133-1140

[44] European Centre for Disease Prevention and Control. Annual 
epidemiological report 2012: Reporting on 2010 surveillance data and 2011 epidemic intelligence data. Solna, Sweden: European Centre for Disease Prevention and Control; 2013

[45] Centers for Disease Control and Prevention. Antibiotic Resistance Threats in the United States, 2013. Atlanta, GA: Centers for Disease Control and Prevention; 2014

[46] Percheson PB, Bryan LE. Penicillinbinding components of penicillinsusceptible and -resistant strains of Streptococcus pneumoniae. Antimicrobial Agents and Chemotherapy. 1980;18: 390-396. DOI: 10.1128/AAC.18.3.390

[47] Tipper DJ, Strominger J. Mechanism of action of penicillins: A proposal based on their structural similarity to acylD-alanyl-D-alanine. Proceedings of the National Academy of Sciences of the United States of America. 1965;54: 1133-1141. DOI: $10.1073 /$ pnas.54.4.1133

[48] Coffey TJ, Dowson CG, Daniels M, Zhou J, Martin C, Spratt BG, et al. Horizontal gene transfer of multiple penicillin-binding protein genes, and capsular biosynthetic genes in natural populations of Streptococcus pneumoniae. Molecular Microbiology. 1991;5: 2255-2260

[49] Kim L, McGee L, Tomczyk S, Beall B. Biological and epidemiological features of antibiotic-resistant Streptococcus pneumoniae in pre- and post-conjugate vaccine eras: A United States perspective. Clinical Microbiology Reviews. 2016;29:525-552 evolution of antimicrobial resistance to beta-lactams, fluoroquinolones and macrolides. Microbes and Infection. 2012;14(7):573-583

[52] Gordon E, Mouz N, Duée E, Dideberg O. The crystal structure of the penicillin-binding protein $2 \mathrm{x}$ from Streptococcus pneumoniae and its acyl-enzyme form: Implication in drug resistance. Journal of Molecular Biology. 2000;299:477-485

[53] Hakenbeck R. $\beta$-Lactam resistance in Streptococcus pneumoniae: Penicillinbinding proteins and non-penicillinbinding proteins. Molecular Microbiology. 1999;33:673-678

[54] Chesnel L, Carapito R, Croizé J, Dideberg O, Vernet T, Zapun A. Identical penicillin-binding domains in penicillin-binding proteins of Streptococcus pneumoniae clinical isolates with different levels of $\beta$-lactam resistance. Antimicrobial Agents and Chemotherapy. 2005;49:2895-2902

[55] Filipe SR, Tomasz A. Inhibition of the expression of penicillin resistance in Streptococcus pneumoniae by inactivation of cell wall muropeptide branching genes. Proceedings of the National Academy of Sciences of the United States of America. 2000;97:4891-4896

[56] Crisóstomo MI, Vollmer W, Kharat AS, Inhülsen S, Gehre F, BuckEnmaier S, et al. Attenuation of penicillin resistance in a peptidoglycan O-acetyl transferase mutant of Streptococcus pneumoniae. Molecular Microbiology. 2006;61:1497-1509

[50] Contreras-Martel C, DahoutGonzalez C, Martins ADS, Kotnik M, Dessen A. PBP active site flexibility as the key mechanism for $\beta$-lactam resistance in pneumococci. Journal of Molecular Biology. 2009;387:899-909

[51] Cornick JE, Bentley SD.

Streptococcus pneumoniae: the 


\section{Edited by Sahra Kırmusaoğlu}

Staphylococcus spp. and Streptococcus spp. have not only got pathogenic isolates, but also non-pathogenic isolates. Staphylococcus spp. and Streptococcus spp. that are Gram positive cocci are the main pathogens in several infections. Virulence factors such as usual and unusual surface proteins encoded by resistance genes are the main causes of pathogenesis. Multidrug-resistant pathogens that are the main causes of morbidity and mortality worldwide have the ability to synthesize a number of destructive enzymes encoded by resistance genes such as $\beta$-lactamases. Resistant pathogens such as methicillin-resistant Staphylococcus aureus (MRSA), Streptococcus pneumoniae, Group A, and Group B Streptococcus have emerged throughout the world. To eliminate these resistant pathogens that cause untreatable, acute, and chronic infections, different new antimicrobials must be developed and used. The goal of this book is to provide the latest information about the above topics. 